\title{
A Comparative Study of Three Growing Media and Four Plant Groups Under Extensive Green Roof Conditions in San Luis Obispo, California
}

A Thesis Presented to the Faculty of California Polytechnic State University San Luis Obispo

In Partial Fulfillment of the Requirements for the Degree of Master of Science in Agriculture

Todd A. Nelson

June 29, 2010 
(C) 2010

Todd A. Nelson

ALL RIGHTS RESERVED 


\section{COMMITTEE MEMBERSHIP}

TITLE:

A Comparative Study of Three Growing Media and Four Plant Groups Under Extensive Green Roof Conditions in San Luis Obispo, California

AUTHOR: $\quad$ Todd A. Nelson

DATE SUBMITTED: June 2010

COMMITTEE CHAIR: Terry L. Vassey, Ph.D.

COMMITTEE MEMBER: Matt Ritter, Ph.D.

COMMITTEE MEMBER: David Hannings, M.S. 


\begin{abstract}
A Comparative Study of Three Growing Media and Four Plant Groups Under Extensive Green Roof Conditions in San Luis Obispo, California
\end{abstract}

\title{
Todd A. Nelson
}

Green roof growing media and plant species are critical factors when deciding on the best materials for a project. Growing media must be chosen in accordance with load bearing capacities of structures and water requirements of the plant material. Plant species must be able to thrive in the climate of the green roof and withstand a green roof's harsh environment. The objectives of this research were: (1) to determine which of three extensive green roof growing media support the most growth of Sedum, a proven extensive green roof plant genus; and (2) to determine which of four plant groups provides the most media coverage under extensive green roof conditions. Sedum growing in a granular growing media blend with higher organic matter and larger particles provided more coverage than Sedum growing in a medium with smaller particles with lower organic matter and an experimental foam medium. Sedges covered the soil faster than Sedum, grasses, and Mediterranean species. These results will help green roof designers and landscape architects anticipate the plant growth rates during the first 36 weeks of new projects and choose more effective growing media blends. They can also observe the growth patterns of the plant groups to choose plant material that will achieve the functional objectives of a green roof more efficiently. These results are applicable to green roofs designed for moderate California coastal climates and regions with similar weather conditions. 


\section{ACKNOWLEDGEMENTS}

We thank the Boyle-McOmie Scholarship, the Central Coast Greenhouse Grower's Association, California Landscape Contractors Association, for their funding. Your support is greatly appreciated.

We thank several industry sponsors and their associates for their material donations and accessibility: Joe Byles and Barbara Helfman - Freedom Garden Products, Charlie Miller Roofscapes, Joe Donnelly - Skyland USA, Lenetta Heiland - Colbond, David Fross and Jennifer Scarano - Native Sons Nursery and Stormy Storm - Pacific Coast Forest Products. We hope your time and investments were well worth it.

I express gratitude to my committee for their efforts throughout this process. A special thank you to my advisor Dr. Terry L. Vassey for his oversight and support; I wish you well in your future endeavors. Thank you to Dr. John Peterson for connecting me with industry experts and organizing funding. I owe a special thank you to Dr. Matt Ritter and Dave Hannings for your constant availability, flexibility and thoughtful direction.

We thank Dr. Karen McGaughey and Dr. Andrew Schaffner for their statistical consultation. Thank you Dr. Chip Appel and Dr. David Headrick for your excellent classes that proved instrumental to my studies. Thank you Dr. Brad Rowe and Dr. Kristin Getter (Michigan State University) for your insight and accessibility in the early stages of this project. Thank you to Dr. Mark Shelton and Melanie Gutierrez for all your help. Thanks to Susan Rosenfeld for your support and editing prowess.

To my parents: without your support and advice, I never would have made it through. Thank you for allowing me to pursue my passions. 


\section{TABLE OF CONTENTS}

Section

List of Tables

List of Figures

Page

ix

$\mathrm{xi}$

Chapter 1: Introduction 1

$1.1 \quad$ Background Information 1

1.2 Context 3

Chapter 2: Literature Review $\quad 7$

$\begin{array}{lll}2.1 & \text { Benefits of Green Roofs } & 7\end{array}$

2.1.1

Stormwater Management

2.1.2

Urban Heat Island Reduction and Energy Conservation 8

$\begin{array}{ll}\text { Legislation and Incentives } & 9\end{array}$

Green Roof Research Methods 9

2.2.1 Testing Platforms 9

2.2.2 Duration of Green Roof Research Experiments 10

2.2.3 Plant Spacing 11

2.2.4 Data Recording Instruments 12

2.3 General Green Roof Materials and Practices 13

2.3.1 Irrigation Methods and Frequency 13

2.3.2 Fertilizing Extensive Green Roofs 14

2.3.3 Growing Media 15

2.3.4 Organic Matter in Growing Medium 16

$2.4 \quad$ Plant Selection $\quad 17$

2.4.1 Sedum $\quad 17$

2.4.2 Common Extensive Green Roof Plants $\quad 18$

2.5 Plant Establishment Methods 19

$\begin{array}{llr}2.5 .1 & \text { Hydroseeding } & 19\end{array}$

2.5.2 Cuttings 19

$\begin{array}{lll}2.5 .3 & \text { Vegetation Mats } & 20\end{array}$

$\begin{array}{lll}2.5 .4 & \text { Plugs } & 20\end{array}$

$\begin{array}{lll}2.6 & \text { Plant Taxa } & 21\end{array}$

$\begin{array}{lll}2.6 .1 & \text { Grasses } & 21\end{array}$

2.6.2 Festuca glauca 22

2.6.3 Buchaloe dactyloides 'UC Verde' 23

2.6.4 Sporobolus airoides 25

2.6.5 Boutelouea gracilis 26 
$\begin{array}{lll}2.7 & \text { Mediterranean Species } & 27\end{array}$

2.7.1

$\begin{array}{lr}\text { Fragaria chiloensis } & 28\end{array}$

Achillea millefolium $\quad 29$

$\begin{array}{ll}2.7 .3 & \text { Dymondia margaretea }\end{array}$

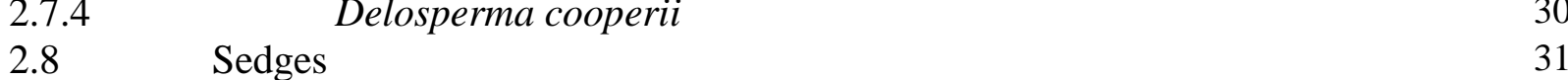

2.8.1 Carex glauca $\quad 32$

2.8.2 Carex pragracilis $\quad 33$

2.8.3 Carex testacea $\quad 34$

2.8.4 Carex divulsa $\quad 35$

$2.9 \quad$ Sedum $\quad 35$

2.9.1 Sedum x rubrotinctum

2.9.2 Sedum acre $\quad 38$

2.9.3 Sedum rupestre 'Angelina' 39

2.9.4 Sedum spurium 'Tricolor' 40

2.9.5 Sedum album 41

Chapter 3: Materials and Methods 43

$3.1 \quad$ General Information 43

3.1.1 Location and Description of Experiment Site 43

3.1.2 Experiment Maintenance 44

$3.2 \quad$ Choosing Plant Taxa 44

3.2.1 Propagation $\quad 45$

3.3 Platform Assembly and Infrastructure 46

$\begin{array}{lll}3.3 .1 & \text { Platform Support } & 47\end{array}$

$\begin{array}{lll}\text { 3.3.2 Waterproof Membrane } & 47\end{array}$

3.3.3 Waterproof Membrane Installation 49

3.3.4 Installing the Drainage Layer and Filtration Cloth 49

$3.4 \quad$ Growing Media $\quad 50$

3.4.1 Growing Medium One $\quad 50$

3.4.2 Growing Medium Two $\quad 52$

3.4.3 Growing Media Three $\quad 54$

3.4.4 Adding Growing Media $\quad 57$

3.5 Plant Material $\quad 57$

3.5.1 Growing Media Experiment Plant Material $\quad 57$

3.5.2 Growing Media Experiment Planting Frame 58

3.5.3 Plant Taxa Experiment Planting $\quad 59$

$\begin{array}{lll}\text { 3.5.4 Plant Taxa Experiment Planting Frame } & 60\end{array}$ 
$\begin{array}{lll}3.6 & 60\end{array}$

$\begin{array}{lll}3.7 & \text { Fertilization } & 63\end{array}$

$\begin{array}{lll}3.8 & \text { Data Collection } & 63\end{array}$

3.8.1 Data Collection with ImageJ $\quad 64$

3.8.2 Data Collection with Wooden Framed Grid (WFG) 65

3.9 $\quad$ Experiment Design and Data Analysis 67

3.9.1 Growing Media Experiment $\quad 67$

3.9.2 Plant Taxa Experiment $\quad 69$

Chapter 4: Results, Discussion and Conclusions 71

4.1 Growing Media Study Results $\quad 71$

$\begin{array}{lll}4.2 & \text { Plant Taxa Experiment Results } & 73\end{array}$

$\begin{array}{llr}4.3 & \text { Discussion } & 80\end{array}$

4.3.1 Growing Media Experiment $\quad 80$

4.3.2 Plant Taxa Experiment $\quad 85$

$4.4 \quad$ Conclusions $\quad 88$

4.4.1 Growing Media Experiment $\quad 88$

$\begin{array}{llr}\text { 4.4.2 Plant Taxa Experiment } & 89\end{array}$

$\begin{array}{ll}\text { Appendix } & 95\end{array}$ 


\section{LIST OF TABLES}

Table

Title

Page

1.1 Comparison of the general characteristics of intensive and extensive green roof styles

2.1 Characteristics of the grass species used in the plant taxa experiment

2.2 Characteristics of the Mediterranean species in the plant taxa experiment

2.3 Characteristics of the sedges used in the plant taxa experiment

2.4 Characteristics of Sedum species used in the plant taxa experiment

3.1 Origin, genus and species, propagation method, and number of days until the plug was considered fully rooted for the 17 plant species used

3.2 ASTM International guidlies met by Protecto Wrap® BT25XL

3.3 Rooflite Extensive MC Specifications with quantity values based on FLL extensive growing media ranges

3.4 Size of each particle and the correlating percentage of Medium Three needed to achieve the proper particle size distribution

3.5 Percent by volume, total quantity and source of each ingredient in growing Medium Three

3.6 Irrigation schedule for the plant taxa and growing media experiments

4.1 Relationship of Media One and Two to Medium Three at time of significance $(\alpha=.05$, $\mathrm{n}=9$ )

4.2 4.1 Mean media coverage (\% MC) \pm Standard errors of the three media treatments 12 , 24 , and 36 weeks after planting

4.3 Comparisons of mean \% MC between plant groups after 12 weeks of growth

4.4 Comparisons of mean \% MC between plant groups after 24 weeks

4.5 Comparisons of mean \% MC between plant groups after 36 weeks

4.6 Comparisons of overall growth rates (linear slopes) of each plant group after 36 weeks

4.7 Comparisons of magnitude of quadratic curvature in growth of each plant group after 36 weeks 
4.8 Comparisons of magnitude of cubic curvature in growth of each plant group after 36 weeks 


\section{LIST OF FIGURES}

Figure

Title

Page

2.1 A steel skewer placed vertically at measuring point on a green roof testing platform

2.2 A stainless steel measuring frame. $50 \mathrm{lb}$. fishing line running vertically and horizontally creates measuring point coordinates.

3.1 Location of experiment testing platforms within the EHS unit at Cal Poly

3.2 Concrete blocks and wooden shims were used for support and slope manipulation

3.3 Fishing line intersections marked plug locations

3.4 Wooden planting frame with $4 \times 4$ fishing line grid used mark plug locations during planting

3.5 Lateral irrigation lines were connected beneath the soil between platforms

3.6 Sprinklers sat at the same level as the growing medium and could be moved aside to make room for the data collection frame

3.7 Wooden frame in the growing media experiment used to measure \% MC

3.8 Wooden frame in the plant taxa experiment used to measure \% MC

3.9a Treatment assignments in growing media experiment 68

3.9b Treatment assignments for each platform in the plant taxa study 69

4.1 \% MC of the three growing media over 36 weeks. Dashes indicate means, bars 73 indicate standard errors.

4.2 Percent $\log _{10} \% \mathrm{MC}$ of the four plant groups over 36 weeks. Dashes indicate 76 means, bars indicate standard errors.

4.3 \% MC of the four plant groups over 36 weeks. Dashes indicate means, bars indicate standard errors.

4.4 Precipitation quantities at California Polytechnic State University during the experiment (www.weatherunderground.com) 


\section{Chapter 1: Introduction}

\subsection{Background Information}

Green roofing is an alternative roofing technology in which plant material is established in a growing medium on top of a structure (Getter and Rowe, 2007). Contemporary green roofing methods can be traced back to the earliest documented rooftop gardens in Syria, called the Hanging Gardens in Semiramis, considered one of the Seven Wonders of the Ancient World (Oberndorfer et al., 2007).

Today, complex roof gardens known as "intensive” green roofs can be constructed on commercial structures like hotels, resorts, businesses, and private homes. These elaborate gardens, consisting of substrate depths of at least $20 \mathrm{~cm}$, are similar to ground level landscaping. They require regular maintenance, provide environments for a broad selection of plant species and typically require irrigation. However, they differ from a ground-level landscape in that construction includes adding thicker and more elaborate layers, including a waterproof membrane, drainage layer, root barrier, and a growing medium at least $20 \mathrm{~cm}$ in depth (Oberndorfer et al., 2007).

"Extensive" green roofs are a contemporary version of the roof-garden concept; they oppose the intensive style. Extensive types are constructed of a shallower growing medium of only 2 to $20 \mathrm{~cm}$ and are more strictly functional in purpose (Oberndorfer et al., 2007). Table 1.1 compares the extensive and intensive green roof styles. 
Table 1.1 Comparison of the general characteristics of intensive and extensive green roof styles (modified From Oberndorfer et al., 2007)

\begin{tabular}{|c|c|c|}
\hline Characteristic & Extensive Green Roof & Intensive Green Roof \\
\hline Objectives & $\begin{array}{l}\text { Stormwater management, } \\
\text { thermal insulation, noise } \\
\text { mitigation }\end{array}$ & $\begin{array}{l}\text { Aesthetic value, increased } \\
\text { living space }\end{array}$ \\
\hline Structural requirements & $\begin{array}{l}\text { Within standard roof } \\
\text { weight-bearing parameters, } \\
\text { additional } 70 \text { to } 170 \mathrm{~kg} \text { per } \\
\mathrm{m}^{2 \dagger}\end{array}$ & $\begin{array}{l}\text { Structural planning or } \\
\text { additional improvements } \\
\text { necessary, additional } 290 \text { to } \\
970 \mathrm{~kg}^{2} \text { per } \mathrm{m}^{2}\end{array}$ \\
\hline Substrate depth & $2-20 \mathrm{~cm}$ & $20+\mathrm{cm}$ \\
\hline Plant selection & $\begin{array}{l}\text { Low growing stress tolerant } \\
\text { species such as Sedum and } \\
\text { mosses }\end{array}$ & $\begin{array}{l}\text { Similar requirements to } \\
\text { ground level landscaping, } \\
\text { must consider substrate } \\
\text { depth }\end{array}$ \\
\hline Irrigation & $\begin{array}{l}\text { Seasonal or none } \\
\text { (depending on climate) }\end{array}$ & Usually requires irrigation \\
\hline Maintenance & $\begin{array}{l}\text { Little to none, regular } \\
\text { weeding, seasonal mowing }\end{array}$ & $\begin{array}{l}\text { Similar maintenance } \\
\text { requirements to ground } \\
\text { level landscaping }\end{array}$ \\
\hline $\begin{array}{l}\text { Cost (excluding waterproof } \\
\text { membrane) }\end{array}$ & $\begin{array}{l}\$ 100-\$ 300 \text { per } \mathrm{m}^{2}(\$ 10-\$ 30 \\
\left.\text { per } \mathrm{ft}^{2}\right)\end{array}$ & $\$ 200$ per $\mathrm{m}^{2}\left(\$ 20+\right.$ per $\left.\mathrm{ft}^{2}\right)$ \\
\hline Human accessibility & $\begin{array}{l}\text { Typically functional rather } \\
\text { than accessible }\end{array}$ & $\begin{array}{l}\text { Typically accessible, } \\
\text { consider maintenance } \\
\text { requirements }\end{array}$ \\
\hline
\end{tabular}

${ }^{\dagger}$ (Dunnett and Kingsbury, 2004) 


\subsection{Context}

Though green roofing, both intensive and extensive, is increasing in popularity, the majority of research is directed toward developing the more sustainable extensive type. Two notable organizations, the FLL (Forschungsgesellschaft Landschaftsentwicklung Landschaftsbau, or The Society for Research into the Development of Landscape and Landscape Construction) and Green Roofs for Healthy Cities (GRHC), have emerged to meet the increased demand. The FLL is a German organization formed in 1977. It acts as the governing body from which the majority of green roof industry standards originate.

Green Roofs for Healthy Cities, based in Toronto, Ontario, is a North American organization dedicated to promoting green roof implementation at the political level and establishing best practices through education and certifications. GRHC was founded in 1999 as a small network of public and private organizations that became a formal not-for-profit 501(c)(6) industry association in 2004 (www.greenroofs.org).

In recent years, annual green roof installations continue to increase globally. From 1980 to1989, the German green roof market averaged 15 to 20 percent annual growth with 241 acres of green roofs per million $\mathrm{m}^{2}$ of total roofs in production by the end of 1989 . By 2003, it was estimated that 15 percent of all flat roofs in Germany were green roofs (www.greenroofs.org).

In North America, Chicago leads the U.S. movement in green roofs with $287,700 \mathrm{~m}^{2}$ of projects completed. Washington D.C., Minneapolis, New York City, Toronto, Montreal, Vancouver, and Winnipeg all have followed this trend with substantial acreage of green roof installations (Cantor, 2008). 
Many municipalities are currently enacting policies that support green roof infrastructure implementation (Cantor, 2008). By 1994, 9.5 million $\mathrm{m}^{2}$ of green roofs were installed worldwide. This number increased to 13.5 million $\mathrm{m}^{2}$ by 2001 (www.greenroofs.org).

To supplement this growth, many organizations support studies related to growing media, plant species, and climate to determine the best methodology for establishing green roofs on structures. Other studies focus on: stormwater retention, stormwater runoff reduction, plant selection and growth, thermal insulation, urban heat island reduction, carbon sequestration, growing media depth, sound insulation, air quality, water filtration, food production, horticultural therapy, habitat provision, and cost/benefit analyses (www.greenroofs.org).

Two of the most important aspects of a green roof, which directly affect its performance, are the constituents of the growing medium and the plant material selection. A growing medium must be capable of supporting specified plant species for a particular green roof while remaining within the structural load capacity of the structure over which it is installed. The plant material must hold the growing medium in place by rapidly covering the medium in a reasonable amount of time (Dunnett and Kingsbury, 2004).

This project tested three growing media, two of which were granular and the third an unconventional foam-like material. The foam, which comes in a modular form, is significantly lighter than the other two media.

This lightweight medium could increase the possibilities of installing green roofs on older structures that possess lower load bearing capacities, as well as on newer structures not designed to withstand the weight of granular media. Further, transporting these modular units to the top of a structure by hand or via elevator could be made easier and more cost effective, rather than 
using lifting equipment generally required for granular growing media. Finally, this technology may be more water efficient than granular media because of its ability to trap and hold water in its waterproof tray. This element significantly reduces water usage and the need for a complex irrigation system. We were unaware of any past work that has compared conventional granular growing media with lighter, unconventional, artificial growing media.

Limited information currently exists regarding the performance of extensive green roofs in California, and none exists for green roofs on the Central Coast. The most complex commercial green roof project in California was installed on the California Academy of Sciences building in San Francisco. Unlike other successful green roofs, this installation uses an unconventional coco fiber growing medium; it also includes several plant species native to California that grow on top of a complex, undulating structure.

Other notable California installations include the green roofs on the GAP headquarters building in San Mateo (extensive) and at North Beach Place in San Francisco (intensive). The GAP green roof plant pallet consists of native grasses and a sedge species planted on a sloped structure reminiscent of the San Bruno foothills that surround the site. The North Beach Place green roof has a diverse plant pallet and provides residents with usable green space in a compact metropolitan setting (Cantor, 2008).

Green roofs are uncommon in California, and the longevity of recently installed projects is still uncertain. Therefore, evaluating several key plant taxa and different growing media should benefit California's green roof and horticulture industry by providing information about the performance of plant species in an extensive green roof environment. The objectives of this study are: (1) to evaluate the performance of three growing media; and (2) to evaluate the 
performance of four plant groups, both under extensive green roof conditions, on the Central Coast of California. 


\section{Chapter 2: Literature Review}

\subsection{Benefits of Green Roofs}

The benefits of green roofing can be categorized as being either environmental or economical. Environmental benefits are quantifiable and include: stormwater management, reduction of the urban heat island effect, erosion management, air pollution mitigation, wildlife habitat provision, and aesthetic appeal. Personal benefits are more difficult to quantify and often result in cost savings for building managers and homeowners, which are realized through energy conservation, noise mitigation, and roof longevity (Dunnett and Kingsbury, 2004; Oberndorfer et al., 2007).

\subsubsection{Stormwater Management}

Urban roofs consist primarily of synthetic surfaces like asphalt and other conventional roofing materials. The nature of these surfaces results in excessive water runoff during and after precipitation, with little water absorption. Water runoff from urbanized hardscapes is the thirdlargest source of contamination in lakes. Thus, stormwater runoff management is one of green roofing's greatest environmental benefits. By capturing precipitation in the growing media and vegetation, green roofs allow this water to be either impounded or returned to the atmosphere via evapotranspiration (VanWoert et al., 2005).

Factors such as slope, plant species, and substrate depth affect the amount of precipitation retained. Research projects have demonstrated runoff reductions as large as 60 to $100 \%$. For example, VanWoert, et al. (2005) demonstrated how a conventional gravel roof and a green roof system without vegetation do not manage stormwater runoff as well as a vegetated green roof. 
Over a 14-month period, the vegetated roof retained $60.6 \%$ of water runoff, whereas the gravel and non-vegetated roofs retained $27.2 \%$ and $50.4 \%$ of water runoff, respectively.

\subsubsection{Urban Heat Island Reduction and Energy Conservation}

Dark colored rooftops, pavement and other impervious surfaces absorb heat energy from the sun during the day and radiate it back into the atmosphere at night. This process, known as the urban heat island effect, creates higher temperatures in urban areas than in adjacent undisturbed land. As vegetated roofs evapotranspire moisture, the air above any green roof may be cooler than air radiating from surrounding impervious surfaces (Scholz-Barth, 2001). Using a simulation model, Oberndorfer et al. (2007) found that if $50 \%$ of the roofs in urban Toronto were "vegetated," temperature reductions of up to $2^{\circ} \mathrm{C}$ could be realized.

Reducing the urban heat island effect can translate into lower heating and cooling costs, as well. Green roofs reduce energy usage by insulating buildings and reducing the roofs' heat flux more effectively than conventional roofs. The green roof layer prevents rapid air exchange between a building's interior and exterior. Furthermore, evapotranspiration from plants provides a natural cooling effect by transforming heat and moisture into humidity, thus naturally cooling the air above the building (Scholz-Barth, 2001). Research by Onmura et al. (2001) in Japan demonstrated a $50 \%$ reduction in heat flux, while a study in Ottawa found a $95 \%$ reduction in annual heat gain on a green roof (Oberdorfer et al., 2007). 


\subsubsection{Legislation and Incentives}

Tax credits are available to owners who install green roofs on private homes and commercial properties. The 2009 Clean Energy Stimulus and Investment Assurance Act, proposed by Senator Maria Cantwell (WA), dedicates a portion of the bill toward green roof tax incentives. Section 506 of the bill gives a 30\% tax credit that is capped at $\$ 5,000$ for residential structures and unlimited for commercial buildings when $50 \%$ of the roof is covered with a "vegetated green roof system" (www.greenroofs.org).

In Germany and other European countries, where green roofing is more common, legislators are imposing stricter regulations on impervious surfaces. This movement has resulted in policies that require pervious systems, like green roofs, in urban areas to reduce runoff and avoid overloading storm sewers (Dunnett and Kingsbury, 2004).

In the United States, the EPA's Clean Water Act, Section 319, provides public funding for green roofs. For instance, the Critical Areas Program in Baltimore allows the city to charge fees on new construction near its inner harbor that uses impervious surfaces and causes runoff (Scholz-Barth, 2001). By encouraging pervious surfaces, Baltimore aspires to eliminate the adverse effects of contaminated runoff that damages native fish populations.

\subsection{Green Roof Research Methods}

\subsubsection{Testing Platforms}

Testing platforms of varying dimensions, built to replicate a commercial green roof environment, are commonly used in green roof research. A typical wood-framed testing platform, as represented in VanWoert et al. (2005), is practical and easily accessible. This testing platform contains layers representative of the commercial green roof, including a growing 
medium, a filter membrane, a drainage layer, a waterproof membrane, and an insulation layer (Oberdorfer et al., 2007).

Platform orientation and overall dimensions depend on the goals of each experiment. Generally, platforms are raised about $1 \mathrm{~m}$ above ground level and positioned on concrete blocks or wooden legs, allowing the researcher to manipulate slope, quantify run off, and maximize sun exposure. A single platform may represent one experimental unit, while other platforms use dividers to separate and randomly distribute different treatments, as in VanWoert et al. (2005). Common research platforms have overall dimensions of $2.44 \mathrm{~m}$ x $2.44 \mathrm{~m}$ and are divided into three equal sections measuring $0.67 \mathrm{~m} \times 2.44 \mathrm{~m}$. The wooden siding and dividers are typically $20.3 \mathrm{~cm}$ above the platform deck and are covered with a waterproof membrane to ensure independence of experimental units (Vanwoert et al., 2005).

In the northern hemisphere, platforms are generally oriented to the South, maximizing sun exposure and likely increasing plant growth (Vanwoert et al., 2005). Concrete blocks are ideal for supporting the platforms because they are relatively inexpensive, and they can be easily adjusted using wooden shims or by adding/subtracting the number of blocks used. Since there is no need to attach the platforms to the blocks (the platforms' weight holds them in place), the platforms can be lifted off the blocks and moved or adjusted, which adds flexibility.

\subsubsection{Duration of Green Roof Research Experiments}

The duration of green roof research experiments varies greatly depending on the goals of the experiment. The Swedish University of Agricultural Sciences completed a six-week experiment that examined the effect of conventional and controlled release fertilizers and their

effect on nutrient run off, while another experiment that examined vegetation development on extensive green roofs took over three years to finish (Emilsson et al., 2007; Emilsson, 2008). 
Several American universities have performed various extensive green roof experiments of different lengths. One particular study, "Effect of Substrate Depth on Initial Growth, Coverage, and Survival of 25 Succulent Green Roof Plant Taxa," by Durhman et al. (2007), uses similar plant taxa, growing media and evaluation methods to those used in our study. This provided an informative indication of the anticipated duration of this study. Their study, which was done in East Lansing, Michigan, lasted for 482 days, but showed discernable differences in percent cover of plant material after 63 to 84 days. Another Michigan State University study by Getter and Rowe (2008), titled "Media Depth Influences Sedum Green Roof Establishment," looked specifically at Sedum, including two species that this experiment uses.

\subsubsection{Plant Spacing}

An extensive green roof experiment by Getter and Rowe (2008) spaced plugs 17 to 20 cm apart in a 135-day study. Durham et al. (2007) and Getter and Rowe (2007) also found distinguishable results with similar planting spacing and experiment durations. These planting densities are greater than the standard recommendation for a commercial green roof setting, where as low as 10 plants $/ \mathrm{m}^{2}$ are recommended for dense plant coverage (Dunnett and Kingsbury, 2004).

\subsubsection{Data Recording Instruments}

A point-frame transect is one method used to measure plant growth over a growing medium (Getter and Rowe, 2008). A $15 \mathrm{~cm}$ skewer, shown in Figure 2.1 and used in Getter and Rowe (2008), is placed vertically at each measuring point on the measuring frame (Figure 2.2) and moved downward. Whether or not the transect contacts plant material and how many species it contacts is recorded at that location. A stainless steel frame, outlined in Getter and Rowe 
(2008), uses vertical and horizontal fishing line to make measuring coordinates, as Figure 2.2 shows; this method ensures that the skewer is inserted into the growing media at the exact same location during each measurement.

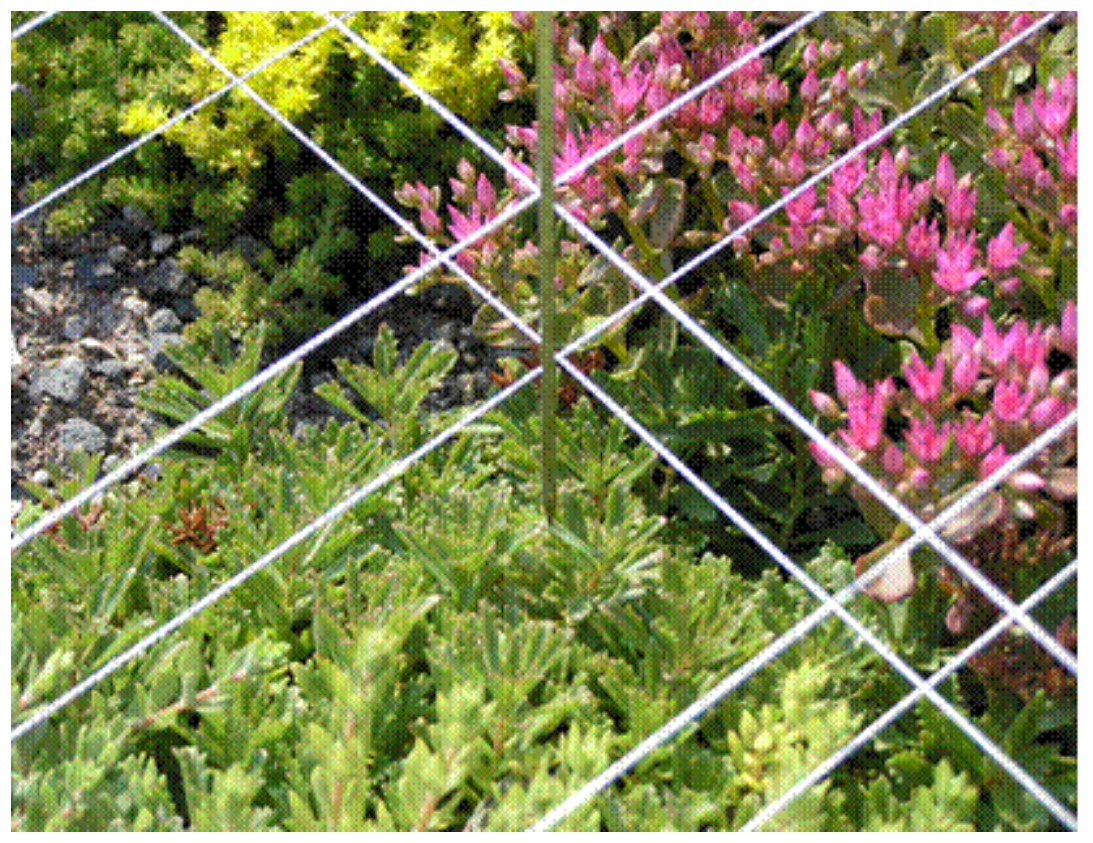

(Photo courtesy of Kristen Getter)

Figure 2.1 A steel skewer placed vertically at measuring point on a green roof testing platform 


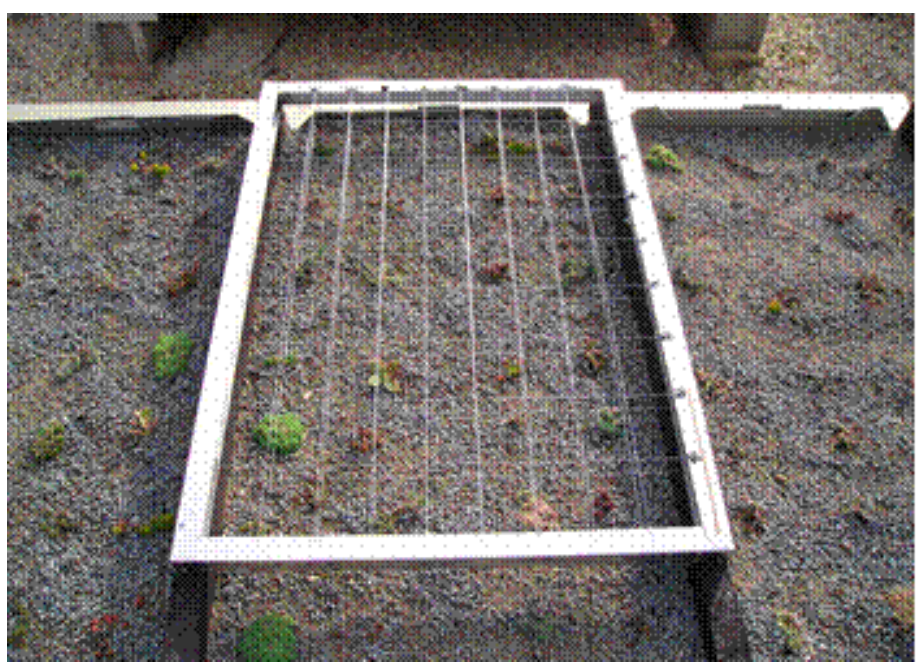

(Photo courtesy of Kristen Getter)

Figure 2.2 A stainless steel measuring frame. $50 \mathrm{lb}$. fishing line running vertically and horizontally creates measuring point coordinates

\subsection{General Green Roof Materials and Practices}

\subsubsection{Irrigation Methods and Frequency}

Irrigation frequency depends on several factors, including green roof type (intensive or extensive), plant material, media depth, sub-media infrastructure, and climate (Dunnett and Kingsbury, 2004). In moist climates, irrigation systems on extensive green roofs are optional, but are recommended for the first two years to aid in plant establishment and to keep plants alive during intense drought (Cantor, 2008). The different irrigation methods are: overhead spray, drip, capillary mat, base drip, and a hose bib (Green Roof Design 101, 2006).

Sedum exhibit superior drought resistance in green roof environments and may only require small, infrequent irrigation. A Michigan State study that consisted of a mix of six Sedum species, three of which (spurium, acre, and album) were used in this study, showed that some plants were still viable after 88 days without water when planted in an extensive green roof growing media with a $12 \mathrm{~cm}$ depth. In this same study, plants that were watered every seven 
days had significantly more growth than those watered every 14 days, but did not grow as much as those watered every two days, based on mean dry weight accumulation (Van Woert et al., 2005).

Deeper media depths consistently produce plants with more growth and greater drought resistance. VanWoert et al. (2005) studied the growth of six Sedum species at 2 and $6 \mathrm{~cm}$ of media. All Sedum planted at $6 \mathrm{~cm}$ exhibited better moisture retention and plant growth than plants in $2 \mathrm{~cm}$ of media (VanWoert et al., 2005).

\subsubsection{Fertilizing Extensive Green Roofs}

Completely eliminating all inputs on a green roof would make it a more sustainable system, but this is unrealistic. Plants like Sedum, which are endemic to nutrient poor soils, benefit from fertilizer, as it enhances growth (and, consequently, aesthetic appeal) and function of the green roof (Dunnett and Kingsbury, 2004; Stephenson, 1994). The FLL states that, although extensive green roofs are designed to be naturalized, they are fertilized during plant production, installation, possibly at one or two additional intervals during the first few years (FLL, 2002).

For extensive green roofs, controlled release fertilizers are usually the best option. It is recommended that $15-20 \mathrm{~g}\left(.05-.07 \mathrm{oz} / \mathrm{ft}^{2}\right)$ of $15-15-15$ osmocote be applied per $\mathrm{m}^{2}$ as a slow release product (Dunnett and Kingsbury, 2004). The FLL recommends using controlled release fertilizers (CRF) at a rate of $5 \mathrm{~g} \mathrm{~N} / \mathrm{year} / \mathrm{m}^{2}$ (FLL, 2002). Controlled release fertilizers are a better and more sustainable option than more easily dissolved conventional fertilizers because CRFs release nutrients at a pace similar to the nutrient requirements of the vegetation and they reduce the amount of nutrients leached into storm water run-off. CRFs can also improve plant growth and quality, increase nutrient use efficiency, reduce nutrient losses to surface water, and reduce 
the cost of maintenance associated with repeat fertilizations (Shaviv, 2001).

Unfertilized extensive green roofs can develop into systems dominated by moss, which may be less desirable. A Swedish study, which did not use CRF, showed moss coverage of $20 \%$ at the first recording, which increased to over $80 \%$ at the experiment's conclusion. A different study, which used fertilizer at the FLL's recommended rate of $5 \mathrm{~g}$ N/year/m $\mathrm{m}^{2}$ showed moss coverage of only $30-40 \%$, which was probably due in part to the use of fertilizer (Emilsson, 2007).

\subsubsection{Growing Media}

Several factors influence a green roof designer's choice regarding growing medium. Cost, viability of plant material, weight, installation convenience, roof accessibility and green roof type must all be considered. Compared to intensive green roofs, extensive green roofs are characterized by having a growing medium that is lightweight, lower in cost, and able to support a smaller diversity of plants (Table 1.1). Extensive growing media vary greatly with the performance goals of the green roof and the climate where it is installed, but a typical substrate consists of a mineral-based mixture of sand, gravel, pumice, expanded shale, and organic matter. It may also include crushed brick, LECA (Lightweight Expanded Clay Aggregate), peat, expanded slate, lava (scoria), and some coarse soil types (Peck and Kuhn, 2007).

A growing media blend should be carefully tested before installation to ensure compliance with critical variables outlined by the FLL, which generated measurements of these critical variables in order to create guidelines surrounding successful growing media. The Agricultural Analytical Service Laboratory (AASL) at Pennsylvania State University tests growing media to determine where its properties fit in relation to FLL guidelines. In addition to

organic matter percentage, the measurements include particle size distribution, density, water, air 
pH, salt content, and nutrients (Skyland USA, 2009). Table 3.3 gives an analysis done by the AASL that is based on FLL standards.

\subsubsection{Organic Matter in Growing Medium}

The ideal amount of organic matter in extensive green roof growing media has been debated among industry experts. The FLL recommends that 3-10\% of the growing medium (based on dry weight) be derived from organic materials that will aid new plant material during establishment (Cantor, 2008). Skyland USA, however, recommends about $8 \%$ organic matter (by volume) in their extensive blend, especially for Southern California (Skyland USA, 2009).

Moran et al. (2004) find that runoff water from green roofs using a medium containing 15 $\%$ or more organic matter (by volume) can contain excessive quantities of phosphorous and nitrates. They also conclude that when the medium contains less organic matter, the amount of phosphorus and nitrates in run-off water decreases.

\subsection{Plant Selection}

Green roof plants must be selected based on local climate and a number of other factors (Dunnett and Kingsbury, 2004). Environmental conditions on a rooftop are likely to be more severe than those experienced by plants in a landscape or native environment, due to a shallow

root zone, drought, high temperatures and windy conditions (Getter and Rowe, 2008). Design intent, aesthetic appeal, environmental conditions, media composition and depth, and maintenance requirements are other factors to consider when selecting green roof plants. Desired benefits and installation methods will also influence plant selection because growth habits affect the rate in which these benefits are realized (Green Roof Design 101, 2006). 
Harsh environments often require drought tolerant plants, but this factor does not automatically make a particular plant ideal for a green roof. In some cases, plants survive drought conditions because of their deep root systems (Dunnett and Kingsbury, 2004). For example, members of the Cactaceae family have roots that grow deeper and thicker with age (Ingram, 2008). This is not possible in thin substrates found with extensive green roofs.

Therefore, the function of plants on an extensive green roof should be considered rather than aesthetic appeal. Furthermore, extensive green roof plants should exhibit five main qualities (modified from Dunnett and Kingsbury, 2004; FLL, 2002):

1. Anchor and cover the growing medium in a reasonable amount of time

2. Form a self-repairing mat that can restore itself if bare areas appear from plant death due to stress

3. Take up and transpire large volumes of water

4. Survive the prevailing climactic conditions on that rooftop including the harshest parts of the year

5. Provide coverage of at least $60 \%$ while conditions are favorable These five characteristics inhibit weeds, improve aesthetics, and reduce the need for future replanting and maintenance (Dunnett and Kingsbury, 2004).

\subsubsection{Sedum}

Sedum is the most popular species for extensive green roofs because of its excellent drought tolerance, adaptability in well-drained substrates, and proven performance over time (Dunnett and Kinsbury, 2008). Drought tolerance in this genus has been well documented; 
several Sedum species have grown successfully in Michigan over extended periods of time without supplemental irrigation (Monterusso et al., 2005).

Sedum utilize a specialized form of photosynthesis, called Crassulacean Acid Metabolism (CAM), which results in improved water use efficiency. CAM plants' stomata open during the night and take in $\mathrm{CO}_{2}$, thereby reducing transpirational water loss that most plants experience when stomata are open during warmer daytime temperatures (Gravatt, 2003).

Research involving plants' adaptability to shallow rooting substrates indicates that several Sedum species grow successfully in substrate depths as little as $4 \mathrm{~cm}$. However, a minimum of $7 \mathrm{~cm}$ is recommended for adequate vegetative growth (Getter and Rowe, 2008).

Finally, soil coverage is a crucial green roof component, since it aids in erosion prevention, stormwater retention, run-off reduction, and increased aesthetic appeal (VanWoert et al., 2005). In Michigan, some Sedum species generated $96 \%$ soil coverage within two years, much greater than the $60 \%$ required by the FLL (Durham et al., 2007, FLL, 2002).

\subsubsection{Common Extensive Green Roof Plants}

Other plant species are emerging as good extensive green roof selections that fulfill the criteria in Section 2.4. Native plants are often successful because of their adaptation to local climates. Other species that evolved in extreme conditions, such as high altitudes, mountainous and rocky terrains, coastal, or arid climates, are promising candidates as well (Oberdorfer et al., 2007).

Succulent species, including Delosperma, Euphorbia, and Sempervivum, can be suitable for extensive green roofs because they limit transpiration and store excess water (Dunnett and Kingsbury, 2008). Getter and Rowe (2008b) provide an extensive list of green roof plants recommended from scientific literature and grower recommendations. 


\subsection{Plant Establishment Methods}

Plant establishment methods change with the scope and size of the green roof. Hydroseeding, cuttings, vegetation mats, and plugs are the four most common establishment methods (Dunnett and Kingsbury, 2004).

\subsubsection{Hydroseeding}

Hydroseeding uses a mixture of seeds, water, and gel or mulch that is sprayed onto the growing medium to germinate. This direct sowing method is the most time-efficient plant establishment method. Hydroseeding is more cost-effective than using cuttings, vegetation mats, or plugs for green roofs of $20 \mathrm{~m}^{2}$ or more (Dunnett and Kingsbury, 2004).

Disadvantages to hydroseeding include a longer period required for plant development and difficulty achieving even distribution, which could result in bare media and wind or water erosion. Considering time of year to hydroseed is crucial because seedlings are not as stress tolerant as more mature plants. Hydroseeding generally requires more irrigation than other methods while seeds germinate and mature (Dunnett and Kingsbury, 2004).

\subsubsection{Cuttings}

Sedum cuttings, or cuttings from other plants that root easily, can be manually planted into the soil or established as sprigs (small cuttings). Cuttings are broadcast across the substrate by hand and incorporated into the soil. At least 60 to 80 sprigs are needed per $\mathrm{m}^{2}$. However, 200 to $250 \mathrm{sprigs} / \mathrm{m}^{2}$ are recommended for rapid media coverage, especially where irrigation may be limited. Cuttings require rain or irrigation immediately following distribution and benefit from a thin layer of mulch. Rooting begins within two weeks, with $60 \%$ media coverage possible after six to eight weeks in ideal climates (Dunnett and Kingsbury, 2004). 


\subsubsection{Vegetation Mats}

Vegetation mats are pre-grown, densely-planted sheets of one or more plant species that act as a vegetative carpet or blanket. Plastic netting is placed over a thin substrate that is planted with cuttings or seeds and grown inside a greenhouse before being moved to the green roof site. Vegetation mats have the advantage of $90-100 \%$ coverage when installed. The disadvantage to this type of planting is the high cost (Getter and Rowe, 2007).

Mats should be placed together so that no gaps exist. This placement prevents the mats from blowing off of the roof and it helps control erosion. Most mats are composed of various Sedum species and are securely rooted after four to five weeks (Dunnett and Kingsbury, 2004).

Vegetation mats are the most expensive method of plant establishment, and they may not be any more effective over time than plugs or cuttings. A study in Sweden that examined the vegetative development of extensive green roofs planted with plugs, cuttings, and vegetation mats showed that there was no discernable difference in plant cover after three years (Emilsson, 2007). However, this study considered only time and disregarded cost; furthermore, vegetation mats provide the most coverage during the establishment phase.

\subsubsection{Plugs}

Directly planting plugs, or small, established plants, into the growing substrate is an effective plant establishment method because a high percentage of plants survive. This survival rate results from a pre-established root system and mature plant (Getter and Rowe, 2007). Plugs can be installed to give an artistic pattern more easily than other methods. However, these designs do not last over time, since species migrate and out-perform one another (Mumford, 2009; Dunnett and Kingsbury, 2004). 
If a tight mat of vegetation is desired, 10 plugs per $\mathrm{m}^{2}$ is recommended. Higher densities may be planted if more rapid coverage is needed or one is using a species with a slower growing habit. As with the use of seed and cuttings, plugs should be irrigated heavily after planting. Postplanting care includes applying a thin layer of mulch quickly after planting (Dunnett and Kingsbury, 2004).

\subsection{Plant Taxa}

Characteristics for each plant used in this project are given in the context of terrestrial landscaping unless information exists about their growth characteristics in an extensive green roof setting. Zone designations in the tables refer to the USDA Plant Hardiness Zone Map, which is used to depict the average annual minimum temperature that a plant can tolerate. Zone ranges (e.g. 4-9) indicate the ideal zones for that species. If one zone is given (e.g. 4), that indicates the lowest temperature a species can tolerate.

\subsubsection{Grasses}

Grasses are commonly used on green roofs throughout North American and Europe. Yang et al. (2008) showed that, from August 2006 to July 2007, short grasses removed air pollutants at a rate of $8.59 \mathrm{~g} / \mathrm{m}^{2} / \mathrm{yr}$. Grasses also offer a leaf form that contrasts with other nongrasslike herbaceous perennials, giving the designer the ability to create designs or patterns with the plant material. Table 2.1 summarizes the characteristics of the grasses used in this experiment. 
Table 2.1 Characteristics of the grass species used in the plant taxa experiment

\begin{tabular}{|c|c|c|c|c|c|c|c|}
\hline Plant & Origin & $\begin{array}{c}\text { Native or } \\
\text { Naturalized } \\
\text { in CA }\end{array}$ & $\begin{array}{l}\text { Spreading } \\
\text { Mechanism }\end{array}$ & $\begin{array}{l}\text { Mature Size } \\
\mathbf{H} \times \mathbf{W}(\mathbf{c m}) \dagger\end{array}$ & Exposure & $\begin{array}{l}\text { Green } \\
\text { Roof } \S\end{array}$ & Zone(s) \\
\hline $\begin{array}{l}\text { Festuca } \\
\text { glauca }\end{array}$ & $\begin{array}{c}\text { Europe, } \\
\text { Asia }\end{array}$ & no & seed & $25 \times 46$ & FS, PS & yes & $4-9$ \\
\hline $\begin{array}{l}\text { Buchloe } \\
\text { dactyloides }\end{array}$ & Great Plains & no & stolons & $\begin{array}{c}6 \mathrm{x} \\
\text { indeterminate }\end{array}$ & FS & yes & 3-9 \\
\hline $\begin{array}{l}\text { Sporabolus } \\
\text { airoides }\end{array}$ & $\begin{array}{c}\text { Southwest } \\
\text { U.S., } \\
\text { Mexico }\end{array}$ & yes & seed & $75 \times 75$ & FS & no & $7-9$ \\
\hline $\begin{array}{l}\text { Boutelouea } \\
\text { gracilis }\end{array}$ & Great Plains & no & rhizomes & $\begin{array}{c}6 \mathrm{x} \\
\text { indeterminate }\end{array}$ & FS & yes & $3-10$ \\
\hline
\end{tabular}

\subsubsection{Festuca glauca}

Blue fescue (Festuca glauca) is a cool-season (defined as using $\mathrm{C}_{3}$ photosynthetic processes and optimizing the conversion of atmospheric carbon dioxide to plant carbon at about $20^{\circ} \mathrm{C}$ (Besnard et al., 2009)), clumping evergreen grass. It is the only cool- season plant in this group. It is indigenous to Spain, Norway, Greece, and parts of Russia. The Festuca genus is found in many different shades of blue and gray and, until recently, these contrasting shades were mixed and sold under the same name (Greenlee, 1992).

Blue fescue crosses a variety of climates and there are many different phenotypes and flowering habits. Plants are propagated solely from division to protect the genetic uniqueness of select cultivars from the mixing that often occurs during seed propagation (Greenlee, 1992).

Blue fescue is known as an attractive ornamental grass because of its hair-like bluishgray foliage that grows in rounded tufts. Heights range from 10 to $15 \mathrm{~cm}$ in small cultivars and up to $46 \mathrm{~cm}$ in larger cultivars. Blue fescue's inflorescence can be barely noticeable to showy 
and usually occurs from May through June, since they are long day flowering plants (Oakes, 1990; Greenlee, 1992).

Blue fescue is drought resistant, but it requires moderate watering in dry months (Greenlee, 1992). It grows equally well in full sun or light shade and prefers well-drained, moist to dry soil. In warmer areas, Blue fescue grows best in partial shade. It grows most vigorously and has the bluest foliage in early spring and fall when temperatures are cooler (Oakes, 1990).

Blue fescue has a variety of uses in the landscape because of its unique texture and year-round color. It is commonly used as a ground cover, a border plant (due to its soft texture), or in rock gardens (Greenlee, 1992). This genus tends to die out in the center of the crown when grown in poorly drained soils in warm climates, but this is remedied by dividing plants every other year to maintain vigor (Oakes, 1990).

Blue fescue exists on extensive green roofs in the United States and Canada. It is currently being used on the Heinz 57 Center, in Pittsburg, PA and on the Clean Water Services Field Yard in Beaverton, Oregon. In both cases, they have found that Blue fescue grows best in about $8 \mathrm{~cm}$ of media. Blue fescue is one of the most abundant plants at Library Square in Vancouver, Canada, a 28,000 square foot extensive green roof (Cantor, 2008). Research by Hauth and Liptan (2003), however, recommend growing Blue fescue in $10.2 \mathrm{~cm}$ of media.

\subsubsection{Buchaloe dactyloides 'UC Verde'}

Buffalograss (Buchaloe dactyloides, 'UC Verde') is a warm-season (defined as using $\mathrm{C}_{4}$ photosynthetic processes and optimizing the conversion of atmospheric carbon dioxide to plant carbon at about $35^{\circ} \mathrm{C}$ (Besnard et al., 2009)) grass native to the North American Great Plains, ranging from Canada to Mexico. Early settlers to the Midwest used Buffalograss to cover and insulate their houses during the settlement period, showing a (far reaching) connection with 
green roofing. Buffalograss is the most commonly used warm-season grass in landscapes and recreational settings in subhumid and semiarid regions (Beard, 1972).

Buffalograss is a short grass, growing only $10-15 \mathrm{~cm}$ tall, forming a fine-textured, lowgrowing, grayish-green turf (Greenlee, 1992). Leaf blades are flat, measure 1-3 mm wide, and have a distinctive curling feature. Buffalograss spreads via stolons and forms a tight sod with a shallow root system (Beard, 1972).

Buffalograss is dioecious (males and females are separate plants) with small flowers extending only slightly higher than the foliage; they mimic those of Boutelouea gracilis, but are smaller and less dramatic (Greenlee, 1992). Vegetative propagation with female plants is the most common establishment method. Female plants are used more commonly in turfgrass situations because male plants have flower stalks that are two to three times longer than those on female plants (Beard, 1972).

Buffalograss is more tolerant of temperature extremes than other warm-season grasses. Buffalograss is drought tolerant and is best suited for regions receiving 30 to $64 \mathrm{~cm}$ of rainfall per year. Buffalograss is slow to establish but, once established, it spreads rapidly (Beard, 1972). Buffalograss will go dormant during extended periods of severe drought and then will produce significant growth after light and infrequent periods of moisture. This plant is adapted to a wide range of soil types, and performs best in fine textured soils. It possesses fair tolerance to alkaline soils, but has poor shade tolerance (Beard, 1972).

Buffalograss was used on a 17,000 square foot semi-intensive green roof at the Peggy Notebaert Nature Museum in Chicago in 1999. In 2006, Buffalograss was planted in a Green Grid® modular green roof at Heifer International's World Headquarters in Little Rock, Arkansas (Cantor, 2008). 


\subsubsection{Sporobolus airoides}

Alkali dropseed (Sporobolus airoides) is a clumping, warm-season grass found in Central Valley grasslands of California before being eliminated during the nineteenth century agricultural influx (Greenlee, 1992). Alkali dropseed is endemic to parts of Mexico, California, Arizona, and it grows from Texas to Montana (Greenlee, 1992).

Alkali dropseed possesses upright arching mounds of sharp edged grayish-green foliage that can grow 60 to $90 \mathrm{~cm}$ tall and wide. Flowers emerge in early summer and form conspicuous pink clouds measuring 13 to $26 \mathrm{~cm}$ forming a stiff pyramidal arrangement 60 to $90 \mathrm{~cm}$ above the foliage. Foliage turns yellowish at the first frost and becomes straw-colored during winter months (Greenlee, 1992).

Alkali dropseed prefers full sun and thrives in a wide range of soil types and climactic conditions. It is extremely heat and drought tolerant and can grow without summer water in arid parts of the western U.S.; however, it grows better with occasional watering. Alkali dropseed is useful for erosion control, as a large-scale ground cover, and as a specimen plant because of its attractive inflorescence (Greenlee, 1992).

No information was uncovered regarding Alkali dropseed's past performance on green roofs. However, Prairie dropseed (Sporobolus heterolepis) thrives on several green roofs throughout North America. Prairie dropseed has similar characteristics to Alkali dropseed and grows to $70 \mathrm{~cm}$ tall. Prairie dropseed is found throughout the Central U.S., from New Mexico eastward to North Carolina, northward Massachusetts, and westward to Montana (USDA, 2010). Prairie dropseed was used in Chicago on Peggy Notebaert Nature Museum's extensive green roof, as well as on the Minneapolis Central Library's $5600 \mathrm{~m}^{2}$ extensive green roof (in $10 \mathrm{~cm}$ of 
growing medium) and on the Green Institute's $465 \mathrm{~m}^{2}$ extensive green roof in Minneapolis (Cantor, 2008).

\subsubsection{Boutelouea gracilis}

Blue grama (Boutelouea gracilis) is a warm-season grass endemic to the North American Great Plains and possesses several characteristics similar to Buffalograss. Blue grama is found from Canada to Texas and from the Ohio River Valley westward to the California desert. Its flowers are particularly interesting, as they resemble tiny combs or mosquito larvae (hence, the name 'Mosquito grass') (Greenlee, 1992). According to Beard (1972), its use is limited in non-irrigated situations like roadsides, where culture practices are low and turfgrass quality is not important. However, Greenlee would argue that Blue grama is useful as a mowed or unmowed turf in the southwest and the prairie states. It makes an excellent choice for unmowed meadows, rock gardens, and as a specimen plant (Greenlee, 1992).

Blue grama has light, greenish-gray foliage that is densely tufted and upright to open. Short, stout rhizomes produce a high shoot density with foliage clumps growing over $20 \mathrm{~cm}$ if unmowed (Beard, 1972; Greenlee, 1992). Leaves are 1-2 mm wide and have a tendency to curl; plants green up slowly from its straw colored dormancy appearance in the spring.

Inflorescences usually have spikes ranging from one to three (usually two), measuring 2.5-5 mm long on erect culms. The root system is fibrous, dense, and somewhat shallow. Blue grama is primarily propagated by seed (Beard, 1972).

Blue grama thrives in full sun and is recommended as a mowed or unmowed lawn in southwestern and prairie states. It grows in zones 3 through 10 (Greenlee, 1992; Oakes, 1990). Blue grama is a warm-season grass, but can tolerate cooler temperatures allowing it to grow in 
cool semiarid and subhumid regions. Blue grama is tolerant to heat and has excellent drought resistance. It performs best in fine upland soils, and is tolerant of alkaline soils (Beard, 1972). Blue grama has been used on several extensive green roofs in North America. The Minneapolis Central Library used this species in $10 \mathrm{~cm}$ of growing media and it is also planted at the Peggy Notebaert Nature Museum green roof. Blue grama was used in $20.3 \mathrm{~cm}$ of a media that included one-third pumice at the Winnipeg Mountain Equipment Co-op in Manitoba, Canada (Cantor, 2008).

\subsection{Mediterranean Species}

The Mediterranean plants are defined as four plant species that exhibit qualities defined in Section 2.4, but do not fit into a particular group such as Sedum, sedges, or grasses. All four plants are endemic to Mediterranean climates. Each plant has been previously used on extensive green roofs, but none of them have been used on the Central Coast of California. Table 2.2 summarizes the four species in this group.

Table 2.2 Characteristics of the Mediterranean species in the plant taxa experiment

\begin{tabular}{|c|c|c|c|c|c|c|c|}
\hline Plant & Origin & $\begin{array}{c}\text { Native or } \\
\text { Naturalized } \\
\text { in CA }\end{array}$ & $\begin{array}{l}\text { Spreading } \\
\text { Mechanism }\end{array}$ & $\begin{array}{l}\text { Mature } \\
\text { Size H x } \\
W(\mathrm{~cm}) \dagger\end{array}$ & Exposure & $\begin{array}{l}\text { Green } \\
\text { Roof } \S\end{array}$ & Zone(s) \\
\hline $\begin{array}{l}\text { Fragaria } \\
\text { chiloensis }\end{array}$ & $\begin{array}{l}\text { Western } \\
\text { North } \\
\text { America }\end{array}$ & yes & $\begin{array}{l}\text { stolons, } \\
\text { seed }\end{array}$ & $\begin{array}{c}15 \mathrm{x} \\
\text { indefinite }\end{array}$ & FS & yes & 5 \\
\hline $\begin{array}{l}\text { Achillea } \\
\text { millefolium }\end{array}$ & $\begin{array}{l}\text { U.S., } \\
\text { Europe }\end{array}$ & yes & $\begin{array}{l}\text { rhizomes, } \\
\text { seed }\end{array}$ & $\begin{array}{c}90 \mathrm{x} \\
\text { indefinite }\end{array}$ & FS & yes & 2 \\
\hline $\begin{array}{l}\text { Dymondia } \\
\text { margaretea }\end{array}$ & $\begin{array}{l}\text { South } \\
\text { Africa }\end{array}$ & no & vegetative & $15 \times 22$ & FS & yes & $9-11$ \\
\hline $\begin{array}{l}\text { Delosperma } \\
\text { cooperii }\end{array}$ & $\begin{array}{l}\text { South } \\
\text { Africa }\end{array}$ & yes & vegetative & $18 \times 60$ & FS, PS & yes & 6 \\
\hline
\end{tabular}




\subsubsection{Fragaria chiloensis}

Beach strawberry (Fragaria chiloensis) is an herbaceous perennial forb that spreads by seeds, short rhizomes, and leafless stolons. It is an ancestor of all commercial strawberries (Anderson and Roderick, 2010; Brandies, 1982). Beach strawberry is found from the coast of Alaska to South America and in Hawaii. In California, Beach strawberry is found in coastal grassland and dune communities below 200 m (Anderson and Roderick, 2010).

Beach strawberry has leathery leaves with toothed margins and with a basal petiole 2 to $20 \mathrm{~cm}$. Shiny green leaves measure $5 \mathrm{~cm}$ wide and turn a reddish hue later in the season and into winter (Anderson and Roderick, 2010; Brandies, 1982). Flowers have five white petals (typical of most Roseaceae), measure $2.5 \mathrm{~cm}$, and can produce red fleshy achene fruit (Anderson and Roderick, 2010; Brandies, 1982).

Beach strawberry grows best in full sun, in a light and loose soil, and performs best with regular water (Brandies, 1982). It is best established in the fall or winter and is best planted at $25 \mathrm{~cm}$ on center (Anderson and Roderick, 2010). This species grows up to $15 \mathrm{~cm}$ and can spread indefinitely (MacKenzie, 1997).

Beach strawberry can be used effectively on slopes or as a ground cover where it receives light foot traffic. Growth of this plant can be stimulated with a light mowing in spring. New plants propagate from stolen sections spaced $30 \mathrm{~cm}$ on center (Brandies, 1982).

Beach strawberry is currently growing on the green roof at the California Academy of Sciences in $15-20 \mathrm{~cm}$ of media. It has been growing successfully since 2008 on slopes as steep as $40 \%$ (Cantor, 2008). 


\subsubsection{Achillea millefolium}

Yarrow (Achillea millefolium) is a drought tolerant perennial forb endemic to parts of Europe and the U.S. (Hurteau, 2006; Wyman, 1956). It is native to every state in the U.S. and Canada (USDA).

Yarrow produces one to several stems that grow $20-40 \mathrm{~cm}$ tall and branch from underground rhizomes (Hurteau, 2006). Yarrow can reach heights of $90 \mathrm{~cm}$ and can spread indefinitely (MacKenzie, 1997). Leaves are evergreen, lance-shaped and finely divided producing a distinctive feathery fernlike texture (Wyman, 1956). Leaves measure 0.6-3.2 cm wide and 3.2-15 cm long (Hurteau, 2006). Flowers appear from July through September in a flattened dome shape of 10-20 ray flowers (Hurteau, 2006; Wyman, 1956). Yarrow is recommended to be spaced $30-45 \mathrm{~cm}$ on center (Hurteau, 2006).

Yarrow spreads outward and is considered a tall, but satisfactory, ground cover able to thrive in a variety of climates. Yarrow prefers full sun, is hardy to zone 2, and can grow where soil is poor and dry. It can to be used as a lawn substitute because it can tolerate light foot traffic, has a tough spreading nature, and can be mowed to $15 \mathrm{~cm}$ (Wyman, 1956). Yarrow has a relatively short life span, which can be prolonged by dividing it every other year (Hurteau, 2006).

Yarrow has been used on several extensive green roofs in North America. The Oak Hammock Marsh and Peggy Notebaert Nature Museum green roofs both used Yarrow in less than $15 \mathrm{~cm}$ of media. It was also used at the green roof on the Clean Water Services Field Yard in Beaverton, OR in 8-10 cm of media (Cantor, 2008). 


\subsubsection{Dymondia margaretea}

Silver carpet (Dymondia margaretea) is a small, evergreen, herbaceous perennial native to South Africa. Leaves are small, leathery, and gray-green on top, with a light grey underside; they measure 5 to $7.5 \mathrm{~cm}$. Silver carpet forms a dense and tough mat of intertwining leaves 5 to $7.5 \mathrm{~cm}$ high as plants grow together. The resulting tight mat can handle light foot traffic. Inflorescences are small, yellow, and inconspicuous, measuring 2.5 to $4 \mathrm{~cm}$. They emerge in spring continuing into summer (Van Der Spuy, 1976).

Silver carpet should be planted at $20 \mathrm{~cm}$ on center, in full sun, and in friable (crumbly with equal amounts of sand, silt, and clay) well-drained soil to achieve good soil coverage. This species grows well in coastal and inland climates, tolerating moderate frost and mild drought conditions (Van Der Spuy, 1976). Its roots grow deep if conditions permit, giving the plant increased drought tolerance. Regular irrigation, however, will result in faster growth (Brenzel, 2001).

Silver carpet was used on the green roof at North Beach Place in San Francisco, CA. This particular green roof is much thicker than an extensive green roof, ranging from 23 to $91 \mathrm{~cm}$ project wide (Cantor, 2008).

\subsubsection{Delosperma cooperii}

Cooper's hardy ice plant (Delosperma cooperii) is a perennial groundcover native to South Africa (Snodgrass, 2006). Cooper's hardy ice plant differs from early common cultivars of Delosperma because it has greater cold tolerance and a high degree of drought tolerance (MacKenzie, 1997). 
Cooper's hardy ice plant has succulent and cylindrical glistening green leaves with a pointed tip that measure $5.5 \mathrm{~cm}$ x $0.6 \mathrm{~cm}$ (Van Der Spuy, 1976; MacKenzie, 1997). Cooper's hardy ice plant performs best in full sun (MacKenzie, 1997).

Cooper hardy ice plant is extremely florific, having pinkish-purple, $5 \mathrm{~cm}$-wide flowers beginning in early summer. The flowers' blanket-like effect until the heavy frosts in fall (MacKenzie, 1997).

Cooper's hardy ice plant may be used as a specimen plant, but it is usually planted as a ground cover used on steep slopes to retain soil since it roots quickly and grows rapidly (Van Der Spuy, 1976; MacKenzie, 1997). Cooper's hardy ice plant does not tolerate foot traffic (MacKenzie, 1997).

Cooper's hardy ice plant is the most commonly used species of this genus on the on green roofs (Snodgrass, 2006). Cooper's hardy ice plant was used on the extensive green roof (15 cm of media) at the Solaire Building in New York City. It was also used in the shallow green roof on the green roof at the Clean Water Services Field Yard.

This plant's rapid growth may increase maintenance costs in a green roof setting. For instance, an extensive green roof in Irvine, CA performed limited maintenance for two years, which resulted in the plant encroaching walkways and becoming intertwined with several surrounding species. This resulted in an undesirable appearance and ultimately changed the design intent (Mumford, personal communication, 2009).

\subsection{Sedges}

The sedge family (Cyperaceae) is similar in growth habit to the grass (Gramineae) family, and consists of roughly 3,000 species distributed among roughly 80 genera under the genus Carex. The leaves of sedges and grasses are similar; grasses, however, are two-ranked, 
whereas sedges are three-ranked forming a triangular stem base. Sedges' lower leaves are often greatly reduced. The most distinct identifier may be the fruit of sedges which are achene (oneseeded) and usually trigonous (triangular cross-section) (Oakes, 1990).

The natural habitat of sedges includes moist soils, but considerable diversity exists among species with respect to drought or wet soil tolerance (Oakes, 1990). Sedges are an important component in a variety of ecosystems, providing food and habitat requirements for a variety of wildlife (Walters and Keil, 1996). Several species of Carex exist on American commercial extensive green roofs with positive results. Table 2.3 summarizes the sedges used in the plant taxa experiment.

Table 2.3 Characteristics of the sedges used in the plant taxa experiment

\begin{tabular}{|c|c|c|c|c|c|c|c|}
\hline Plant & Origin & $\begin{array}{c}\text { Native or } \\
\text { Naturalized } \\
\text { in CA }\end{array}$ & $\begin{array}{l}\text { Spreading } \\
\text { Mechanism }\end{array}$ & $\begin{array}{c}\text { Mature } \\
\text { Size } H \times \text { W } \\
(\mathrm{cm}) \dagger\end{array}$ & Exposure & $\begin{array}{l}\text { Green } \\
\text { Roof } \S\end{array}$ & Zone(s) \\
\hline $\begin{array}{l}\text { Carex } \\
\text { glauca }\end{array}$ & Europe & no & rhizomes & $20 \times 20$ & PS & yes & $5-9$ \\
\hline $\begin{array}{l}\text { Carex } \\
\text { pragracilis }\end{array}$ & $\begin{array}{c}\text { North } \\
\text { America }\end{array}$ & yes & $\begin{array}{c}\text { rhizomes, } \\
\text { seed }\end{array}$ & $60 \times 90$ & FS, PS & no & 7 \\
\hline $\begin{array}{l}\text { Carex } \\
\text { testacea }\end{array}$ & New Zealand & no & seed & $30 \times 38$ & FS, PS & no & $8-9$ \\
\hline $\begin{array}{l}\text { Carex } \\
\text { divulsa }\end{array}$ & $\begin{array}{c}\text { Western North } \\
\text { America }\end{array}$ & yes & seed & $46 \times 46$ & FS, PS, S & no & $8-10$ \\
\hline
\end{tabular}

$\dagger$ Measurements of height by width in cm of plant at maturity

+ FS = Full Sun, PS = Part Shade, $\mathrm{S}=$ Shade

$\S$ Has been used on an extensive green roof before

\subsubsection{Carex glauca}

Blue sedge (Carex glauca) is a perennial graminoid endemic to Europe. This species is small compared to other sedges, rarely exceeding $15 \mathrm{~cm}$ tall (Greenlee, 1992). Blue sedge is more drought tolerant than most other Carex species, especially once established. It grows best in full sun and spreads via rhizomes forming a mat (Oakes, 1990). 
Blue sedge has distinct blue-gray foliage that measures 0.3 to $0.6 \mathrm{~cm}$ wide and 15 to 30 $\mathrm{cm}$ long (Greenlee, 1992). Leaves grow in clusters of 8 to 15 near the base of the plant and blooms are largely inconspicuous, occurring from June to July (Oakes, 1990; Greenlee, 1992). This species makes a good ground cover and is an acceptable lawn substitute (Oakes, 1990).

Blue sedge has been used on several extensive American green roof projects. In 2007, Blue sedge was used in on an extensive green roof in $10 \mathrm{~cm}$ of media New York, NY on the Wild Project Theatre (The Green Roof Projects Database, 2007). Blue sedge also thrives atop the Center for the Advancement of Green Roof Technology in Vancouver, British Columbia, due to its 2003 installation as part of an extensive green roof research project (Connelly, 2006). According to Snodgrass (2006), Blue sedge can grow $20 \mathrm{~cm}$ high and spreads $20 \mathrm{~cm}$ at a media depth of $15 \mathrm{~cm}$ in a green roof setting.

\subsubsection{Carex pragracilis}

Western meadow sedge (Carex pragracilis) is a highly adaptable evergreen graminoid species native to Alaska, parts of Canada and the U.S.; it has been naturalized in California. The use of western meadow sedge is rapidly spreading across the U.S. as an alternative lawn species and can be found as far east as Pennsylvania (Darke, 2007).

Western meadow sedge thrives in dry or moist habitats, including meadows, prairies, and along waterways. This species prefers full sun, but it can tolerate light shade. It is best established with plug plantings, as seeds are difficult to germinate. Western meadow sedge is salt tolerant and grows naturally in alkaline soils. It will go dormant when grown in climates with extremely dry and hot summers (Darke, 2007).

Western meadow sedge makes an ideal substitute to conventional lawns. Leaves are deep green and finely textured, growing to $30 \mathrm{~cm}$ if left unmowed. The plant spreads via 
rhizomes and grows into an extensive mat. It can tolerate considerable foot traffic and can be mowed or trimmed with a string trimmer. Western meadow sedge should not be mowed below $10 \mathrm{~cm}$ (Darke, 2007). Although this species is not found on any existing green roof plant palettes, its characteristics are consistent with those outlined in Section 2.4, which defines a successful green roof plant.

\subsubsection{Carex testacea}

Orange-colored sedge (Carex testacea) is endemic to New Zealand and is distinctly identified by its evergreen glossy foliage that turns an intense orange as it matures. Arching leaves are thin $(0.08$ to $0.16 \mathrm{~cm})$, and can reach $30 \mathrm{~cm}$ to $45 \mathrm{~cm}$ long. The inflorescences are largely inconspicuous and are arranged in long strands (Greenlee, 1992).

Orange-colored sedge prefers full sun in all but the hottest climates, but it also tolerates full shade. Nonetheless, this species needs strong light for at least half of the day to achieve its distinct green and orange coloring (Greenlee, 1992).

Orange-colored sedge's drought tolerance has been debated among industry experts. Darke (2007) describes it as one of the hardiest and drought-resistant of all the New Zealand sedges. However, King (1996) found that Orange-colored sedge preferred a more moist soil condition. Greenlee (1992) found that Orange-colored sedge thrives best in moist soil, but adds that soil should be well drained and rocky.

Orange-colored sedge was not found on any existing green roofs. However, it is commonly grown under challenging conditions in urban environments that exemplify some of the conditions of an extensive green roof described in Section 2.4 (Darke, 2007). 


\subsubsection{Carex divulsa}

Berkeley sedge (Carex divulsa) is an herbaceous perennial native to western North America. It is found in coastal prairie, pine, and redwood forests at elevations ranging from 0 to 1220 m (Calflora, 2010).

Berkeley sedge can reach 45 to $60 \mathrm{~cm}$ tall and can grow as wide, but usually forms smaller clumps 20 to $30 \mathrm{~cm}$. Its dark green leaves are $0.31 \mathrm{~cm}$ wide and 20 to $30 \mathrm{~cm}$ long and arch out gracefully. In the spring, brownish flowers emerge and are held on by thin, floppy stems (Greenlee, 1992).

Berkeley sedge is a moderately fast grower compared to other sedges, and it tolerates a variety of soil and light conditions. Berkeley sedge is somewhat drought tolerant once established, but prefers regular watering. In cold climates on the border of zone 8 , it may become semi-deciduous, but mowing or trimming back once or twice annually may help give it a fresh appearance. Berkeley sedge grows in sun or shade (Greenlee, 1992). While this species was not found on any green roof plant palettes, it fits many of the criteria outlined in Section 2.4.

\subsection{Sedum}

Stonecrops (Sedum) are the most commonly used genus on extensive green roofs because of their drought tolerance and adaptability to shallow substrates (Getter and Rowe, 2007). Most stonecrops prefer a climate with a large diurnal temperature range and employ Crassulacean Acidic Metabolism (CAM). Non-CAM plants, which conduct gas exchange through their stomata during the day, experience incredible water loss during the warmest parts of the day or under windy conditions. CAM plants prevent this by operating under a specialized form of photosynthesis, where stomata open at night for gas exchange. During the day, the plant 
stores light energy to be used to convert carbon (stored in the form of malic acid) into sugars (Stephenson, 1994).

Stonecrops are found all over the world, but are generally endemic to the Northern Hemisphere. Three contrasting regions, the Mediterranean, Himalayas, and Central Mexico have a particularly high number of species. The Mediterranean Sea margins and islands, plus its new fold mountain ranges (especially the Sierra Nevada, Pyrenees, Central Massif, Alps, Apennines, Dinaric Alps, Balkan Uplands, and Atlas ranges) experience intense summer drought and are home to over 100 species. The Himalayan Mountains, which house several Sedum species, experience intense winters at extremely high altitudes. Mexico, home to an additional 100 species, possesses diverse geography that allows stonecrops grow in a relatively new volcanic upland zone, damp shady canyons, and at high altitudes (Stephenson, 1994).

Stonecrops grow in a well-drained medium where there is little competition from other vegetation. In the landscape, they can grow in any soil in full sun or part shade (Brandis et al., 1982). Most stonecrops will survive if not watered for a month or more, but they prefer weekly irrigation during the growing season. Fertilizer should be used sparingly because plants take on an uncharacteristic appearance if provided with too much nutrition. They will benefit from a low nitrogen organic source or CRF (Stephenson, 1994). Table 2.4 outlines the stonecrop species used in the growing media and plant taxa experiments. 
Table 2.4 Characteristics of Sedum species used in the plant taxa experiment

\begin{tabular}{lccccccc}
\hline Plant & Origin & $\begin{array}{c}\text { Native or } \\
\text { Naturalized } \\
\text { in CA }\end{array}$ & $\begin{array}{c}\text { Spreading } \\
\text { Mechanism }\end{array}$ & $\begin{array}{c}\text { Mature } \\
\text { Size }(\mathbf{H ~ x} \\
\text { W) }(\mathbf{c m}) \dagger\end{array}$ & Exposure $\dagger$ & $\begin{array}{c}\text { Green } \\
\text { Roof } \S\end{array}$ & Zone(s) \\
\hline $\begin{array}{l}\text { Sedum } x \\
\text { rubrotinctum }\end{array}$ & horticultural & no & shoots, seed & $20 \times 15$ & FS & yes & 7 \\
\hline Sedum acre $^{\mathrm{B}}$ & $\begin{array}{c}\text { Europe, } \\
\text { Asia }\end{array}$ & yes & shoots & $5 \times 20$ & FS & yes & $4-9$ \\
\hline $\begin{array}{l}\text { Sedum rupestre } \\
\text { 'Angelina, }\end{array}$ & Europe & no & shoots & $12 \times 20$ & FS & yes & 4 \\
\hline $\begin{array}{l}\text { Sedum spurium } \\
\text { 'Tricolor'B }\end{array}$ & Europe & no & shoots & $15 \times 20$ & FS & Yes & 5 \\
\hline $\begin{array}{l}\text { Sedum album } \\
\text { Ped }\end{array}$ & $\begin{array}{c}\text { Europe, } \\
\text { Asia }\end{array}$ & yes & shoots & $15 \times 20$ & FS & yes & $4-8$ \\
\hline
\end{tabular}

$\dagger$ Measurements of height by width in $\mathrm{cm}$ of plant at maturity

$\$ \mathrm{FS}=$ Full Sun, $\mathrm{PS}=$ Part Shade, $\mathrm{S}=$ Shade

$\S$ Has been used on an extensive green roof before

${ }^{\mathrm{B}}$ Used in growing media and plant taxa experiment

${ }^{\mathrm{P}}$ Used in the plant taxa experiment

\subsubsection{Sedum $x$ rubrotinctum}

Pork and beans (Sedum x rubrontictum) is a cultivar of horticultural origin and has distinctive cherry red-tipped, thick, spirally arranged leaves. Pork and beans is generally desired for its aesthetic appeal rather than the characteristic hardiness of most stonecrops (Stephenson, 1994). Pork and beans foliage is particularly responsive to high light and low soil moisture, which causes its leaves to turn cherry red. It becomes deep green when overwatered or in heavy shade (Stephenson, 1994).

Stems are 7.5 to $15 \mathrm{~cm}$ long and have leaves originating on the top half of the stem (Brandies, 1982). Pork and beans self seeds and readily spreads by vegetative sections. Yellow flowers emerge in spring to midsummer and provide a striking contrast to its red foliage (Stephenson, 1994). 
Pork and beans can only withstand mild winters, but exhibits extreme drought tolerance. A study by Terri et al. (1986) found that, after two years without irrigation, greenhouse-grown pork and beans still had apical leaves that remained turgid. It was presumed that these plants maintained turgor by an osmotic adjustment (Terri et al., 1986).

Pork and beans has been used specifically in extensive green roof experiments because of its adaptability to harsh environments. Durham et al. (2007) showed that pork and beans rapidly covered bare soil, independent of depth $(2.5,5$, and $7.5 \mathrm{~cm})$ in as little as five months. Pork and beans was used on several shallow extensive green roofs, with media depths ranging from 2.5-7 cm at various slopes, at Autonomous University of Chapingo in Mexico City. This study aimed to observe an extensive green roof system that required minimal maintenance and irrigation (Cantor, 2008).

\subsubsection{Sedum acre}

Biting stonecrop (Sedum acre) is endemic to almost every country in Europe and to regions as remote as Greenland and New Zealand. It is identified by its broad leaf bases. Yet this species' most distinctive characteristic is its sepals (leaf-like bracts enclosing a petals), which are free and spurred. In fact, free sepals are unique to Biting stonecrop and the yellow flowers are unique in the European stonecrop species (Stephenson, 1994). Biting stonecrop has showy, bright yellow inflorescences and is known to be a facultative CAM species, meaning it can alter its photosynthetic pathway in response to environmental stresses (Stephenson, 1994; Sayed, 2001).

Biting stonecrop grows vigorously, reaching a height of $10 \mathrm{~cm}$. Each leaf is short and broad-based with an obtuse, short, broadly triangular spur. Inflorescences measure $2 \mathrm{~cm}$ in diameter and grow on a few simple branches. When flowering, shoots senesce and several others 
grow out of the base, some of which will be the following year's inflorescence (Stephenson, 1994).

Biting stonecrop produced marginal results in an extensive green roof experiment conducted in Sweden. The researchers used 30, 40, and $70 \%$ biting stonecrop in three plant mixes and concluded that, over the first 18 months, the three plant mixes covered only $20-65 \%$ of the media. This decreased to $10 \%$ at the end of three years. In the same experiment, it was noted that it flowered profusely in the first 18 months, increasing its aesthetic value in the short term (Emilsson, 2007).

Biting stonecrop showed different growth rates at different media depths. Durhman and Rowe (2007) planted plugs of biting stonecrop in media of 2.5, 5, and $7.5 \mathrm{~cm}$ depth and found increases in growth of 47,106 , and $281 \mathrm{~cm}^{2}$, respectively, after 15 months.

\subsubsection{Sedum rupestre 'Angelina'}

Crooked stonecrop (Sedum rupestre 'Angelina') is endemic to Central and Western Europe. It possesses stiff, succulent, apiculate (sharp, abrupt ends) and terete (round crosssection) leaves that are light green to yellow. Crooked stonecrop can be found in many contrasting locations and soils, ranging from coastal sand dunes to $2000 \mathrm{~m}$ altitudes in the Pyrenees Mountains. In warmer, drier climates, leaves cluster at the ends of sturdy and erect bare stems. Although crooked stonecrop can be used as a ground cover, it grows more erect than pork and beans and biting stonecrop. Therefore, crooked stonecrop is commonly used in rock gardens or as a border plant (Stephenson, 1994).

Yellow flowers emerge (inconsistently) in midsummer and can reach $30 \mathrm{~cm}$ (Stephenson, 1994). The cultivar 'Angelina' is able to withstand harsh winters. In general, 
individual plants can be expected to reach heights of $12 \mathrm{~cm}$ and spread $20 \mathrm{~cm}$ under green roof environments (Snodgrass, 2006).

Crooked stonecrop is commonly used in northern parts of the U.S on green roofs (Snodgrass, 2006). Yet, research at Michigan State University found that crooked stonecrop is an undesirable green roof plant because it achieved slightly more than $1 \%$ soil coverage in media depths of $10 \mathrm{~cm}$ after 135 days when initiated in late spring. Less soil coverage was found at substrate depths of 7 and $4 \mathrm{~cm}$.

\subsubsection{Sedum spurium 'Tricolor'}

Sedum spurium 'Tricolor' is possibly the most common cultivated species of stonecrop used for green roofs. Sedum spurium 'Tricolor' is a rapidly growing ground cover with green leaves that have either a creamy white or wine red edge, or both. In Europe, 'Tricolor' is sold as Sedum spurium var. variegatum. This name is actually more appropriate, since the plant is not found in the wild. 'Tricolor' is endemic to the Caucasus mountain range, Armenia, and northern Iran. It is marketed under several names, including S. oppositifolium Sims, S. involucratum Marschall von Bieberstein, Asterosedum spurium (Marschall von Bieberstein) Grulich, and Spathulata spuria (Marschall von Bieberstein). 'Tricolor' is characterized by its large, flat, crenately-serrate leaves, which are opposite-decussate (leaves in pairs at right angles to next pair) and reduce to terminal buds in winter when long, slender visible stems are exposed (Stephenson, 1994).

Sedum spurium 'Tricolor' is able to survive temperatures as low as $-40^{\circ} \mathrm{F}$ (Brandies et al, 1982). Sedum spurium 'Tricolor' is a common choice for green roof experiments. Getter and Rowe (2008) tested 12 species of stonecrop in northern Michigan and found Sedum spurium 'John Creech' (cultivar with smaller foliage) to be suitable; it was surpassed by only one other 
species. Durham et al. (2007) found that Sedum spurium 'Summer Glory' grew well at media depths of $7.5 \mathrm{~cm}$ and $10 \mathrm{~cm}$, but was less effective at a depth of $5 \mathrm{~cm}$.

Sedum spurium 'Tricolor' has been used on several extensive green roofs in North America (Cantor, 2008). This species grows $15 \mathrm{~cm}$ high and spreads $20 \mathrm{~cm}$ in a green roof environment (Snodgrass, 2006).

\subsubsection{Sedum album}

White stonecrop (Sedum album) is the most commonly used garden plant across Europe. It may be available in more varieties than any other species of stonecrop. White stonecrop is endemic to every country in Europe except for Ireland and Iceland. It is also found in North Africa and is reported to grow as far east as Mongolia. White stonecrop adapts to a multitude of climates, altitudes, and terrains (Stephenson, 1994).

White stonecrop is a prolific ground cover, and can regenerate itself from a single fallen leaf. When using white stonecrop, one must consider encroachment upon less vigorous species (Stephenson, 1994).

White stonecrop is characterized by its blunt, scattered leaves and by its flower development. Budding flowers, called reflexed inflorescences, turn upright to form flattish cymes (compact inflorescences), each carrying numerous white or pink-white flowers. Generally, White stonecrop grows $12 \mathrm{~cm}$ high with inflorescences growing upward an additional $5 \mathrm{~cm}$ (Stephenson, 1994).

White stonecrop has been used in research experiments and on many existing extensive green roofs in the United States. For instance, The Green Institute in Minneapolis and the Peggy

Notebaert Nature Museum both maintain white stonecrop on their extensive green roofs (Cantor, 2008). Durhman et al. (2007) used Sedum album 'Bella d' Inverno' and found favorable growth 
under extensive green roof conditions at $2.5,5$, and $7.5 \mathrm{~cm}$ media depths over $482 \mathrm{~d}$. Sedum album 'Bella d' Inverno' was the only species to have a growth rate greater than $1.5 \mathrm{~cm}^{2}$ in coverage per day at a depth of $2.5 \mathrm{~cm}$. 


\section{Chapter 3: Materials and Methods}

\subsection{General Information}

\subsubsection{Location and Description of Study Site}

Both experiments were conducted at the Environmental Horticultural Science (EHS) unit at the northeastern end of the California Polytechnic State University campus. Testing platforms were located in a sunny location within the EHS unit (Figure 3.1). Platforms were positioned near water sources for irrigation.

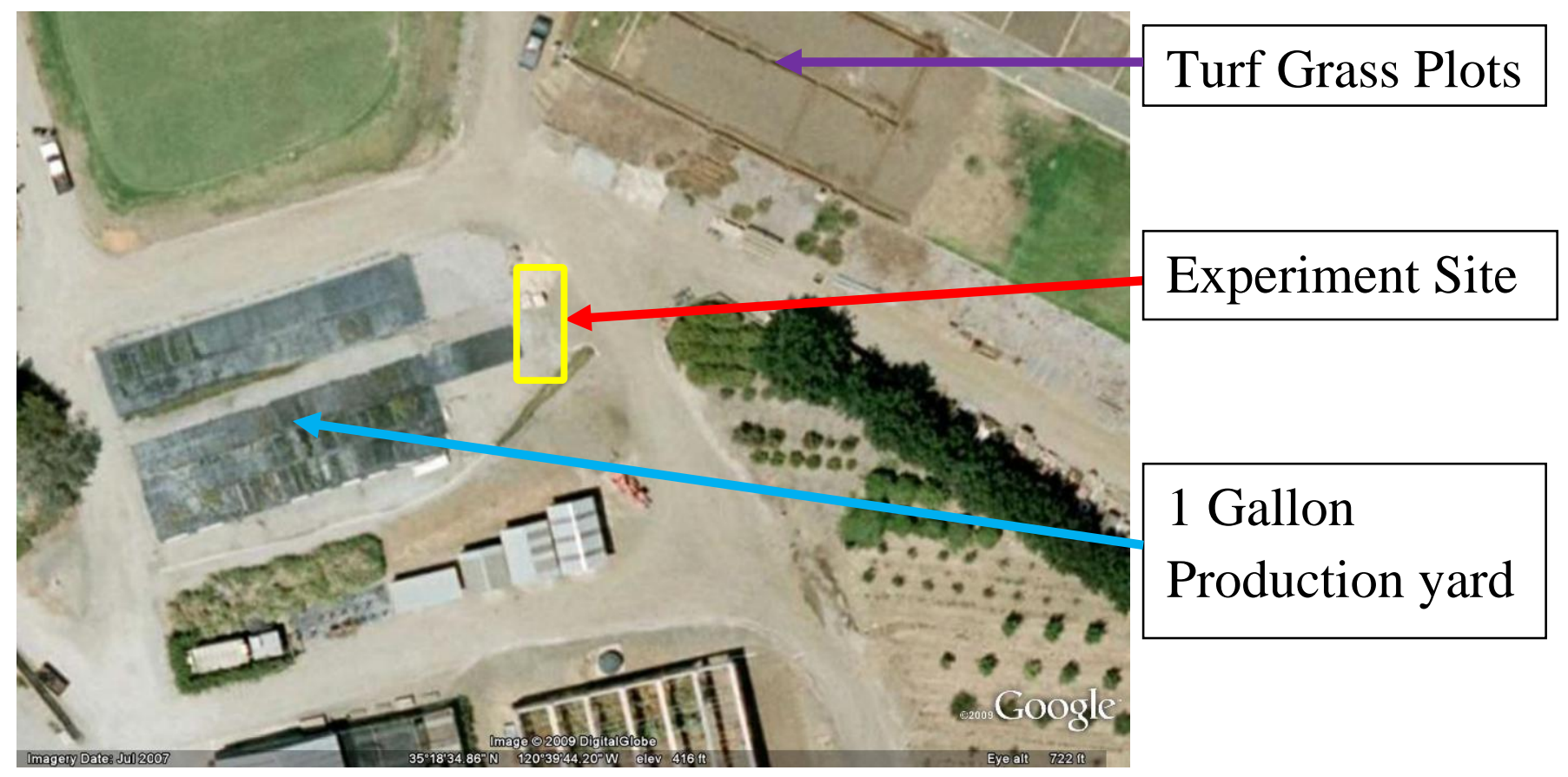

Figure 3.1 Location of experiment testing platforms within the EHS unit at Cal Poly 


\subsubsection{Experiment Maintenance}

Several maintenance duties were performed over the course of the experiment. On a few occasions, weather caused unanticipated problems that required corrective action, but most items were expected and similar to what is required in a commercial environment.

Weeds in the growing media were controlled by hand pulling weekly. Larger weeds growing in the soil surrounding the platforms were controlled with a string trimmer and a hula hoe.

\subsection{Choosing Plant Taxa}

Plant species were chosen from the plant pallets of over 20 successful United States green roof projects and by looking at species used in similar studies. From this appraisal, plants were selected and placed in four groups. The first three groups, Sedum, grasses and sedges were selected because they were common plants used in other green roof studies. A fourth group, called "Mediterranean species" contained a mix of plants; it was created to encompass four plants that have desirable green roof characteristics (Section 2.4) but did not fit into a defined group. These four plants were Fragaria chiloensis, Achillea millefolium, Dymondia margaretea, and Delosperma cooperii.

Each plant group has four species. Sedum, the most common and successful genus employed for green roofs, was the only group used for the growing media experiment because of its proven performance on green roofs. The other three plant groups were chosen because of their commonality and adherence to the green roof plant characteristics outlined in Section 2.4. 


\subsubsection{Propagation}

All plant material was propagated as described in Table 3.1. Plants were harvested from the CPSU Leaning Pine Arboretum and some plants were purchased from Native Sons Nursery in Arroyo Grande, California.

All plants were established in plug trays using a 1:1:1 mixture of peat moss, Perlite and fir bark and amended with dolomite $\left(21 \mathrm{oz} / .75 \mathrm{~m}^{3}\right)$ and triple superphosphate $\left(17 \mathrm{oz} / .75 \mathrm{~m}^{3}\right)$.

Table 3.1 displays the plant material origin and propagation method.

Table 3.1 Origin, genus and species, propagation method, and number of days until the plug was considered fully rooted for the $\mathbf{1 7}$ plant species used

\begin{tabular}{|c|c|c|c|c|c|}
\hline Plant Taxa & Origin $\dagger^{\dagger}$ & $\begin{array}{l}\text { Propagation } \\
\text { Method }\end{array}$ & $\begin{array}{l}\text { Days Until } \\
\text { Rooted }\end{array}$ & $\begin{array}{c}\text { Quantity } \\
\text { Propagated }\end{array}$ & $\begin{array}{l}\text { Quantity } \\
\text { Used }\end{array}$ \\
\hline Sedum $x$ rubrontictum $\$$ & $\mathrm{CP}$ & Cuttings & 40 & $122 \ddagger$ & 61 \\
\hline Sedum acre & NS & Cuttings & 30 & $122 \ddagger$ & 61 \\
\hline Sedum rupestre 'Angelina' & NS & Cuttings & 34 & $122 \ddagger$ & 61 \\
\hline Sedum spurium $\ddagger$ & $\mathrm{CP}$ & Cuttings & 33 & $122 \ddagger$ & 61 \\
\hline Sedum album & NS & Cuttings & 31 & 50 & 25 \\
\hline Festuca glauca 'Blue Note' & NS & Dividing & 45 & 50 & 25 \\
\hline $\begin{array}{l}\text { Buchaloe dactyloides 'UC } \\
\text { Verde' }\end{array}$ & $\mathrm{CP}$ & Dividing & 29 & 50 & 25 \\
\hline Sporobolus airoides & NS & Dividing & 31 & 50 & 25 \\
\hline Boutelouea gracilis & $\mathrm{S}$ & Seed & 27 & 50 & 25 \\
\hline Carex glauca & NS & Dividing & 39 & 50 & 25 \\
\hline Carex pragracilis & $\mathrm{CP}$ & Dividing & 57 & 50 & 25 \\
\hline Carex flacca & NS & Dividing & 46 & 50 & 25 \\
\hline Carex divulsa & NS & Dividing & 43 & 50 & 25 \\
\hline Fragaria chiloensis & $\mathrm{CP}$ & Cuttings & 40 & 50 & 25 \\
\hline Achillea millefolium & $\mathrm{CP}$ & Cuttings & 42 & 50 & 25 \\
\hline Dymondia margaretae & $\mathrm{CP}$ & Cuttings & 56 & 50 & 25 \\
\hline Delosperma cooperii & $\mathrm{CP}$ & Cuttings & 21 & 50 & 25 \\
\hline
\end{tabular}

$\dagger$ Origin: $\mathrm{CP}=\mathrm{Cal}$ Poly Horticulture Unit or Leaning Pine Arboretum; NS=Native Sons Nursery in Arroyo Grande, $\mathrm{CA}$; $\mathrm{S}=$ seed

$\ddagger$ Sedum were used in both experiments so more plants were needed 
All rootless cuttings were planted directly into the propagation medium and moved into the mist house for two weeks, where they began to root. Cuttings of inconsistent size were trimmed or discarded until uniform. Once rooted, propagules were moved outdoors into a shade house to harden. In the shade house, plants were maintained for optimum growth and uniformity. After 30 days in the shade house, they were moved to full sun to be acclimated to normal environmental test conditions.

Grasses and sedges were removed from the arboretum in large clumps. These plants were divided using a sterilized handsaw into smaller sections (e.g. 10-15 cm). Hand pruners were used to reduce the root mass and vegetation into propagules that would fit into plug cells. Once planted, the grasses and sedges were maintained in the same manner as the cuttings.

The only plant propagated by seed was the blue grama grass, which was purchased online (www.seedsource.com). Seeds were placed in a plastic bag filled with water, pre-soaked for 36 hours, and then drained before planting. Five to seven pre-soaked seeds were planted in a 72-cell count plug tray filled with the 1:1:1 medium described above. Seeds were covered with media and the plug tray was placed in a mist house.

After 48 hours of mist, there was evidence of germination. Following 10 days under mist, they were moved to a shade house where they remained moist. After two weeks, the plugs were transferred to outdoor benches for acclimatization.

\subsection{Platform Assembly and Infrastructure}

Platforms were constructed using the tools and materials in Appendices B and C. Appendix E includes the step-by-step construction process taken, and Appendix F shows two drawings that correlate with the steps in Appendix E. 


\subsubsection{Platform Support}

The platforms were raised about $1 \mathrm{~m}$ above ground level and supported by concrete blocks. Both experiments represent a flat roof, but require a $2 \%$ slope for drainage. Figure 3.2 illustrates the method by which the platforms were leveled using wooden shims placed between the platform deck and the blocks.

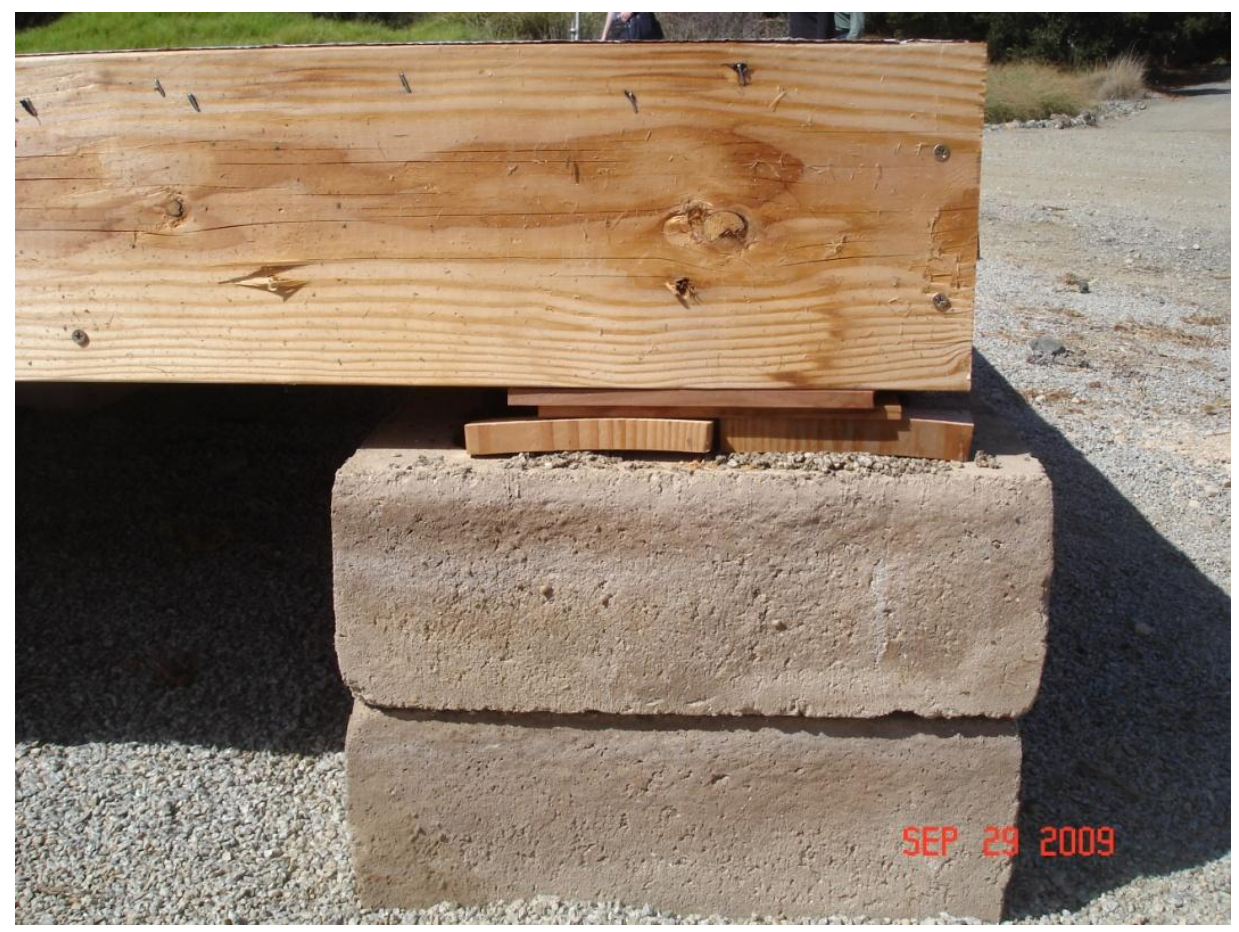

Figure 3.2 Concrete blocks and wooden shims were used for support and slope manipulation

\subsubsection{Waterproof Membrane}

Protecto Wrap ${ }^{\circledR}$ BT25XL Window and Door Sealing Tape was used to provide a waterproof membrane. BT25XL is a $25-\mathrm{mil}(0.64 \mathrm{~mm})$ polyethylene backed rubberized selfadhering air/vapor barrier and waterproofing membrane. This material can be applied to a wide range of materials, including vinyl, plywood, Oriented Strand Board (OSB), concrete, metal, 
block and masonry surfaces (Protectowrap, 2009). The American Society for Testing and Materials (ASTM) guidelines for BT25XL are shown in Table 3.2.

Table 3.2 ASTM International guidlies met by Protecto Wrap ${ }^{\circledR}$ BT25XL (Protectowrap, 2009)

\begin{tabular}{|c|c|}
\hline $\begin{array}{l}\text { ASTM } \\
\text { Standard }\end{array}$ & Description \\
\hline ASTM D412 & $\begin{array}{l}\text { Standard test method for vulcanized rubber and thermoplastic elastomers- } \\
\text { tension }\end{array}$ \\
\hline ASTM E96 & Standard test method for water vapor transmission of materials \\
\hline ASTM E2112 & Weatherproofing around doors and windows in building construction. \\
\hline ASTM E331 & $\begin{array}{l}\text { Standard test method for water penetration of exterior windows, skylights, } \\
\text { doors and curtain walls under by uniform static air pressure difference (the } \\
\text { only flashing tape to pass this test which involves hurricane force wind- } \\
\text { driven rain) }\end{array}$ \\
\hline
\end{tabular}

BT25XL can be used to create a waterproofing membrane that forms an impenetrable barrier on the following applications (Protectowrap, 2009):

- Window and door perimeters to the building substrate

- Joints in stucco insulation systems

- Wallboard joints in roof assemblies

- Beneath metal cap flashings for full building coverage as an air/vapor barrier

- Other areas where a water or air seal is required

BT25XL becomes sticky and difficult to install when temperatures exceeded $24^{\circ} \mathrm{C}$.

For this reason, installation was done either in early morning or evening, when temperatures decreased. 


\subsubsection{Waterproof Membrane Installation}

To begin installing BT25XL on the platform deck, a single $10 \times 10 \mathrm{~cm}$ piece was placed in each of the four corners to bridge the connection between the two boards that conjoin to form a corner (see Appendix G, Figure A). Sections of membrane were applied starting at the low end after determining in which direction the platform would drain. Sections of BT25XL were laid on the bottom sideboard and spanned across the $90^{\circ}$ angle at the low end. Since there were two $90^{\circ}$ angles to cover, it was easier to handle and apply this layer in sections about $30 \mathrm{~cm}$ across (see Appendix G, Figure B). Subsequent membrane layers were overlapped starting at the low end and moving upwards, as shown in Appendix G, Figure C. Overlapping allowed water to drain more efficiently and eliminated pooling. These horizontal layers started at the top of one sideboard and ended at the top of the other, spanning the entire deck.

The last layer of BT25XL was installed at the high end of the platform in the same manner as the first layer applied at the low end. However, this layer was applied on top of the lower layer for drainage purposes (Appendix G, Figure D). After the platform deck was completely covered with the waterproof membrane, (Appendix G, Figure E) drainage holes were drilled into the low end of the platform to allow water to exit after draining through the medium (Appendix G, Figure F).

\subsubsection{Installing the Drainage Layer and Filtration Cloth}

Colbond Enkadrain® 3611R served as the drainage layer and filtration cloth and was

placed between the waterproof membrane and growing medium in both experiments. The core of Enkadrain ${ }^{\circledR}$ is made of post-industrial recycled polypropylene. It is produced by fusing entangled filaments and a geocomposite fabric that is bonded to one side. Enkadrain ${ }^{\circledR}$ can 
contribute up to two LEED (Leadership in Engineering and Environmental Design) points when used in conjunction with other recycled materials (Enkadrain, 2009). Enkadrain ${ }^{\circledR}$ fibers filter drainage water and stop all but the smallest particles. Water remaining in the fiber drains through the porous layer and follows gravity out of the system.

Three pieces of Enkadrain $®$, cut lengthwise, were used to cover the deck of each platform. Starting along one edge of the platform, pieces were laid cloth side up and cut to fit the length of the platform. The next piece was laid parallel to the first piece and fit in the same manner (Appendix H, Figure A). A third piece was cut at its length and width to fit over the remaining portion of the platform deck.

Each section of Enkadrain ${ }^{\circledR}$ had a loose flap of soil filtration fabric about $7.5 \mathrm{~cm}$ long running lengthwise down one side. This flap was laid over the neighboring section of Enkadrain ${ }^{\circledR}$ and a continuous piece of duct tape secured the sections together (Appendix H, Figure B). Duct tape was also placed along the perimeter of the inside of the platforms, where the Enkadrain ${ }^{\circledR}$ met the side walls of the platforms. This secured the Enkadrain ${ }^{\circledR}$ to the platform and prevented growing medium from spilling beneath the drainage layer (shown in Appendix $\mathrm{H}$, Figure C).

\subsection{Growing Media}

\subsubsection{Growing Medium One}

Medium One is a modular green roof system invented by Joe Byles of New Braunfels, Texas and sold by Freedom Garden Products. It is shipped as 107 x $107 \mathrm{~cm}$ squares, that are 5 $\mathrm{cm}$ thick, and it contains a growing medium called Aqualok ${ }^{\mathrm{TM}}$. The growing medium is made of high molecular weight polyethylene material derived from recycled plastic (Freedom Garden 
Products, 2009). Aqualok ${ }^{\mathrm{TM}}$ supports a wider range of green roof plants compared to conventional granular media, including shrubs, woody ornamentals, bedding plants, and turf. It makes efficient use of water by absorbing it through its pores, while still allowing plant roots to breathe (Landscape Management, 2008).

Medium One has many advantages compared to granular media. Generally, granular media are heavy and require cranes, conveyor systems, blower trucks, or scissor lifts to transport the media to a roof (Green Roof Design 101, 2006). Medium One can be transported atop the roof through an elevator, by hand, or using a ladder. Coordinating installation may be easier because Aqualok ${ }^{\mathrm{TM}}$ can be stacked virtually anywhere on the roof, which is not an option with granular media because of the load bearing capacity of the structure during installation. On level roofs, another advantage is that irrigation frequency can be reduced by the waterproof basin, which traps water and increases its availability to the plant, as opposed to draining through the medium.

Currently, Medium One is used on the Los Angeles Water Board Building's extensive green roof, as well as on several green roofs on the East Coast. At the time of this study, these installations are performing well and considered a success (Helfman, 2009).

Medium One did not fit our platform dimensions and was modified to fit into the experimental design. An Ethylene Propylene Dione Monimer (EPDM) pond liner was used to simulate the water retention that occurs from the waterproof basin of Medium One. Nine square sections of pond liner were cut to fit the dimensions of the nine sections (three per platform). The corners of each pond liner section were folded and tucked downward to minimize any obstruction. Small boards $(0.635 \times 3.81 \times 76.3 \mathrm{~cm})$ were cut to fit the top perimeter of each section with pond liner. These were placed over the pond liner and secured with one-inch 
drywall screws. Appendix I, Figure A shows a completed section before Medium One was placed inside. The figure also illustrates the modified waterproof basin and small holding boards. Medium One was then trimmed from its original size of $106.68 \times 106.68 \mathrm{~cm}$, resulting in pieces that were roughly $76.3 \times 76.3 \mathrm{~cm}$. The area was calculated as follows:

Platform: $\quad 244 \times 244 \mathrm{~cm}-$ width of divider boards $=229 \times 229 \mathrm{~cm}=52,443 \mathrm{~cm}^{2}$

Each Platform Section:

Three Sections per Platform:

Three Platforms:
$52,441 \mathrm{~cm}^{2} / 9$ platform sections $=5827 \mathrm{~cm}^{2}$

$$
5827 \mathrm{~cm}^{2} \times 3 \text { sections }=17,481 \mathrm{~cm}^{2}
$$

$17,481 \mathrm{~cm}^{2} \times 3$ platforms $=52,443 \mathrm{~cm}^{2}$ needed

Nine Total Sections Needed, Each: $\quad 76.3 \times 76.3 \mathrm{~cm}$

Aqualok ${ }^{\mathrm{TM}}$ thickness (depth) predetermined by Freedom Garden Products: $5.08 \mathrm{~cm}$

By January 5, 2010, it became apparent that Medium One was degrading from the sun. Freedom Garden Products recommended that a $2 \mathrm{~cm}$ layer of landscape mulch be applied atop Medium One. Mulch was carefully spread, by hand, around the plant material and watered with a hose to clean off the plant material. Additional mulch had to be added on two occasions because it was blown away by the wind.

\subsubsection{Growing Medium Two}

Medium Two was developed by Skyland USA (Avondale, PA) and is sold under the brand Rooflite ${ }^{\circledR}$ Extensive MC (multi-course). Medium Two is more established in the green roof industry than Medium One, as it is granular and derived from natural sources. Medium Two has one main performance goal: water management. This water management has been accomplished through material testing to achieve a proper porosity and particle size gradation 
that drains water rapidly and also retains $50 \%$ water by volume after a rain event (Donnelly, 2009). Medium Two meets all FLL guidelines for extensive green roof growing media when tested by several laboratories in both Germany and the U.S. (Skyland USA, 2009). Table 3.3 shows the soil analysis for Medium Two, which was conducted by the Agricultural Analytical Laboratory Service at Pennsylvania State University. Several critical green roof performance variables and their relation to FLL ranges are shown.

Table 3.3 Rooflite Extensive MC Specifications with quantity values based on FLL extensive growing media ranges (Skyland USA, 2009)

\begin{tabular}{|c|c|c|}
\hline Item & Measurement Unit & $\begin{array}{c}\text { FLLRange } \dagger / \\
\text { Amount } \\
\end{array}$ \\
\hline $\begin{array}{l}\text { Particle Size Distribution } \\
(\leq 0.05 \mathrm{~mm})\end{array}$ & Mass \% & $13.8 \div(\leq 15)$ \\
\hline $\begin{array}{l}\text { Density Measurements } \\
\text { Bulk Density (dry weight basis) } \\
\text { Bulk Density (dry weight basis) } \\
\text { Bulk Density (at max. water-holding capacity) } \\
\text { Bulk Density (at max. water-holding capacity) }\end{array}$ & $\begin{array}{l}\mathrm{g} / \mathrm{cm}^{3} \\
\mathrm{~kg} / \mathrm{m}^{3} \\
\mathrm{~g} / \mathrm{cm}^{3} \\
\mathrm{~kg} / \mathrm{m}^{3}\end{array}$ & $\begin{array}{r}(0.70-0.85) \\
(705-848) \\
(1.15-1.35) \\
(1153-1362) \\
\end{array}$ \\
\hline $\begin{array}{l}\text { Water / Air Measurements } \\
\text { Total Pore Volume } \\
\text { Maximum water-holding capacity } \\
\text { Air-filled porosity at max. water-holding capacity } \\
\text { Water permeability (saturated hydraulic conductivity) } \\
\text { Water permeability (saturated hydraulic conductivity) }\end{array}$ & $\begin{array}{r}\text { volume } \% \\
\text { volume } \% \\
\text { volume } \% \\
\mathrm{~cm} / \mathrm{sec} \\
\mathrm{in} / \mathrm{min}\end{array}$ & $\begin{array}{r}(\geq 65) \\
(35-65) \\
(\geq 10) \\
(0.00-0.12) \\
(0.024-2.83) \\
\end{array}$ \\
\hline $\begin{array}{l}\text { pH and Salt Content } \\
\text { pH in }\left(\mathrm{CaCl}_{2}\right) \\
\text { Soluble salts (water extract) } \\
\text { Soluble salts (gypsum extract) }\end{array}$ & $\begin{array}{l}\mathrm{g} / 1 \\
\mathrm{~g} / 1\end{array}$ & $\begin{array}{l}(6-8.5) \\
(<3.5) \\
(<2.5)\end{array}$ \\
\hline $\begin{array}{l}\text { Organic Measurements } \\
\text { Organic matter content }\end{array}$ & Mass \% & 8.3 \\
\hline $\begin{array}{l}\text { Nutrients } \\
\text { Phosphorus, } \mathrm{P}_{2} \mathrm{O}_{5}(\mathrm{CAL}) \\
\text { Potassium, } \mathrm{K}_{2} \mathrm{O}(\mathrm{CAL}) \\
\text { Magnesium, } \mathrm{Mg}\left(\mathrm{CaCl}_{2}\right) \\
\text { Nitrate + Ammonium }\left(\mathrm{CaCl}_{2}\right)\end{array}$ & $\begin{array}{l}\mathrm{mg} / \mathrm{l} \\
\mathrm{mg} / \mathrm{l} \\
\mathrm{mg} / \mathrm{l} \\
\mathrm{mg} / \mathrm{l}\end{array}$ & $\begin{array}{l}(<200) \\
(<700) \\
(<200) \\
(<80)\end{array}$ \\
\hline
\end{tabular}

$\uparrow$ FLL ranges are represented in parenthesis

$\$$ Numbers not in parenthesis are actual readings for Medium Two 
Medium Two was blended at Pacific Coast Forest Products in Arvin, California and was delivered in super sacks. Medium Two was used in both experiments. The quantity of Medium Two for the growing media experiment was calculated as follows:

Platform: $\quad 244 \times 244 \mathrm{~cm}-$ width of divider boards $=229 \times 229 \mathrm{~cm}=52,443 \mathrm{~cm}^{2}$

Media Depth:

Three platforms:

Divided evenly amongst each medium:

$\mathrm{cm}^{3} \rightarrow \mathrm{m}^{3}:$
$52,443 \mathrm{~cm}^{2} \times 10 \mathrm{~cm}($ depth $)=524,430 \mathrm{~cm}^{3}$

$524,430 \mathrm{~cm}^{3} \times 3$ platforms $=1,573,290 \mathrm{~cm}^{3}$

$1,573,290 \mathrm{~cm}^{3} / 3$ media $=524,430 \mathrm{~cm}^{3}$

$524,430 \mathrm{~cm}^{3}=0.524 \mathrm{~m}^{3}$

The plant taxa experiment required $2.16 \mathrm{~m}^{3}$ :

Platforms: $\quad 244 \times 244 \mathrm{~cm}-$ width of divider boards $=232.4 \times 232.4 \mathrm{~cm}=54,010 \mathrm{~cm}^{2}$

Media depth:

Four platforms:

$\underline{\mathrm{cm}^{3} \rightarrow \mathrm{m}^{3}}:$

$$
54,010 \mathrm{~cm}^{2} \times 10 \mathrm{~cm}(\text { depth })=540,100 \mathrm{~cm}^{3}
$$$$
540,100 \mathrm{~cm}^{3} \times 4 \text { platforms }=2,160,400 \mathrm{~cm}^{3}
$$$$
2,160,400 \mathrm{~cm}^{3}=2.1604 \mathrm{~m}^{3}
$$

Total amount of Growing Medium Two for both experiments: $0.524 \mathrm{~m}^{3}+2.1604 \mathrm{~m}^{3}=2.6844 \mathrm{~m}^{3}$

\subsubsection{Growing Medium Three}

Growing Medium Three is a granular extensive green roof media developed by Roofscapes Inc. of Philidelpha, PA, and is recommended for the West Coast. Medium Three is a mixture of and It also includes 


$$
\text { Mineral portions of Medium Three (_ ) are sterile; however, }
$$

the is not. According to Roofscapes, the biological activity of the activates the medium. The quantity matches FLL guidelines for multi-course extensive green roof growing media. Medum Three was $\quad$ (by volume), but this typically results in However, it should be

noted that

(Charlie Miller, 2009). Table 3.4 shows the ideal particle size distribution recommended in the formula for Medium Three.

Table 3.4 Size of each particle and the correlating percentage of Medium Three needed to achieve the proper particle size distribution (Modified from Charlie Miller, personal communication)

\begin{tabular}{ll}
\hline Size of Granule & Percentage \\
\hline & $\leq 2 \%$ \\
$\geq 2 \%$ & $10-15 \%$ \\
$55-70 \%$ \\
$\geq 95 \%$ \\
$100 \%$ \\
\hline
\end{tabular}

Growing Medium Three called for a specific particle size distribution and was the only medium blended onsite. Table 3.5 identifies the constituents used, but quantities are proprietary. It was estimated that $75 \%$ of the granules were larger than specified, so some of the pumice granules were crushed in a mechanical soil mixer during the mixing process. This brought the 
final mixture closer the specified particle size distribution, but it was estimated that $\mathrm{cm}$ in diameter.

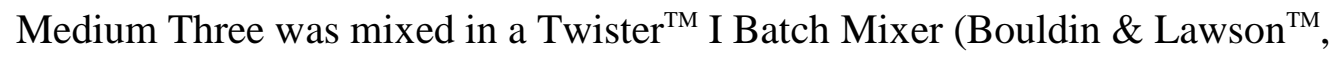
McMinnville, TN) mechanical soil mixer on September 24, 2009. It was stored in a soil bin for two weeks until needed.

When determining the quantities needed for the growing media study, it was important to account for a shrink factor. Medium Three typically shrinks by $25 \%$ from its initial volume after mixing; therefore, $25 \%$ more of each ingredient was added, except for the osmocote.

Total medium needed (using the same calculations as Medium Two):

$0.0582 \mathrm{~m}^{3}$ of soil needed per section $\mathrm{x} 9$ sections $=0.524 \mathrm{~m}^{3}$

$0.524 \mathrm{~m}^{3} \mathrm{x}$ shrink factor of $25 \%=0.524 \mathrm{~m}^{3} \times 1.25=0.655 \mathrm{~m}^{3}$

: $\quad$ 0. $\quad$ x $0.655 \mathrm{~m}^{3}=0 . \quad \mathrm{m}^{3}$ needed

: $\quad 0 . \quad \mathrm{x} 0.655 \mathrm{~m}^{3}=0 . \quad \mathrm{m}^{3}$ needed

: $\quad 0 . \quad \mathrm{x} 0.655 \mathrm{~m}^{3}=0 . \quad \mathrm{m}^{3}$ needed

Osmocote: $\quad 0.655 / 0.75=87.3 \%$

$0.873 \times 8$ oz. $=7$ oz. needed

Table 3.5 Percent by volume, total quantity and source of each ingredient in growing Medium Three

\begin{tabular}{lccc}
\hline Ingredient & $\begin{array}{c}\text { Percentage of } \\
\text { total }\end{array}$ & Total Quantity & Source
\end{tabular}




\subsubsection{Adding Growing Media}

Media Two and Three were added to their respective experimental units in the growing media experiment using a shovel. After a section appeared full, a thin, flat board was used to level the medium. Depth of $10 \mathrm{~cm}$ for Medium Two and $12.5 \mathrm{~cm}$ for Medium Three (to account for the $25 \%$ shrink factor) was checked by digging down to the Enkadrain ${ }^{\circ}$, placing a ruler perpendicular to the Enkadrain ${ }^{\circledR}$ and observing depth. All media was uniformly moistened with a hose to achieve similar compaction that would result from rain. This compaction caused the media level to drop, additional material was added and the process repeated until proper depth was achieved.

\subsection{Plant Material}

\subsubsection{Growing Media Experiment Plant Material}

Sixteen $(3.81 \times 5.08 \mathrm{~cm})$ total plugs - 4 of Sedum acre, Sedum x rubrotinctum, Sedum rupestre 'Angelina', and Sedum spurium 'Tricolor' - were randomly planted in each experimental unit of the three platforms on October 6, 2009. A planting frame, placed above each section, ensured that the plugs were planted in the same pattern in each section. Plugs were planted directly beneath the intersection of two fishing lines with the top of the root ball flush with the medium (Figure 3.3). Each platform had 144 plants at a density of 27 plants $/ \mathrm{m}^{2}$. 


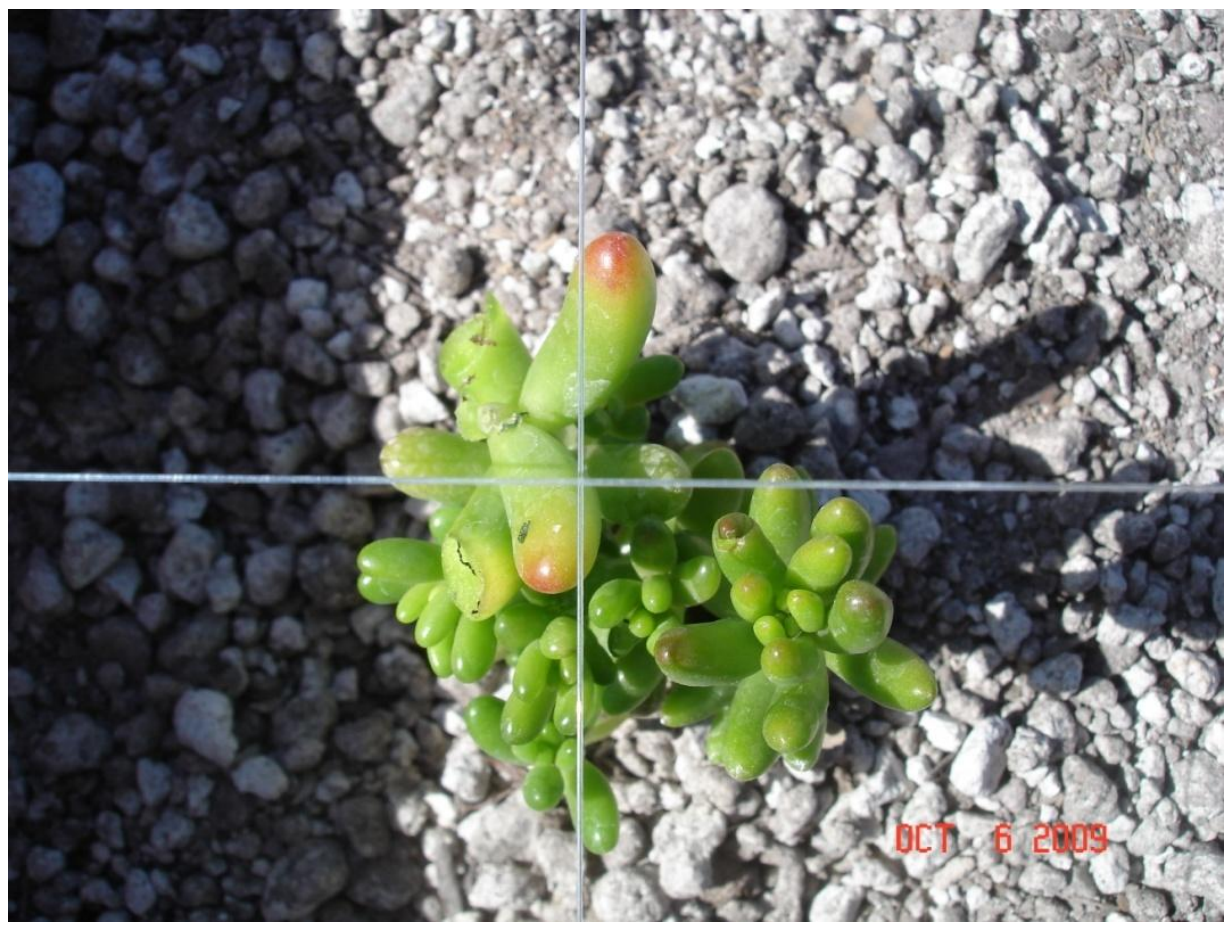

Figure 3.3 Fishing line intersections marked plug locations

\subsubsection{Growing Media Experiment Planting Frame}

A wooden planting frame, shown in Figure 3.4, was constructed using four equal boards that measured $2.54 \times 7.62 \times 96.5 \mathrm{~cm}$. Boards were secured together at the corners with nails, making a square that measured $96.5 \times 96.5 \mathrm{~cm}$.

Four lines of 15-lb test fishing line ran horizontally and four equal lines ran vertically, each attached to a nail, making the $4 \times 4$ grid pattern shown in Figure 3.4. Nail locations on the plating frame were placed $18.54 \mathrm{~cm}$ apart from each other with a $10 \mathrm{~cm}$ gap between the corner and the outermost nail; this accounted for the $10 \mathrm{~cm}$ vegetation-free zone in each section. This zone is just larger than half the distance between each plug, which allowed enough space for a full square on the evaluation frame (the frame placed over each section to track growth) to fit between the outermost plugs and the dividing boards. This ensured that each plug had at least $343.73 \mathrm{~cm}^{2}$ of uninterrupted growing space. 


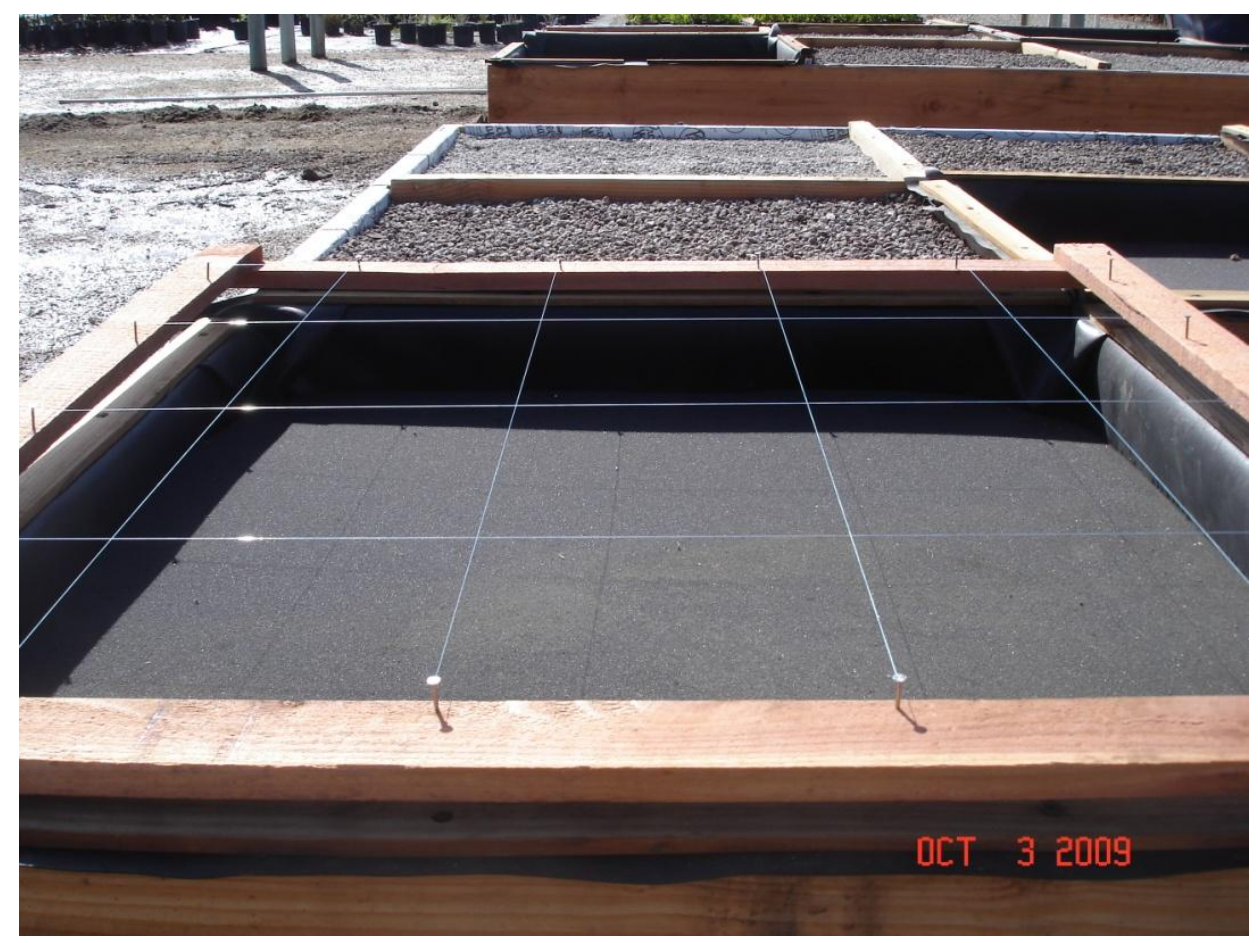

Figure 3.4 Wooden planting frame with $4 \times 4$ fishing line grid used mark plug locations during planting

\subsubsection{Plant Taxa Experiment Planting}

Twenty-five $(3.81 \times 5.08 \mathrm{~cm})$ plugs, divided into four groups, were planted in each section of the plant taxa experiment using the same planting frame method as described above, but with a larger frame. Each of the four plant groups had seven plugs in one of the four platforms (because four does not divide equally into 25). For example, each platform had four plant groups and four species per group, totaling 25 plugs per section; therefore, one of the treatment assignments per plant group was chosen at random to have seven plugs, while the other three needed to have six making a total of 25 plugs per section. This allowed for plugs to be planted in 5 x 5 grid patterns. Planting locations of each plug were randomly chosen using the random number generator in Minitab. Each section had 25 plugs, 100 plugs per platform, planted at a density of 19 plants $/ \mathrm{m}^{2}$. 


\subsubsection{Plant Taxa Experiment Planting Frame}

Plug locations were determined by using a 136 x $136 \mathrm{~cm}$ wooden planting frame placed over each experimental unit. The planting frame had four 3.81 x 8.89 x $136 \mathrm{~cm}$ wooden boards that were cut with a chop saw at $45^{\circ}$ on each side in opposing directions, and secured together with 3-inch drywall screws, forming a square.

Five lines of 15-lb test fishing line were secured horizontally to a nail on each end and Five equal lines were secured vertically to make a 5 x 5 grid pattern. Nails were $22 \mathrm{~cm}$ apart, with a $15 \mathrm{~cm}$ gap between the last nail and the corner, to account for a $15 \mathrm{~cm}$ vegetation free zone. The vegetation free zone ensured that each plug, regardless of its location, had at least 484 $\mathrm{cm}^{2}$ of space to grow.

\subsection{Irrigation}

The plant taxa and growing media experiments were both watered using identical overhead spray irrigation systems with two sprinklers per platform. One $2.54 \mathrm{~cm}$ (1-inch) Hunter PGV (Hunter, San Marcos, CA) automatic irrigation valve was used to irrigate each study. After the valve, PVC pipe was reduced from 1 inch, to 0.75 inch and then to $0.5 \mathrm{inch}$. Figure 3.5 shows how irrigation lines were connected between platforms by running beneath the soil, making it easier to navigate around the platforms. 


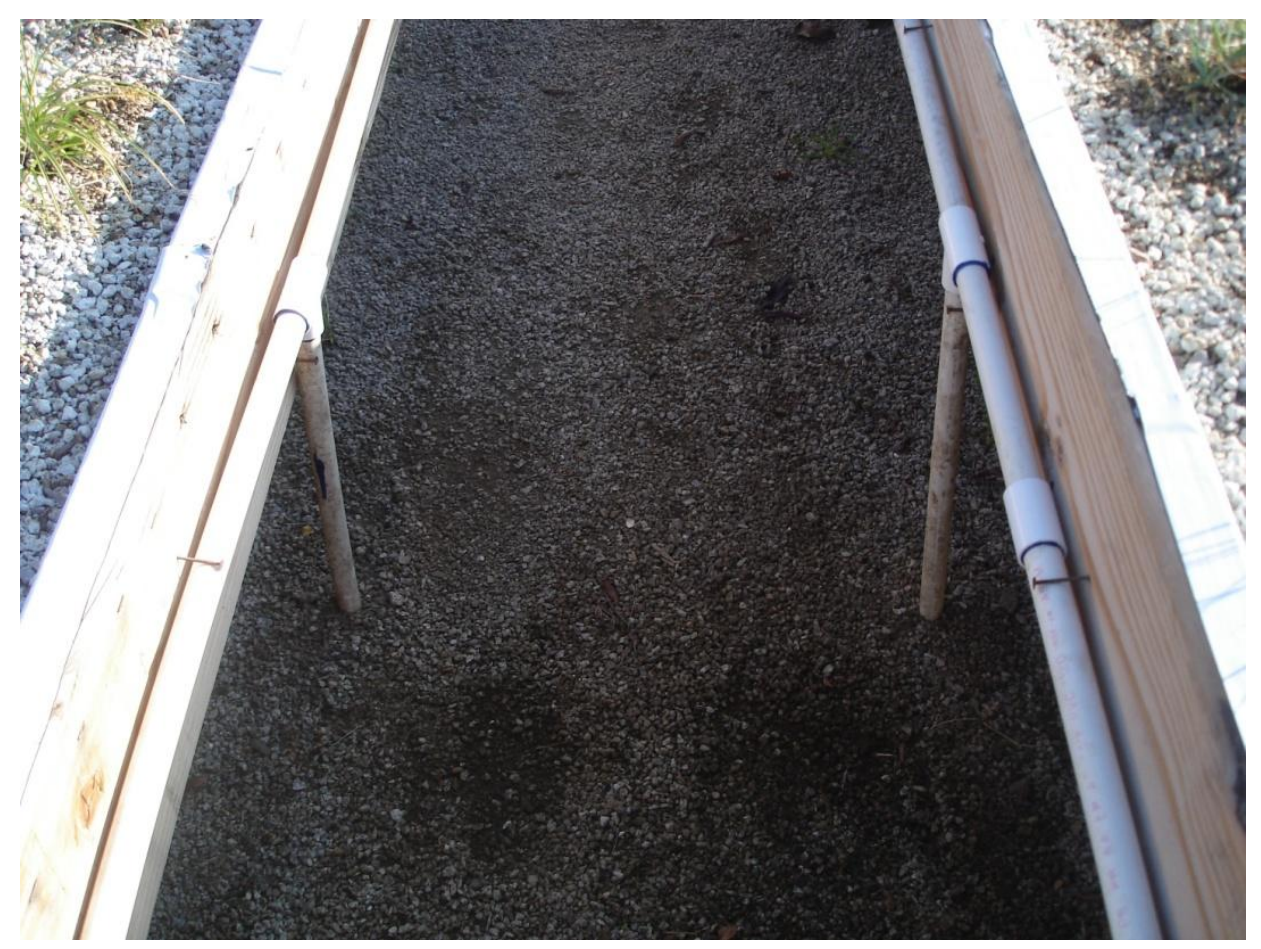

Figure 3.5 Lateral irrigation lines were connected beneath the soil between platforms

Two Rain Bird 1804 Series pop-up sprinklers (Rain Bird, Azusa, CA) were used on each platform. All platforms had two sprinklers, which were positioned at grade-level, in opposite corners. Figure 3.6 shows how $5.08-\mathrm{cm}$ nails were used to secure the lateral line and sprinkler assembly to the sides of each platform.

Sprinklers were attached to the lateral lines at a " $\mathrm{T}$ " using $90^{\circ} \mathrm{PVC}$ fittings. Sprinklers were connected to the lateral lines using two half-inch marlixes $\left(1 / 2 " 90^{\circ}\right.$ fittings with one male and one female threaded end) that were attached to each end of a $15.24 \times 1.27 \mathrm{~cm}$ riser. The sprinkler was screwed onto one end, while the other end screwed into the " $\mathrm{T}$," or the $90^{\circ} \mathrm{PVC}$ fitting, attached to the lateral line. These assemblies, shown in Figure 3.6, allowed the sprinklers to be moved outward to prevent the data collection frame's obstruction. 


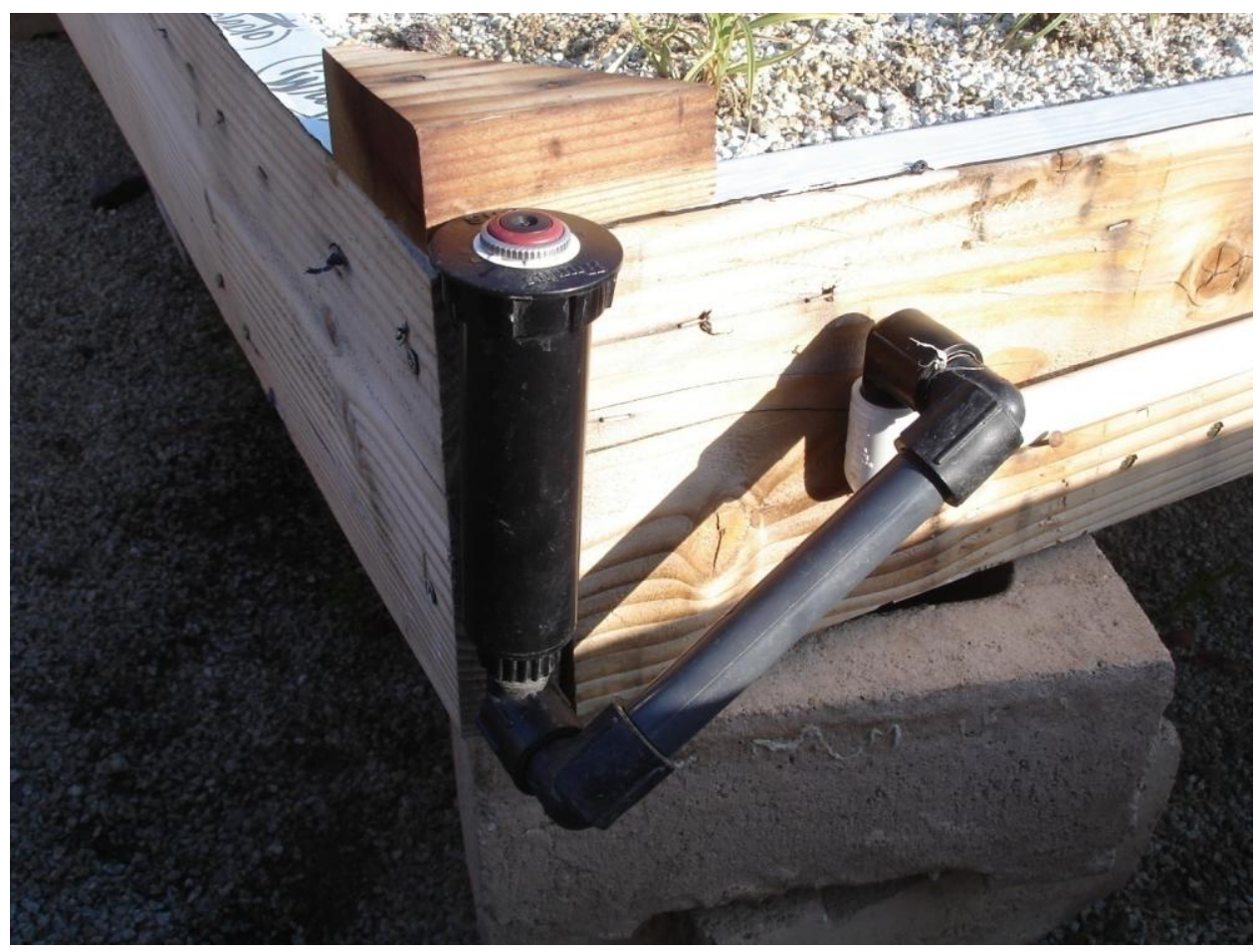

Figure 3.6 Sprinklers sat at the same level as the growing medium and could be moved aside to make room for the data collection frame

During the plant establishment period (the first month), the media was kept moist by irrigating each time the first $2-3 \mathrm{~cm}$ of media became dry in both experiments. During this time period, all of the sprinklers used 8Q nozzles (8 Series MPR, Rain Bird, Azusa, CA). After one month, nozzles were changed to MP Rotators (MP 1000, 90-210 ${ }^{\circ}$, Hunter, San Marcos, CA) for the remainder of the experiment.

On November 24, 2009, a battery-operated, two-station irrigation controller (Hunter SVC-200, Hunter, San Marcos, CA) was installed. As temperatures began to cool, the irrigation schedules were adjusted accordingly. When a rain event occurred, irrigation was shut off completely and then resumed when the first $2-3 \mathrm{~cm}$ of soil were considered dry. Table 3.6 displays the irrigation schedules for each experiment. 
Table 3.6 Irrigation schedule for the plant taxa and growing media experiments

\begin{tabular}{|c|c|c|c|}
\hline \multicolumn{4}{|c|}{ Growing Media Experiment } \\
\hline Time Period & Method & Water Days & Watering Duration \\
\hline $10 / 8 / 09-11 / 8 / 09$ & Overhead spray† & Every other day & 10 minutes \\
\hline $11 / 08 / 09-11 / 24 / 09$ & Overhead spray & $\mathrm{M}, \mathrm{W}, \mathrm{F}$ & 10 minutes \\
\hline $11 / 24 / 09-4 / 5 / 10$ & Overhead spray & As necessary§ & Until saturated \\
\hline $4 / 5 / 10-6 / 20 / 10$ & Overhead spray & $\mathrm{M}, \mathrm{Th}$ & 12 minutes \\
\hline \multicolumn{4}{|c|}{ Plant Taxa Experiment } \\
\hline Time Period & Method & Water Days & Watering Duration \\
\hline $10 / 15 / 09-11 / 15 / 09$ & Overhead spray† & Every other day & 12 minutes \\
\hline $11 / 15 / 09-11 / 24 / 09$ & Overhead spray & $\mathrm{M}, \mathrm{W}, \mathrm{F}$ & 12 minutes \\
\hline $11 / 24 / 09-4 / 5 / 10$ & Overhead spray & As necessary§ & Until saturated \\
\hline $4 / 5 / 10-6 / 20 / 10$ & Overhead spray & $\mathrm{M}, \mathrm{Th}$ & 15 minutes \\
\hline
\end{tabular}

$\dagger$ Sprinklers used 8Q (8 Series MPR) Rain Bird spray nozzles tSprinklers used Hunter MP Rotator (MP $100090^{\circ}-210^{\circ}$ ) nozzles

$\S$ Irrigation was only used between rain events when the top $2-3 \mathrm{~cm}$ of media was dry. Frequent rainfall was received during this period (Figure 4.4)

The MP Rotators' irrigation uniformity was checked by conducting a precipitation test, as the Texas A \& M Agrilife Extension outlines (Earth Kind, 2009). The precipitation rate was found to be $6.5 \mathrm{~cm}^{3} / \mathrm{hr} \pm 1.2 \mathrm{~cm}^{3} / \mathrm{hr}$ across all seven platforms.

\subsection{Fertilization}

All platforms were fertilized twice at a rate of $20 \mathrm{~g} / \mathrm{m}^{2}\left(0.07 \mathrm{oz} / \mathrm{ft}^{2}\right)$ of $15-9-12$

Osmocote ${ }^{\circledR}$ Plus Multi-Purpose Plant Food (Scotts-Sierra Horticultural Products, Marysville, OH; Dunnett and Kingsbury, 2004). The first application occurred on 11/1/09 and the second application took place on 5/1/10.

\subsection{Data Collection}

Percent media coverage (\% MC) was recorded for each study, each week for 36 weeks. The growing media experiment data collection started on October 15, 2009 and concluded on June 17, 2010. The plant taxa experiment data collection started on October 22, 2009 and 
concluded on June 24, 2010. Percent MC was initially recorded using two methods: ImageJ and manually with a wooden framed grid (WFG). After four weeks of data recording, the ImageJ method was abandoned because of inconsistent readings so the WFG technique was used for the remainder of the experiment.

\subsubsection{Data Collection with ImageJ}

Even though we chose not to use ImageJ, it is an image analysis program created by the National Institute of Health and has been used in a variety of disciplines and downloaded for free at http://rsb.info.nih.gov/ij/. ImageJ evaluates by contrasting the growing medium and vegetation to generate \% MC. Percent MC can be determined manually or automatically with ImageJ.

\section{Manual Version Percent Cover (modified from Colleen Butler, 2009)}

1. Take overhead image of an experimental unit with digital camera

2. Give image a label that corresponds to the experimental unit

3. Crop to appropriate size (just one section or experimental unit showing)

4. Open Image $\mathbf{J}$

5. In ImageJ, File - Open (open your 1st photo)

6. Image - Type - change from RGB color to HSB stack

Now the image is broken into Hue, Saturation, and Brightness (aka HSB), you will only use the Hue image from here on

7. Image - Adjust - Threshold

8. In threshold window, choose Black and White (not red)

9. Adjust the bars so that the plants are black and everything else is white. This is subjective, it helps to look at the original image to see if you have chosen a proper threshold; then click "Apply"

10. Program gives you message:

Convert all images in stack to binary? Calculate threshold for each image or black background Don't check either box, click OK

11. Analyze - Set Measurements

Select Area Fraction and Limit to Threshold, unselect all others, click OK 12. Analyze - Measure

The manual process helps the user understand how to adjust threshold levels to get the most accurate recordings. This is done by comparing the original picture to the ImageJ threshold 
screen and adjusting threshold values so the vegetation quantities equal to the original image (Butler, 2009).

The automated version is faster and performs the manual process using a saved "macro" file. The user should note that the automated version is only as accurate as the threshold values placed in the macro file. Pictures should be taken under the same light conditions and threshold values should make the background appear as white as possible and the vegetation black, as in the manual version (Butler, 2009).

\section{Automated version (modified from Colleen Butler, 2009)}

1. Open ImageJ

2. File - Open - "percent cover macro"

3. In macro window, Macros - Run Macro

4. A window will pop up to ask what folder to choose. Make sure this folder only has your pictures (no word files, excel files, etc) or the program will get confused

5. Wait a few moments for the program to run and produce $\% \mathrm{MC}$ values

Certain parameters must be followed to produce accurate measurements using ImageJ. Images should be taken directly overhead and under the proper light conditions, usually before sunrise or on an overcast day. Images are cropped, using Microsoft@ Office Picture Manager (Microsoft@, Windows 2007), so that the entire experimental unit was contained within the image. Finally, images are labeled according to the experimental unit that they represented and then saved.

\subsubsection{Data Collection with Wooden Framed Grid (WFG)}

Two wooden frames, measuring $97 \times 97 \mathrm{~cm}$ and 135 x $135 \mathrm{~cm}$ to fit the sections (experimental units) of the growing media (Figure 3.7) and plant taxa experiments (Figure 3.8), respectively, were constructed. The perimeter of each frame was constructed using four equally- 
sized pieces of $3.2 \mathrm{~cm} \times 9 \mathrm{~cm}$ wood secured into a square. Eleven nails were placed along each side of the frame at an equidistant spacing of $7.49 \mathrm{~cm}$ (for the growing media experiment) and $11.01 \mathrm{~cm}$ (for the plant taxa experiment). Fifteen $\mathrm{lb}$. test fishing line was tied to each nail, across the frame to the nail on the opposite side and tied to achieve a $(10 \times 10) 100$-square grid pattern.

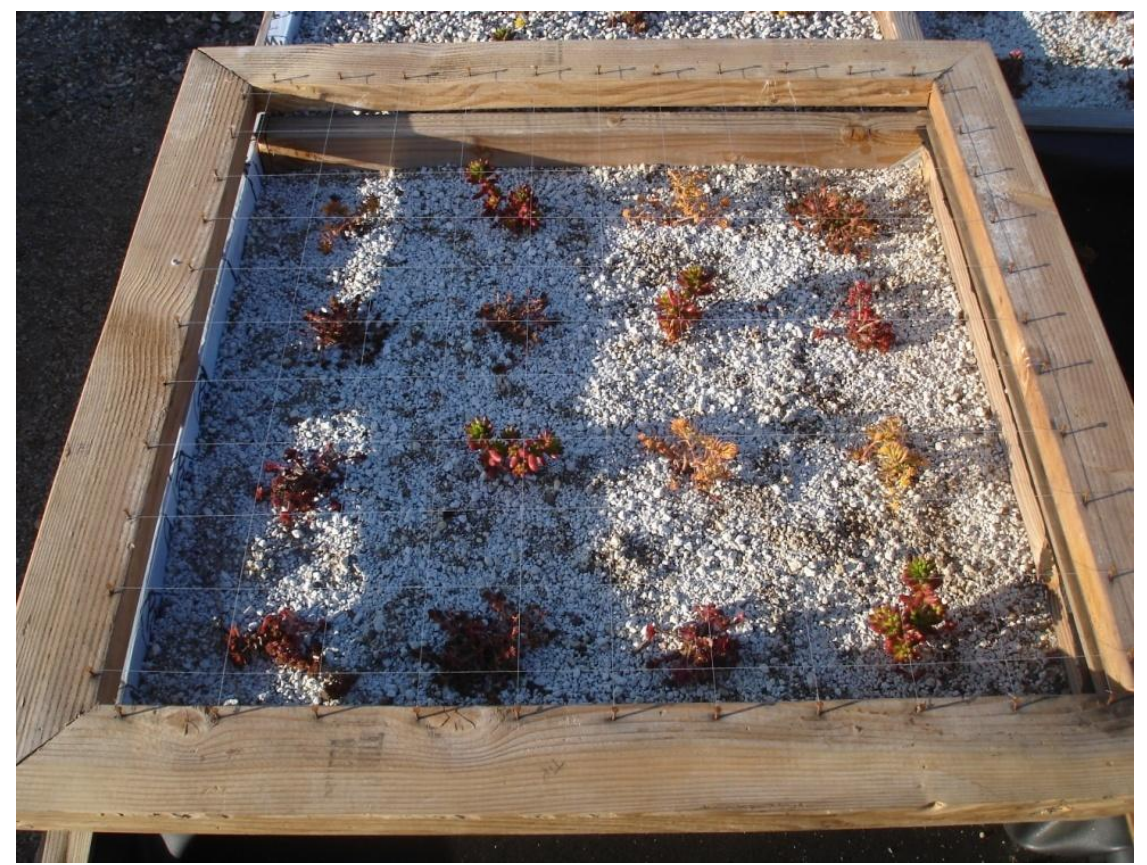

Figure 3.7 WFG in the growing media experiment used to measure \% MC 


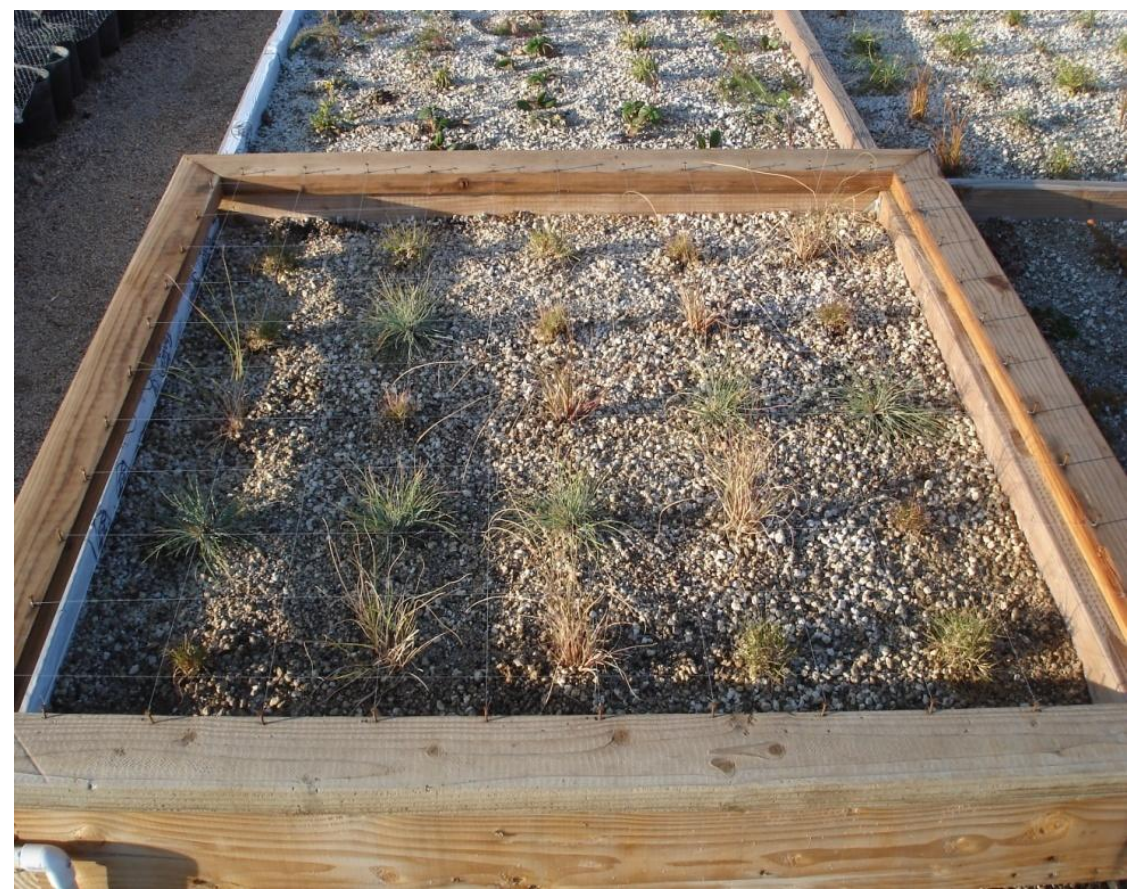

Figure 3.8 WFG in the plant taxa experiment used to measure \% MC

Percent MC was determined by placing the WFG directly over each section and counting the number of squares filled with vegetation. Measurements were taken in increments of 0.25 and added together for each section. For example, if 17.75 squares were filled with vegetation, that section recorded $17.75 \% \mathrm{MC}$.

\subsection{Experiment Design and Data Analysis}

\subsubsection{Growing Media Experiment}

A 3 x 3 Latin square design was used in the growing media experiment to control two anticipated sources of variability arising from the platforms' slopes and irrigation overspray from nearby sprinklers (Ott and Longnecker, 2001). This design was used instead of a randomized complete block design (RCBD) because it guaranteed unbiased replication between platforms and controlled for row and column variability. For example, if a RCBD was used and there was a 
row and column effect (i.e. \% MC depended on which row and column), the analysis between treatments would be more complicated.

Treatments were randomly assigned to each platform, as in Figure 3.9a, so that each column and each row received each treatment once, in a different order (Ott and Longnecker, 2001). There were three replicates (platforms), totaling 27 observations. Treatment assignments were randomly chosen using the random number generator in Minitab (Minitab 15, State College, PA).

Platforms:
\begin{tabular}{c|c|c|}
\hline $3 \dagger$ & $1 \uparrow$ & $2 \S$ \\
\hline 1 & 2 & 3 \\
\hline 2 & 3 & 1 \\
\hline
\end{tabular}

\begin{tabular}{|l|l|l|}
\multicolumn{1}{c}{ B } \\
\hline 1 & 2 & 3 \\
\hline 3 & 1 & 2 \\
\hline 2 & 3 & 1 \\
\hline
\end{tabular}

\begin{tabular}{|l|l|l|}
\hline \multicolumn{1}{|c}{ C } \\
\hline 3 & 2 & 1 \\
\hline 2 & 1 & 3 \\
\hline 1 & 3 & 2 \\
\hline
\end{tabular}

Figure 3.9a Treatment assignments in growing media experiment †Media 1 $\S$ Media 2 $\dagger$ Media 3

A $\log _{10}$ transformation was used on $\%$ MC values prior to analysis to stabilize the variance and normalize the data (Ott and Longnecker, 2001). Repeated measures mixed model ANOVA, with treatment as a fixed effect and platform, row, and column being random effects, was conducted using SAS (version 9.1, SAS Institute, Cary, NC) to determine the affects of treatment and time on \% MC. An experimental unit was defined as each individual $(76.2 \times 76.2$ cm) square section of a platform.

Between unit variables were treatment and block and the within unit variable was time. Treatment means were analyzed at weeks 12, 24, and 36 (at the end of the experiment) to represent common maintenance milestones (Mumford, 2009). Treatment means were compared 
using differences of least squares means with a Tukey-Kramer adjustment and alpha at 0.05 (Ott and Longnecker, 2001). Performance of each medium over time was graphed using R (version 2.10.1).

\subsubsection{Plant Taxa Experiment}

A Randomized Complete Block Design (RCBD) with four platforms (blocks) was used to compare the four treatments (plant groups) and control for platform-to-platform variability. Each platform had four experimental units that randomly received a treatment, totaling 16 observations.

Treatments were assigned using the random number generator in Minitab 15. Each treatment - Sm, Gr, Ca and Ms (Figure 3.9b) - was assigned a number (1 to 4), and four samples were randomly chosen for each platform. Figure $3.9 \mathrm{~b}$ displays the treatment assignments and lists the plant species in each plant group for the plant taxa experiment.

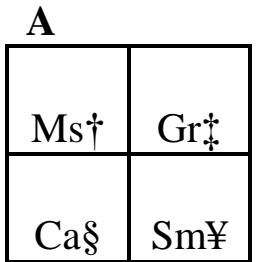

C

\begin{tabular}{|l|l|}
\hline $\mathrm{Ca}$ & $\mathrm{Sm}$ \\
\hline $\mathrm{Ms}$ & $\mathrm{Gr}$ \\
\hline
\end{tabular}

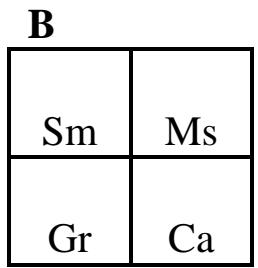

D
\begin{tabular}{|c|c|}
\hline $\mathrm{Gr}$ & $\mathrm{Ca}$ \\
\hline $\mathrm{Sm}$ & $\mathrm{Ms}$ \\
\hline
\end{tabular}

Figure 3.9b Treatment assignments for each platform in the plant taxa study $\dagger \mathbf{M s}=$ Mediterranean species: Fragaria chiloensis, Achillea millefolium, Dymondia margaretae, Delosperma cooperii † Gr = grasses: Festuca glauca, Buchaloe dactyloides, Sporobolus airoides, Boutelouea gracilis

$\S \mathbf{C a}=$ Sedges: Carex glauca, Carex. divulsa, Carex. pragracilis, Carex. testacea $¥ \mathbf{S m}=$ Sedum: Sedum acre, Sedum spurium 'Tricolor, Sedum x rubrotinctum, Sedum rupestre 'Angelina' 
A $\log _{10}$ transformation was used on $\% \mathrm{MC}$ values to stabilize the variance and normalize the data (Ott and Longnecker, 2001). Multiple regression analysis was conducted at weeks 12, 24 , and 36 to account for common maintenance milestones using treatment contrasts in $\mathrm{R}$ (version 2.10.1) with treatment as a fixed effect and platform and week being random effects (Grafen and Hails, 2002). Mean separation tests were conducted using Tukey-Kramer adjusted pvalues (Ott and Longnecker, 2001). Plant growth by group over time was graphed using R (version 2.10.1).

Orthogonal polynomials were used to observe the linear, quadratic and cubic slopes of the treatments (Grafen and Hails, 2002). These comparisons, done on the transformed data, illustrated the curvature of each plant group. 


\section{Chapter 4: Results, Discussion, and Conclusions}

\subsection{Growing Media Study Results}

Percent $\mathrm{MC}$ values of interest were obtained from the treatment $\mathrm{x}$ date interaction in the differences of least squares means output which compared each treatment each week. Percent MC of Medium One (experimental foam), Two (granular, 8.3\% organic matter) and Three (granular, $15 \%$ organic matter) were $10.69,10.75$, and $10.86 \%$ percent respectively after week 1 , and were not significantly different $(\alpha=0.05)$ at this time because plugs were uniform in size. There was a $100 \%$ survival rate of plant material across all three treatments.

Percent MC of Medium Three was significantly higher $(\alpha=0.05)$ than Media One and two starting in week 10, with adjusted Tukey's p values of 0.001 and 0.014 , respectively. Percent MC of Medium Three remained significantly higher than Media One and Two throughout the remainder of the experiment. Table 4.1 shows the $\% \mathrm{MC}$ values of Media One and Two compared to Medium Three when \% MC values became significantly different. Figure 4.1 shows the \% MC values for the three media at each week of the experiment.

Table 4.1 Relationship of media one and two to medium three at time of significance ( $\alpha=$ $0.05, \mathrm{n}=9$ )

\begin{tabular}{cccccc}
\hline Medium & Week & Mean \pm SE & $\begin{array}{c}\text { Medium Three } \\
\text { \% MC } \uparrow\end{array}$ & $\begin{array}{c}\text { Tukey } \\
\text { p-value }\end{array}$ \\
\hline One & 10 & $16.08 \pm 1.30$ & 19.03 & 0.001 \\
Two & 10 & $16.72 \pm 1.30$ & 19.89 & 0.014 \\
\hline
\end{tabular}

$\uparrow$ Displays mean \% MC for Medium Three at week it became significantly higher than Media One and Two

After 12 weeks, mean \% MC of Medium Three was significantly higher than Media One and Two (Table 4.2). Mean \% MC of Medium Three was 20.42\%, with Media One and Two recording $16.94 \%$ and $17.11 \%$, respectively. 
After 24 weeks, mean \% MC of Medium Three was significantly higher than Media One and Two (Table 4.2). Mean \% MC of Medium Three was 29.81\%, with Media One and Two recording $21.69 \%$ and $20.69 \%$, respectively. All three media, however, had significantly higher mean \% MC after 24 weeks compared to after 12 weeks (Table 4.2).

Medium Three had the highest mean \% MC of all media, after 36 weeks (Table 4.2).

Mean \% MC of Medium Three was 53.22\%, with Media One and Two recording $30.78 \%$ and $31.67 \%$, respectively.

Table 4.2 Mean media coverage ( $\%$ MC) \pm Standard errors of the three media treatments 12, 24, and 36 weeks after planting. Means are separated by Tukey-Kramer adjusted pvalues $(\alpha=0.05)$

\begin{tabular}{cccc}
\hline Media/Time & 12 weeks (12.31.09) & 24 weeks $\mathbf{( 3 . 2 5 . 1 0 )}$ & 36 weeks $(6.17 .10)$ \\
\hline One & $16.94 \pm 1.30 \mathrm{a} \dagger \mathrm{A} \dagger$ & $21.69 \pm 1.30 \mathrm{a} \mathrm{B}$ & $30.78 \pm 1.30 \mathrm{a} \mathrm{C}$ \\
Two & $17.11 \pm 1.30 \mathrm{a} \mathrm{A}$ & $20.69 \pm 1.30 \mathrm{a} \mathrm{B}$ & $31.67 \pm 1.30 \mathrm{a} \mathrm{C}$ \\
Three & $20.42 \pm 1.30 \mathrm{~b} \mathrm{~A}$ & $29.81 \pm 1.30 \mathrm{~b} \mathrm{~B}$ & $53.22 \pm 1.30 \mathrm{~b} \mathrm{C}$ \\
\hline
\end{tabular}

Weeks After Planting 


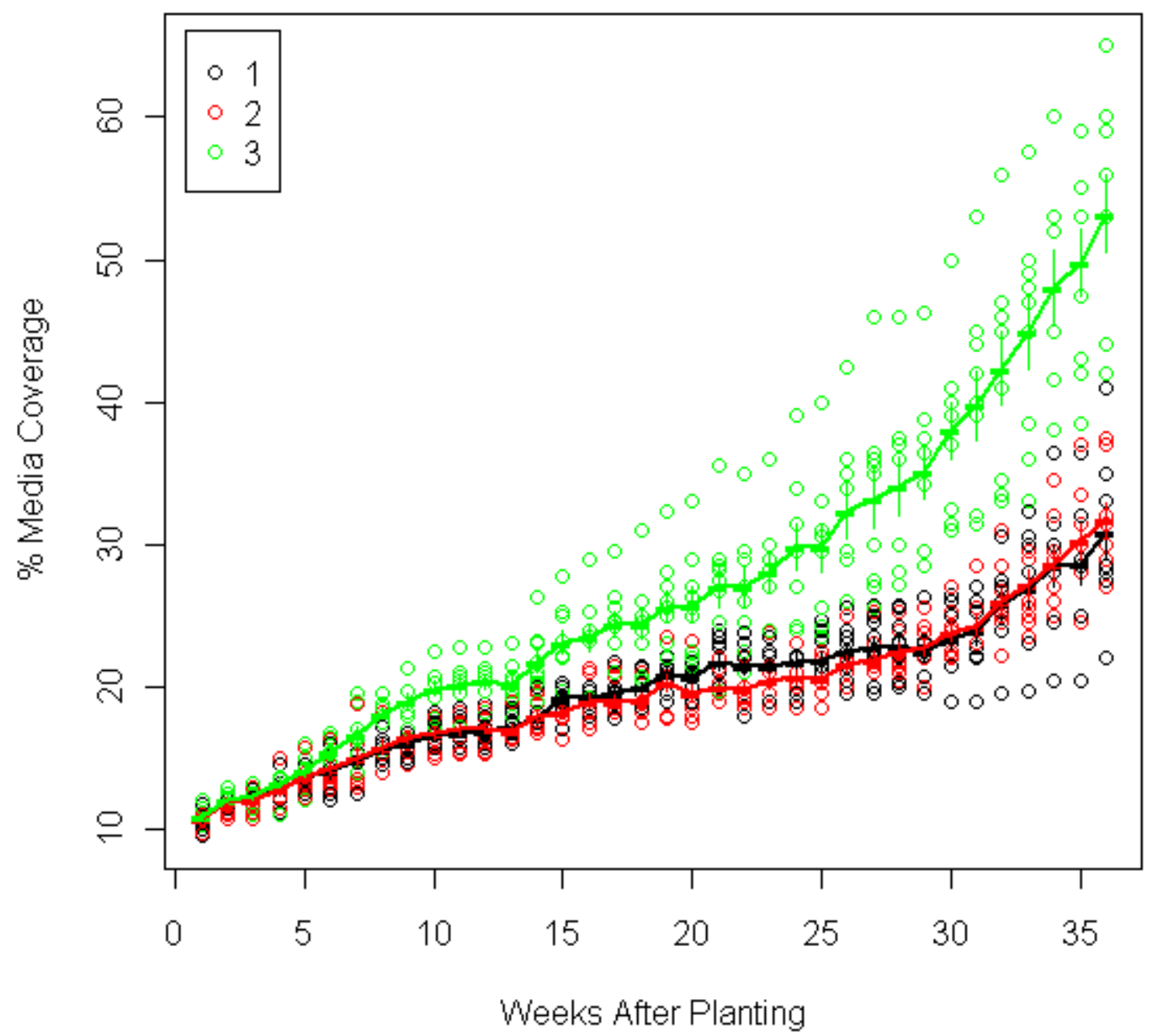

Figure 4.1\% MC of the three growing media over 36 weeks. Dashes indicate means, bars indicate standard errors.

\subsection{Plant Taxa Experiment Results}

The four plant groups, Sedum, sedges, Mediterranean species and grasses demonstrated different growth rates and patterns after 36 weeks. All groups exhibited positive growth after comparing the beginning and end of the experiment. There was $100 \%$ survival of all individual plants in each group. Figure 4.3 shows \% MC for each plant group over 36 weeks. 
After 12 weeks there were significant differences between some treatments (Table 4.3).

Sedges and Mediterranean species had significantly more growth than Sedum and grasses.

Sedges had significantly less growth than Mediterranean species; however, there was no evidence for a difference in \% MC between grasses and Sedum after 12 weeks (Table 4.3).

Percentage comparisons of each plant group after 12 weeks are shown in Table 4.3. The mean \% MC of grasses, sedges, and Mediterranean species were 0.90, 1.48, and 1.23 times that of Sedum, respectively. Sedges and Mediterranean species had 1.64 and 1.37 times the \% MC of grasses. Mediterranean species had 0.83 times the growth of sedges.

Table 4.3 Comparisons of mean \% MC between plant groups after 12 weeks of growth

\begin{tabular}{|c|c|c|c|c|c|c|c|c|c|}
\hline \multirow[t]{2}{*}{ Plant Group } & \multicolumn{3}{|c|}{ Sedum } & \multicolumn{3}{|c|}{ Grasses } & \multicolumn{3}{|c|}{ Sedges } \\
\hline & $\% \dagger$ & $\mathrm{p}$-val + & Tukey's§ & $\%$ & p-val & Tukey's & $\%$ & p-val & Tukey’s \\
\hline Sedum & - & - & - & - & - & - & - & - & - \\
\hline Grasses & 0.90 & 0.069 & 0.236 & - & - & - & - & - & - \\
\hline Sedges & 1.48 & $3.68 \mathrm{e}^{-05}$ & 0.000 & 1.64 & $5.18 e^{-06}$ & 0.000 & - & - & - \\
\hline $\begin{array}{l}\text { Mediterranean } \\
\text { species }\end{array}$ & 1.23 & 0.004 & 0.015 & 1.37 & 0.000 & 0.000 & 0.83 & 0.006 & 0.025 \\
\hline
\end{tabular}

$\dagger \% \mathrm{MC}$ of vertically listed group relative to that of horizontally listed group

$\$ \mathrm{P}$-values are from a t-test of \% MC of vertically listed group compared to horizontally listed group $(\alpha=0.05)$

$\S$ Tukey's adjusted p-value $(\alpha=0.05)$

After 24 weeks, significant differences emerged between some treatments as shown in (Table 4.4). Sedges and Mediterranean species had significantly higher \% MC than Sedum and grasses. Sedum had significantly higher \% MC than grasses. There was no evidence for a difference between Mediterranean species and Sedum or Mediterranean species and sedges.

Percentage comparisons of each plant group after 12 weeks are shown in Table 4.3. The mean \% MC of grasses, sedges, and Mediterranean species were $0.75,1.16$, and 1.15 times that of Sedum, respectively. Sedges and Mediterranean species had 1.54 and 1.52 times the $\%$ MC of grasses. Mediterranean species had 0.99 times the growth of sedges after 12 weeks. 
Table 4.4 Comparisons of mean \% MC between plant groups after 24 weeks

\begin{tabular}{|c|c|c|c|c|c|c|c|c|c|}
\hline \multirow[t]{2}{*}{ Plant Group } & \multicolumn{3}{|c|}{ Sedum } & \multicolumn{3}{|c|}{ Grasses } & \multicolumn{3}{|c|}{ Sedges } \\
\hline & $\% \dagger$ & $\mathrm{p}-\mathrm{val}+$ & Tukey's $\S$ & $\%$ & p-val & Tukey's & $\%$ & $\mathrm{p}$-val & Tukey's \\
\hline Sedum & - & - & - & - & - & - & - & - & - \\
\hline Grasses & 0.75 & 0.001 & 0.006 & - & - & - & - & - & - \\
\hline Sedges & 1.16 & 0.039 & 0.145 & 1.54 & $6.31 \mathrm{e}^{-05}$ & 0.000 & - & _ & - \\
\hline $\begin{array}{l}\text { Mediterranean } \\
\text { species }\end{array}$ & 1.15 & 0.063 & 0.217 & 1.52 & $8.67 e^{-05}$ & 0.000 & 0.99 & 0.783 & 0.991 \\
\hline
\end{tabular}

$\dagger \% \mathrm{MC}$ of vertically listed group relative to that of horizontally listed group

$\ddagger \mathrm{p}$-values are from a t-test of \% MC of vertically listed group compared to horizontally listed group $(\alpha=0.05)$

$\S$ Tukey's adjusted p-value $(\alpha=0.05)$

After 36 weeks, significant differences emerged between particular treatments (Table 4.4). Sedges and Mediterranean species had significantly higher \% MC than Sedum. Sedges had significantly higher $\% \mathrm{MC}$ than grasses. There was no evidence for a difference between grasses and Sedum, Mediterranean species and grasses, as well as Mediterranean species and sedges.

Percentage comparisons of each plant group after 36 weeks are shown in Table 4.5. The mean \% MC of grasses, sedges, and Mediterranean species were 1.12, 1.30 and 1.18 times that of Sedum, respectively. Sedges and Mediterranean species had 1.16 and 1.05 times the $\% \mathrm{MC}$ of grasses. Mediterranean species had 0.91 times the growth of sedges.

Table 4.5 Comparisons of mean \% MC between plant groups after 36 weeks

\begin{tabular}{|c|c|c|c|c|c|c|c|c|c|}
\hline \multirow[t]{2}{*}{ Plant Group } & \multicolumn{3}{|c|}{ Sedum } & \multicolumn{3}{|c|}{ Grasses } & \multicolumn{3}{|c|}{ Sedges } \\
\hline & $\% \dagger$ & $\mathrm{p}-\mathrm{val} \$$ & Tukey's§ & $\%$ & p-val & Tukey's & $\%$ & p-val & Tukey's \\
\hline Sedum & - & - & - & - & - & - & - & - & - \\
\hline Grasses & 1.12 & 0.106 & 0.332 & - & - & - & - & - & - \\
\hline Sedges & 1.30 & 0.002 & 0.010 & 1.16 & 0.039 & 0.146 & - & - & - \\
\hline $\begin{array}{l}\text { Mediterranean } \\
\text { species }\end{array}$ & 1.18 & 0.026 & 0.100 & 1.05 & 0.414 & 0.827 & 0.91 & 0.157 & 0.452 \\
\hline
\end{tabular}

$\dagger \% \mathrm{MC}$ of vertically listed group relative to that of horizontally listed group

$\$ \mathrm{P}$-values are from a t-test of $\% \mathrm{MC}$ of vertically listed group compared to horizontally listed group $(\alpha=0.05)$

$\S$ Tukey's adjusted p-value $(\alpha=0.05)$ 
Tables 4.6 - 4.8 show orthogonal polynomial comparisons of the growth patterns of the plant groups. They can be used to compare the linear slopes and quadratic and cubic curvature of the growth patterns. All comparisons are done with transformed \% MC values. These comparisons are more accurately characterized by Figure 4.2 , which shows the $\% \log _{10} \% \mathrm{MC}$ (normality and homogeneity of variance) of the four plant groups over 36 weeks, rather than Figure 4.3, which displays untransformed data.

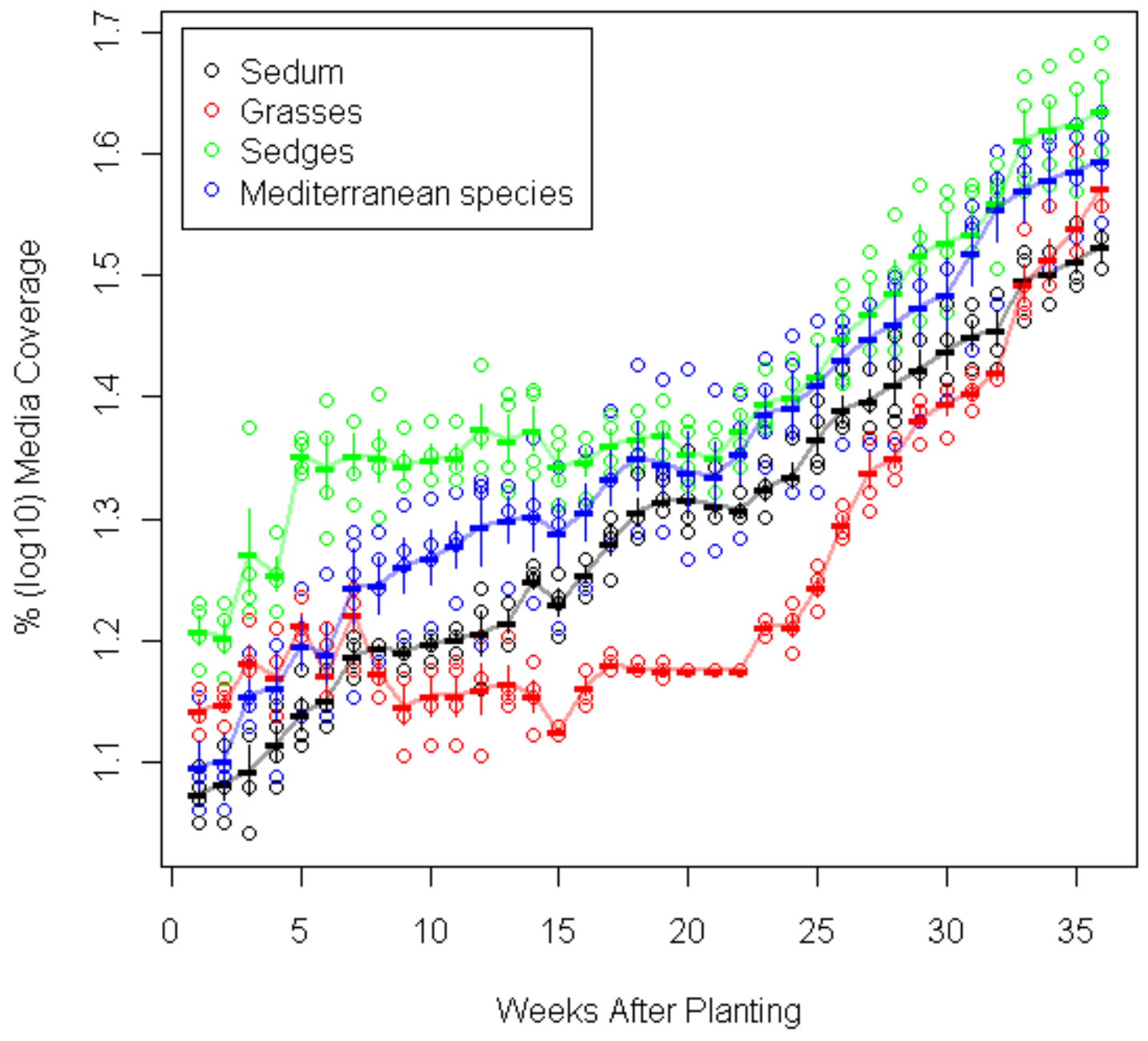

Figure 4.2 Percent $\log _{10} \%$ MC of the four plant groups over 36 weeks. Dashes indicate means, bars indicate standard errors 
Linear slopes of each plant group are compared to one another in Table 4.6. Linear slopes can be used to judge how constant the growth patterns of plant groups compare to each other. The linear slope of grasses and sedges were significantly different, and not as steep as Sedum. There was no evidence for a difference between the slope of Mediterranean species and Sedum. The slope of Sedges was slightly less steep compared to grasses, but there was no evidence for a difference. Mediterranean species had a steeper slope compared to grasses and sedges.

Table 4.6 Comparisons of overall growth rates (linear slopes) of each plant group after 36 weeks of growth

\begin{tabular}{c|cc|cc|cc}
\hline Plant Group & \multicolumn{2}{|c|}{ Sedum } & \multicolumn{2}{|c|}{ Grasses } & \multicolumn{2}{c}{ Sedges } \\
\hline Sedum & - & - & - & - & - & - \\
Grasses & - & $\left(\mathbf{3 . 3 5}^{-\mathbf{0 7}}\right) \dagger$ & - & - & - & - \\
& $0.53 \dagger$ & & & & & \\
Sedges & -0.64 & $\left(\mathbf{8 . 4 6 \mathbf { e } ^ { - 1 0 }}\right)$ & -0.11 & $(0.281)$ & - & - \\
Mediterranean & 0.13 & $(0.206)$ & 0.66 & $\left.\mathbf{( 2 . 7 \mathbf { e } ^ { - 1 0 }}\right)$ & 0.78 & $\left(\mathbf{2 . 3 4 \mathbf { e } ^ { - 1 3 }}\right)$ \\
species & & & & & & \\
\hline
\end{tabular}

$\dagger$ First number is coefficient of the line of vertically listed group compared to the horizontally listed group on $\left(\log _{10}\right.$ scale)

$\$$ Number in parentheses is the $p$-value from t-test that compares linear slopes of the vertically listed group compared to the horizontally listed group. Significant $\mathrm{p}$-values are in bold $(\alpha=0.05)$

Table 4.7 compares the quadratic curvature of the plant groups' growth patterns.

Quadratic comparisons evaluate presence and judge the magnitude of overall curvature in the growth patterns of each plant group.

Grasses and sedges exhibited significantly more positive quadratic curvature compared to Sedum. There was no evidence for a difference in the curvature of Mediterranean species compared to Sedum. Sedges and Mediterranean species each had significantly more negative quadratic curvature than grasses. Mediterranean species showed significantly more negative curvature than sedges. When a group has negative curvature, this suggests that its growth rate is leveling off compared to another group. 
Table 4.7 Comparisons of magnitude of quadratic curvature in growth of each plant group after 36 weeks

\begin{tabular}{c|cc|cc|cc}
\hline Plant Group & \multicolumn{2}{|c|}{ Sedum } & \multicolumn{2}{|c|}{ Grasses } & \multicolumn{2}{c}{ Sedges } \\
\hline Sedum & - & - & - & - & - & - \\
Grasses & $1.48 \dagger$ & $\left(<2 \mathbf{e}^{-16}\right) \dagger$ & - & - & - & - \\
Sedges & 0.48 & $\left(\mathbf{4 . 0 9 \mathbf { e } ^ { - \mathbf { 0 6 } }}\right)$ & -0.99 & $\left(<\mathbf{2 \mathbf { e } ^ { - 1 6 }}\right)$ & - & - \\
Mediterranean & -0.06 & $(0.588)$ & -1.42 & $\left(<2 \mathbf{e}^{-16}\right)$ & -0.42 & $\left(\mathbf{4 . 5 3 e ^ { - 0 5 }}\right)$ \\
species & & & & & & \\
\hline
\end{tabular}

$\dagger$ First number is coefficient of the line of vertically listed group compared to the horizontally listed group

$\$$ Number in parentheses is the p-value from t-test that compares quadratic slopes of the vertically listed group compared to the horizontally listed group. Significant $\mathrm{p}$-values are in bold $(\alpha=0.05)$

Cubic or growth patterns with two curves are compared in Table 4.8. Cubic comparisons judge presence and magnitude of two curves in the growth patterns of plant groups.

Grasses, sedges and Mediterranean species all exhibited significantly more positive cubic curvature than Sedum. Sedges had significantly more positive cubic curvature than grasses.

However, there was no evidence for a difference between Mediterranean species and grasses. Mediterranean species did have significantly more negative cubic curvature than sedges.

Significant cubic curvature suggests that growth rates fluctuated at least twice during this experiment. 
Table 4.8 Comparisons of magnitude of cubic curvature in growth of each plant group after 36 weeks

\begin{tabular}{c|ccc|cc|cc}
\hline Plant Group & \multicolumn{2}{|c|}{ Sedum } & \multicolumn{2}{|c|}{ Grasses } & \multicolumn{2}{c}{ Sedges } \\
\hline Sedum & - & - & - & - & - & - \\
Grasses & $0.19 \dagger$ & $(0.073) \dagger$ & - & - & - & - \\
Sedges & 0.47 & $\left.\mathbf{( 6 . 1} \mathbf{e}^{\mathrm{e} 06}\right)$ & 0.29 & $\mathbf{( 0 . 0 0 6 )}$ & - & - \\
Mediterranean & 0.25 & $\mathbf{( 0 . 0 1 5 )}$ & 0.07 & $(0.511)$ & -0.22 & $\mathbf{( 0 . 0 3 5 )}$ \\
species & & & & & & \\
\hline
\end{tabular}

$\uparrow$ First number is coefficient of the line of vertically listed group compared to the horizontally listed group

$\$$ Number in parentheses is the $p$-value from t-test that compares quadratic slopes of the vertically listed group compared to the horizontally listed group. Significant p-values are in bold $(\alpha=0.05)$ 


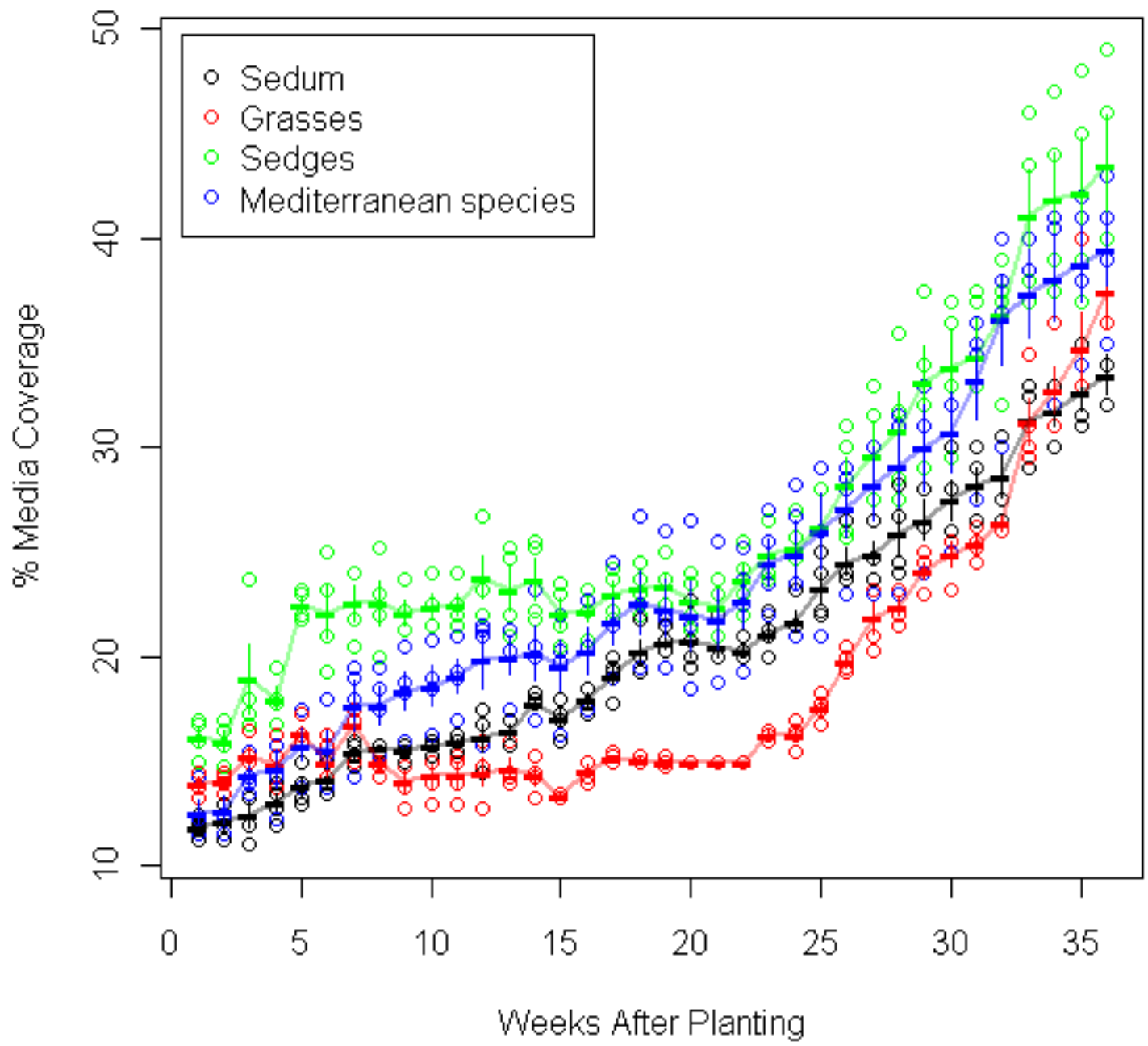

Figure 4.3 Percent MC of the four plant groups over 36 weeks. Dashes indicate means, bars indicate standard errors

\subsection{Discussion}

\subsubsection{Growing Media Experiment}

We observed significant variation in plant growth within the three media studied over the duration of the experiment. This variation was likely due to the differences in ingredient 
makeup and textures of each. The two fertilizer applications likely affected plant growth in all three media, particularly in Medium One. Irrigation and rain also influenced growth since moisture availability differed due to varying drainage rates. Each medium has different particle size distributions and this affected water holding capacity in Media Two and Three and the water retention in the EPDM basin of Medium One.

Results from this experiment support findings by Durhman et al. (2007), which successfully grew Sedum acre, S. spurium, and S. album under extensive green roof conditions. These results also support conclusions by Emilsson (2008), which state that higher initial nutrient content was found to support more vegetation development compared to media with lower nutrient levels.

Initial differences in organic matter and fertilizer levels was likely the largest factor in varying plant growth rates across the three media. The faster growth of Sedum species in Medium Three likely occurred due to higher initial organic matter content. Additionally, the inclusion of CRF in the initial formulation may have also been a factor.

Higher \% MC of Medium Three may be explained by ingredient differences, however, this does not account for similar \% MC of Media One and Two throughout the experiment (Figure 4.1). Initially, plants in Medium One likely utilized the residual nutrients in the plug until the first application of fertilizer on $11 / 1 / 09$, just three weeks after the experiment started, to maintain growth rates similar to Medium Two. Medium One may also have had better moisture availability than Medium Two from water retained in the EPDM basin. Medium One likely supported quick initial root growth in the first month, which was demonstrated in a pilot study shown in Appendix J. Medium Two started with $8.3 \%$ organic matter (by volume) which may account for the growth of its plant material (Skyland USA, 2009). 
The $2 \mathrm{~cm}$ application of landscape mulch seems to have affected plant growth in Medium One. The mulch provided moisture retention and held fertilizer granules uniformly distributed during and after the two CRF applications. This additional moisture combined with the CRF likely helped facilitate plant growth. Yet, mulching to prevent sun degradation is not a realistic solution in extensive green roof settings. Mulch blew off the platforms, making its use impractical in metropolitan areas where most green roofs are installed. Furthermore, mulch increases labor and material expenses, and it can add significant weight to the roof, especially when saturated.

Particle size distribution differences between Media Two and Three also likely impacted plant growth. Media Two was composed of smaller particles with $13.8 \%$ (by volume) passing < $0.05 \mathrm{~mm}$ sieve (Table 3.3), whereas Medium Three had less than $2 \%$ passing $0.05 \mathrm{~mm}$ sieve (Table 2.3 ) and was primarily (60-75 \% by volume) composed of particles $0.64-0.95 \mathrm{~cm}$ in diameter (Section 3.4.3). Medium Three, with the larger particles and quicker drainage, was probably more similar to the native, rocky, well-drained soils to which Sedum are accustomed, resulting in faster plant growth.

Regular irrigation likely increased plant growth (Table 3.6). Additionally, San Luis Obispo received $142 \%$ of normal rainfall since July 1, 2009, increasing moisture availability compared to average years (Weather Underground, 2010). Figure 4.4 shows precipitation quantities over the duration of the experiment. 


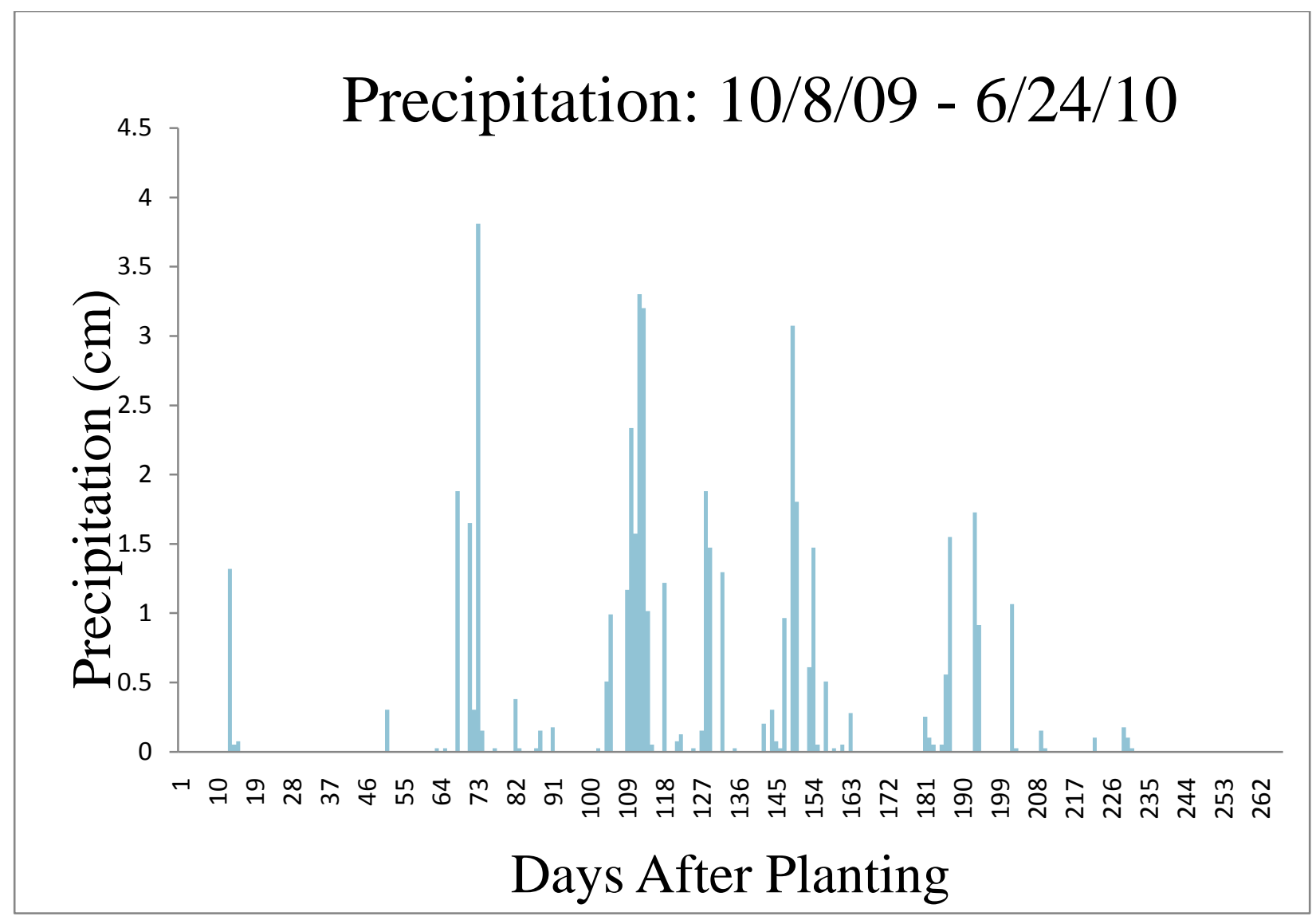

Figure 4.4 Precipitation quantities at California Polytechnic State University during the experiment (Weather Underground, 2010)

If available moisture was the only influencing factor and conditions were drier, Medium Two would likely support a higher ratio of plant growth compared to Medium Three than was shown. Medium Two (50\% water holding capacity) is likely capable of retaining more moisture than Medium Three because of its smaller particle size distribution (Skyland USA, 2009). Therefore, Medium Two likely provides more moisture availability to plants than Medium Three.

Further testing is needed to determine how Medium One would compare to Media Two and Three under drier conditions. Medium One, which is $5 \mathrm{~cm}$ shallower than Media Two and Three and much more porous, may allow water to evaporate more quickly resulting in drought 
stressed plants. However, the EPDM basin of Medium One may store more water than Media Two and Three because it would not drain out. This is true, especially, if there was $100 \%$ media coverage.

One should be careful when emphasizing statistical significance (\% MC) between Medium Three and Media One and Two occurring in week 10 (Table 4.1). Depending on the objectives of a green roof, statistical differences may not result in significantly better performance. For example, if the goal of a particular green roof was to provide aesthetic value, Medium Three may not be significantly better than Media One or Two because aesthetic value is subjective.

In the context of stormwater management, \% MC values of this study would likely not lead to functional advantages. For instance, VanWoert et al. (2005) found that during medium rain events $(2-6 \mathrm{~mm})$ a vegetated roof or media only retained the same amount of stormwater, $82.9 \%$ and $82.3 \%$, respectively. Therefore, it is unlikely that Media Two and Three would perform differently under medium rain events, even though statistically, they demonstrated different $\%$ MC.

It is realistic to presume that the \% MC of Media Two and Three found in this study can be expected in a green roof environment. However, Medium One requires more post-installation inputs to perform as we experienced. Without regular fertilization, Medium One would not support the growth rates we found. Media Two and Three, which had higher nutrient contents from organic matter and CRF, would support plant growth longer without additional CRF applications. Furthermore, Medium One required mulch for water retention and uniform fertilizer application. However, installation ease and weight of Medium One may make it the only option for older buildings with lower structural load capacity. Medium One may be cheaper 
because of quicker installation and, depending on climate, less water requirements due to the water-proof basin.

\subsubsection{Plant Taxa Experiment}

Fluctuating growth patterns of plant groups resulted in different mean $\% \mathrm{MC}$ at 12,24 , and 36 weeks (Figure 4.2) and displayed in Tables 4.2-4.4. Plant groups responded differently to environmental stimuli like day length and temperature. However, there were also similar responses among some groups like Sedum and Mediterranean species (Tables 4.6 and 4.7). Figure 4.2 suggest that starting the experiment in October affected each plant group differently. Plant growth across all groups was likely increased due to steady periods of rain (Figure 4.4), higher than average total precipitation and regular irrigation (Table 3.6). The larger initial plug size of sedges compared to other plant groups likely contributed to their \% MC.

The most apparent factor responsible for these differences seemed to be day length and temperature. For example, Figure 4.2 illustrates that grasses showed positive growth through week $7(12 / 3 / 09)$, but then slowed with the first frost. Nor further growth occurred until week 23 $(3 / 25 / 10)$. The sedges showed positive growth through week $6(11 / 26 / 09)$ and then also slowed until week $22(3 / 18 / 10)$.

Regrowth of both groups resumed at the end of winter when day length decreased and temperatures increased. Sedges and grasses both began to show regrowth by weeks 22 and 23, respectively. This is not surprising, as grasses and sedges are closer relatives to each other.

Sedum and Mediterranean species had more constant growth patterns as they responded to cooler temperatures in the same way; they slow their growth, but do not lose their pigment.

If this experiment began at a different time of year, growth patterns - and thus \% MC differences - between groups would have differed. For example, if the experiment started in the 
spring, the grasses and sedges would have had much steeper initial growth curves than what occurred during the first 23 weeks of this experiment, since they would not have gone through the winter as soon after planting. Starting in the spring would allow them to establish more quickly, having more advanced vegetation and root systems which would likely produced a growth pattern more similar to a quadratic curve rather than a cubic pattern (Table 4.8). Based on these results, Sedum and Mediterranean species would produce a linear growth pattern regardless of the time of year.

The linear correlation between Sedum and Mediterranean species, shown in Table 4.6 (p $=0.206)$ is more difficult to explain than the relationship between grasses and sedges because their characteristics are less similar. Percent MC could be skewed by individual plants, which would not be detected because \% MC was measured for the entire plant group that encompasses four species. However, the similarities in native climates of Sedum and Mediterranean species likely explain this correlation. For example, three of the four Sedum species (album, spurium 'Tricolor', and rupestre 'Angelina') are native to Mediterranean parts of Europe, which has a similar climate to western California, to which two of the Mediterranean species (Yarrow and Beach strawberry) are native. In addition, the other two Mediterranean species, Silver carpet and Cooper's hardy ice plant, are native to South Africa, which is also a Mediterranean climate.

Figure 4.3 shows that there were differences in plug sizes when the experiment started. These larger plant sizes, particularly among the sedges, likely allowed those plants to produce more photosynthates, resulting in more growth compared to the smaller plants. This increased growth likely caused their root systems to expand faster and access more of the medium's nutrients. If the experiment were repeated, all plugs would be trimmed until uniform prior to planting. 
The orthogonal polynomial comparisons shown in Tables 4.6 - 4.8, compare the growth patterns of the four plant groups. This may aid in anticipating growth patterns of plant groups at a particular time of year. For example, if the objective of a green roof was for quick media coverage, Tables 4.7 and 4.8 show that grasses and sedges have significantly more fluctuation, or curves, in their growth patterns than Sedum when planted in the fall. Figure 4.2 illustrates that this curvature includes a period of stagnant growth during the winter, and will not provide quick growth. This suggests that initial, constant positive growth is needed from the grass and sedge species used in this experiment; thus, they should be planted in the spring or the summer when temperatures are warmer and days are longer.

The $100 \%$ survival and constant growth of Sedum concur with the findings of Durhman et al. (2007), which suggest that Sedum can be successfully grown on an extensive green roof. These results differ from Monterusso et al. (2005), in that Sedum exhibited more growth than native species. However, the Monterusso experiment lasted 2.5 years and eliminated irrigation halfway through the second season. It is unclear how many of the species that performed poorly would have reacted to regular precipitation, which was a constant in this study.

Regular precipitation was likely a significant factor in determining \% MC differences. Wolf and Lundholm (2008), which examined moisture responses of four plant groups grown in pots containing green roof media, found that grasses had significantly higher water loss than succulent and herbaceous perennial plants under dry conditions. This suggests that, if conditions were drier, Sedum would have higher \% MC than the other three groups.

Though species were grouped according to morphological and genetic similarities, recent research indicates greater benefits to planting in combinations rather than monocultures or according to plants possessing similar forms. Lundholm et al. (2010) concluded that a variety of 
ecosystem services from green roofs can be optimized by planting forbs, grasses and succulents together. These increased benefits of polystands over monocultures are likely due to increased biodiversity and greater water use efficiency from less exposed soil and niche exploitation (Lundholm et al., 2010).

\subsection{Conclusions}

The environmental benefits of green roofs are great and research advancing the possibilities for green roof implementation is important. Residential homeowners are discovering that they can save money and positively impact the environment by installing green roofs. It is evident that green roofs are a great way to manage stormwater, reduce urban temperatures, decrease erosion, improve air quality, and beautify their city. Many world governments are responding to this by offering tax credits to building owners and putting public money aside for green roof implementation.

\subsubsection{Growing Media Experiment}

This experiment provides information on how these three media will perform in the first 36 weeks after installation. When using a mixture of Sedum species in an extensive green roof setting, we found that that Medium One provides similar media coverage to Medium Two.

However, Medium One required a higher maintenance budget due to CRF, mulch and increased labor. Medium Three provided significantly more media coverage in week 10 than Media One and Two because of higher organic matter and the benefits of CRF in the initial mixture. The increased Sedum growth in Medium Three should allow the functional goals of the green roof to be achieved more efficiently. 


\subsubsection{Plant Taxa Experiment}

This experiment provides information on how four plant groups perform in a granular growing medium for 36 weeks after installation. Sedges are recommended for quick and significant media coverage compared to grasses, Sedum and Mediterranean species as they provided higher \% MC over the majority of the experiment.

However, it is not recommended to plant sedges and grasses before the fall season's shorter days and cooler temperatures, as this experiment proves that they rapidly went dormant. The Sedum and Mediterranean species can be expected to produce more constant growth than sedges and grasses regardless of day length and temperature. Sedges can be expected to provide significantly more media coverage than Sedum and grasses. 


\section{REFERENCES}

Abramoff, M.D., P.J. Magelhaes, and S.J. Ram. “Image Processing with ImageJ.” Biophotonics International 11.7 (2004): 36-42.

Anderson, Kat M., Roderick, Wayne. "Beach Strawberry Fragaria chiloensis.” USDA Plant Guide. July 2006. Accessed 11 May 2010 http://plants.usda.gov/java/profile?symbol=FRCH

Beard, James. Turfgrass: science and culture. Englewood Cliffs N.J.: Prentice-Hall, 1972.

Besnard, Guillaume, A. Muthama Muasya, Flavien Russier, Eric H. Roalson, Nicolas Salamin and Pascal-Antione Christin. Phylogenomics of C4 Photosynthesis in Sedges (Cyperaceae): Multiple Appearances in Genetic Convergence 21 May 2009 http://mbe.oxfordjournals.org/cgi/reprint/msp103v1.pdf

Brandies, Monica, and Ortho Books. All about ground covers. San Ramon CA: Ortho Books, 1993.

Brenzel, Kathleen. Sunset western garden book. Completely rev. and updated, [New century ed.]. Menlo Park CA: Sunset Pub. Corp., 2001.

Butler, Colleen. Telephone INTERVIEW. 28 August 2009.

Calflora. Carex tumulicola Mackenzie. Accessed April 112010. http://www.calflora.org/cgi-bin/species_query.cgi?where-calrecnum=1645.

Cantor, Steven. Green roofs in sustainable landscape design. 1st ed. New York: W.W. Norton \& Co., 2008.

Connelly, Maureen. "BCIT Green Roof Research Program, Phase 1 Summary of Data Analysis." Report to Canada Mortgage and Housing Corporation 11 Sept. 2006: 22.

Curto, Michael. Telephone INTERVIEW. 10 June 2009.

Darke, Rick. The encyclopedia of grasses for livable landscapes. Portland Or.: Timber Press, 2007.

Donnelly, Joe. Personal INTERVIEW. April 242009.

Dunnett, Nigel, and Kingsbury, Noel. Planting green roofs and living walls. Portland Or.: Timber Press, 2004. 
Durhman, Angela K., Bradley D. Rowe, and Clayton L. Rugh. "Effect of substrate depth on initial growth, coverage, and survival of 25 succulent green roof plant taxa.." Hortscience 42.3 (2007): 588-595.

"Earth Kind Texas Agrilife Extension Service." Landscape Irrigation Audit Procedures. 29 Sept. 2009. Accessed 4 May 2010. http://aggie-horticulture.tamu.edu/earthkind/docs/pubs/audit.pdf

Emilsson, Tobias. "Vegetation development on extensive vegetated green roofs: Influence of substrate composition, establishment method and species mix." Ecological Engineering 33.3-4 (2008): 265-277.

Emilsson, Tobias et al. "Effect of using conventional and controlled release fertilixer on nutrient runoff from various vegetated roof systems." Ecological Engineering 29.3 (2007): 260271.

Forschungsgesellschaft Landschaftsentwicklung--Landschaftsbau. Guideline for the planning, execution and upkeep of green-roof sites: roof-greening guidelines, January 2002 edition with Methods to be employed when investigating vegetation substrates and. 2002nd ed. Bonn: Forschungsgesellschaft Landschaftsentwicklung Landschaftsbau e.V., 2002.

Freedom Garden Products. "Freedom Garden Products Specifications.” Sept. 2009.

Getter, Kristen L., and Bradley D. Rowe. "Media depth influences Sedum green roof establishment." Urban Ecosystems 11 (2008a): 361-372.

Getter, Kristen L., and D. Bradley Rowe. "Selecting plants for extensive green roofs in the United States." Michigan State University Extension Bulletin E-3047 (2008b).

Getter, Kristen L., and D. Bradley Rowe. (2007). "Effect of substrate depth and planting season on sedum plug survival on green roofs. Journal of Environmental Horticulture 25:95-95." Journal of Environmental Horticulture 25.2 (2007): 95-99.

Grafen, Alan and Rosie Hails. Modern statistics for the life sciences. Oxford ;New York: Oxford University Press, 2002.

Gravatt, D. A. "Crassulacean Acid Metabolism and Survival of Asexual Propagules of Sedum wrightii." Photosynthetica 41.3 (2003): 449-452.

Green Roofs for Healthy Cities (GRHC). 2009. "About Green Roofs.” Accessed 21 Ocotober 2009. http://www.greenroofs.org/index.php/about-green-roofs

Green Roofs for Healthy Cities (GRHC).Green Roof Design 101. 2nd ed. 2006. 
Green Roofs for Healthy Cities (GRHC). "Green Roof Tax Incentive Introduced To US Congress.” 30 January 2009. Accessed 2 May 2010.

http://www.greenroofs.org/index.php?option=com_content\&task=view\&id=1426\&Itemi $\mathrm{d}=113$

Greenlee, John. The encyclopedia of ornamental grasses: how to grow and use over 250 beautiful and versatile plants. Emmaus Pa. ;[New York]: Rodale Press ;Distributed in the book trade by St. Martin's Press, 1992.

Hauth, E., and T. Liptan. "Plant Survival Findings in the Pacific Northwest." 1st North American Green Roof Conference: Greening Rooftops for Sustainable Communities. Chicago: Green Roofs for Healthy Cities, 2003.

Helfman, Barbara. Personal INTERVIEW. 10 October 2009.

Horwitz, Marni. "The Green Roofs Project Database." Wild Project Theatre Accessed 10 January 2010. http://www.greenroofs.com/projects/pview.php?id=699

Hurteau, Matthew D. “Common Yarrow Achillea millefolium.” USDA Plant Guide 30 May 2006. Accessed 28 April 2010. http://plants.usda.gov/factsheet/pdf/fs_acmi2.pdf

Ingram, Stephen. Cacti, agaves, and yuccas of California and Nevada. 1st ed. Los Olivos Calif.: Cachuma Press, 2008.

Joni L. Janecki \& Associates, Inc. "Stormwater Development Standards, City of Salinas." LID Planting Zones and Planting List 16 May 2008. Accessed 12 February 2010. http://www.ci.salinas.ca.us/services/engineering/pdf/SWDS_Jan09/Appendix/AppendixG__Plant-List-ppG2-3updated.pdf

Jun Yang, Yu Qian, and Peng Gong. "Quantifying air pollution removal by green roofs in Chicago.” Atmospheric Environment 42.31 (2008): 7266-7273.

King, Michael. Gardening with grasses. London: Frances Lincoln, 1998.

Landscape Management. December 2008. Accessed January 2009. http://www.landscapemanagement.net/business/trends-statistics/news/freedom-gardenproducts-introduces-recycled-growin-5590

Lundholm, Jeremy, Scott J. Maclovor, Zachary MacDougall, and Melissa Ranalli. 2010. "Plant Species and Functional Group Combinations Affect Green Roof Ecosystem Functions." PLoS One 5(3): e9677. Doi:10.1371/journal.pone.0009677

MacKenzie, David. Perennial ground covers. Portland Or.: Timber Press, 1997.

Miller, Charlie. Personal INTERVIEW. 26 August 2009. 
Monterusso, Michael A., Bradley D. Rowe, and Clayton L. Rugh. "Establishment and Persistence of Sedum spp. and Native Taxa for Green Roof Applications." Hortscience 40 (2005): 391-396.

Moran, Amy, Bill Hunt, and Greg Jennings. "A North Carolina Field Study to Evaluate Greenroof Runoff Quantity, Runoff Quality, and Plant Growth.” Accessed 21 February 2010. http://www.bae.ncsu.edu/greenroofs/GRHC2004paper.pdf

Oakes, Albert. Ornamental grasses and grasslike plants. New York: Van Nostrand Reinhold, 1990.

Oberndorfer, Erica et al. "Oberndorfer, E., J. Lundholm, B. Bass, R.R. Coffman, H. Doshi, N. Dunnett, S. Gaffin, M. KHler, K.K.Y. Liu, and B. Rowe. 2007. Green Roofs as Urban Ecosystems: Ecological Structures, Functions, and Services. Bioscience 57.10 (2007): 823-833.

Onmura, S., M. Matsumoto, and S. Hokoi. "Study on evaporative cooling effect of roof lawn gardens." Energy and Buildings 33.7 (2001): 653-666(14).

Ott, Lyman, and Michael Longnecker. An introduction to statistical methods and data analysis. 5th ed. Australia ;Pacific Grove CA: Duxbury, 2001

Peck, Steven, and Monica Kuhn. "Design Guidelines for Green Roofs."Ontario Association of Architects. 2007. Accessed 11 January 2010. http://www.cmhc.ca/en/inpr/bude/himu/coedar/loader.cfm?url=/commonspot/security/get file.cfm\&PageID $=70146$

Protecto Wrap. Accessed 8 September 2009. http://www.protectowrap.com/prod-bt25xl.html

Skyland USA. Rooflite extensive MC documentation. Accessed 10 Mar. 2010. http://www.skylandusa.us/docimg/specs_rooflite_ext_mc.pdf

Sayed, OH. “Crassulacean Acid Metabolism 1975-2000, a Check List.” Photosynthetica 39.3 (2001): 339-352.

Scholz-Barth, Katrin. "Green Roofs: Stormwater Management From the Top Down - Archives EDC Magazine.” 15 Jan. 2001. Accessed 12 January 2010. http://www.edcmag.com/CDA/Archives/d568f635d8697010VgnVCM100000f932a8c0

Shaviv, A. "Advances in Controlled-Release Fertilizers." Advances in Agronomy 71 (2001): 149.

Snodgrass, Edmund. Green roof plants : a resource and planting guide. Portland Or.: Timber Press, 2006. 
Stephenson, Ray. Sedum : cultivated stonecrops. Portland Or.: Timber Press, 1994.

Terri, James A., Matthew Turner, and Jessica Gurevitch. "The Response of Leaf Water Potential and Crassulacean Acid Metabolism to Prolonged Drought in Sedum rubrotinctum." Plant Physiology 81 (1986): 678-680.

USDA. Sporobolus heterolepis http://plants.usda.gov/java/profile?symbol=SPHE

Van der Spuy, Una. Gardening with ground covers : ground covers of the world for gardens in the southern hemisphere and other temperate regions. Wellington: A.H. \& A.W. Reed, 1976.

VanWoert, Nicholaus D. et al. "Green Roof Stormwater Retention: Effects of Roof Surface, Slope, and Media Depth.” Journal of Environmental Quality 34.3 (2005): 1036-1044.

Weather Underground. Historical weather data for San Luis Obispo, CA. Accessed June 25, 2010. http://www.wunderground.com/

Walters, Dirk and David Kiel Vascular plant taxonomy. 4th ed. Dubuque Iowa: Kendall/Hunt Pub. Co., 1996.

Wolf and Lundholm. "Water Uptake in Green Roof Microcosms: Effects of Plant Species and Water Availability" Ecological Engineering 33 (2008): 179-186.

Wyman, Donald. Ground Cover Plants. New York: Macmillan, 1956.

Yang, Jun, Qian Yu and Peng Gong. Quantifying Air Pollution Removal by Green Roofs in Chicago. Atmospheric Enviornment 42 Issue 31 October (2008):7266-7273 


\section{APPENDIX}

\section{Appendix A: Propagation Equipment}

- Pruners

- $\quad 72$ cell plug trays with cells measuring $3.81 \mathrm{~cm}$ x $5.08 \mathrm{~cm}(1.5 \times 2$ inches $)$

- Cuttings of plant material to be propagated

- Transplant mix ( 0.25 cubic feet for each plug tray)

\section{Appendix B: Testing Platform Construction Materials (per platform)}

- (2) $12 \mathrm{ft}$ of 2 in x 4 in wood board

- (4) $12 \mathrm{ft}$ of 2 in x 8 in wood board

- (1) $8 \mathrm{ft} \times 8 \mathrm{ft} \times 1$ in particle board

- (1) box 2.5 in wood screws

- (2) 3 in x 6 in masonry bricks

\section{Appendix C: Tools Used}

- Skill saw

- 18 volt cordless drill

\section{Appendix D: Irrigation Equipment and Materials}

- (2) 1 in automatic Rainbird plastic valve with scrubber

- (1) $20 \mathrm{ft} \times 1$ in piece schedule 40 pipe

- 1 in pipe fittings

- Pipe cement and primer

\section{Appendix E: Step by Step Process to Construct Testing Platforms}

1. Make the square frame using (4) $2 " \times 8 " \times 8$ pieces of lumber. Ensure each piece of wood overlaps the other exactly one time making a perfect square. 
2. With the square frame lying on a level surface, measure the distance from the inside of one side of the frame to the inside of the other and divide by two, marking this point; this will be exactly half way. Do the same process on the opposite side. Now measure the distance between the two halfway points (which are on parallel sides) and cut (1) 2"x 4" piece of lumber (board B) to this length. Using 3" wood screws, secure this piece of wood to the frame on each side at the marked locations ensuring that it is flush with the bottom of board A.

3. Board C is a 2" $\mathrm{x} 4$ " and will provide support for material placed on top of the platform. Cut four pieces in to 5' 7' pieces. Using the chop saw, turn the dial to $45^{\circ}$ and cut both sides of each board directly at the corner so each piece has a $45^{\circ}$ angle, making sure that the long sides of the board are on the same side ensuring that the total length is 5 '7'. Using the cordless drill and four 3" wood screws per board (two on each side), secure the boards, flush with the bottom of board A, so that they make two isosceles triangles with board B.

4. Board D is cut and fastened in the same manner as board C, but it is 2' 8 ' in length. Board D provides further support to platform materials and, when finished, makes a right triangle at the corner where two board A's join.

5. Board E, the 4' $\times 8^{\prime} \times 3 / 4$ ' plywood, sits directly inside the box and is secured to boards B, C, and D. Board E should be slightly smaller than the frame so it fits in easily. Cut board E so it measures 3'11 1/4" x 7'10 1/4". Place each piece of board E inside the frame so it is parallel to board B and sits one side along it for additional support. Using the 2" wood screws, secure board E to boards B, C, and D. Use 4 
screws through board $\mathrm{E}$ into board $\mathrm{B}, 3$ through board $\mathrm{E}$ into board $\mathrm{C}$, and two through board E into board D.

6. Finally, inspect the platform for any splinters, sharp edges, or other debris that may pierce the membrane; sand them down, remove, or repair as necessary. At this point, you will have a completed box that is ready to move out to the testing site. However, before moving the placement site should be prepared. 
Appendix F: Testing platform construction plans (1 of 2)

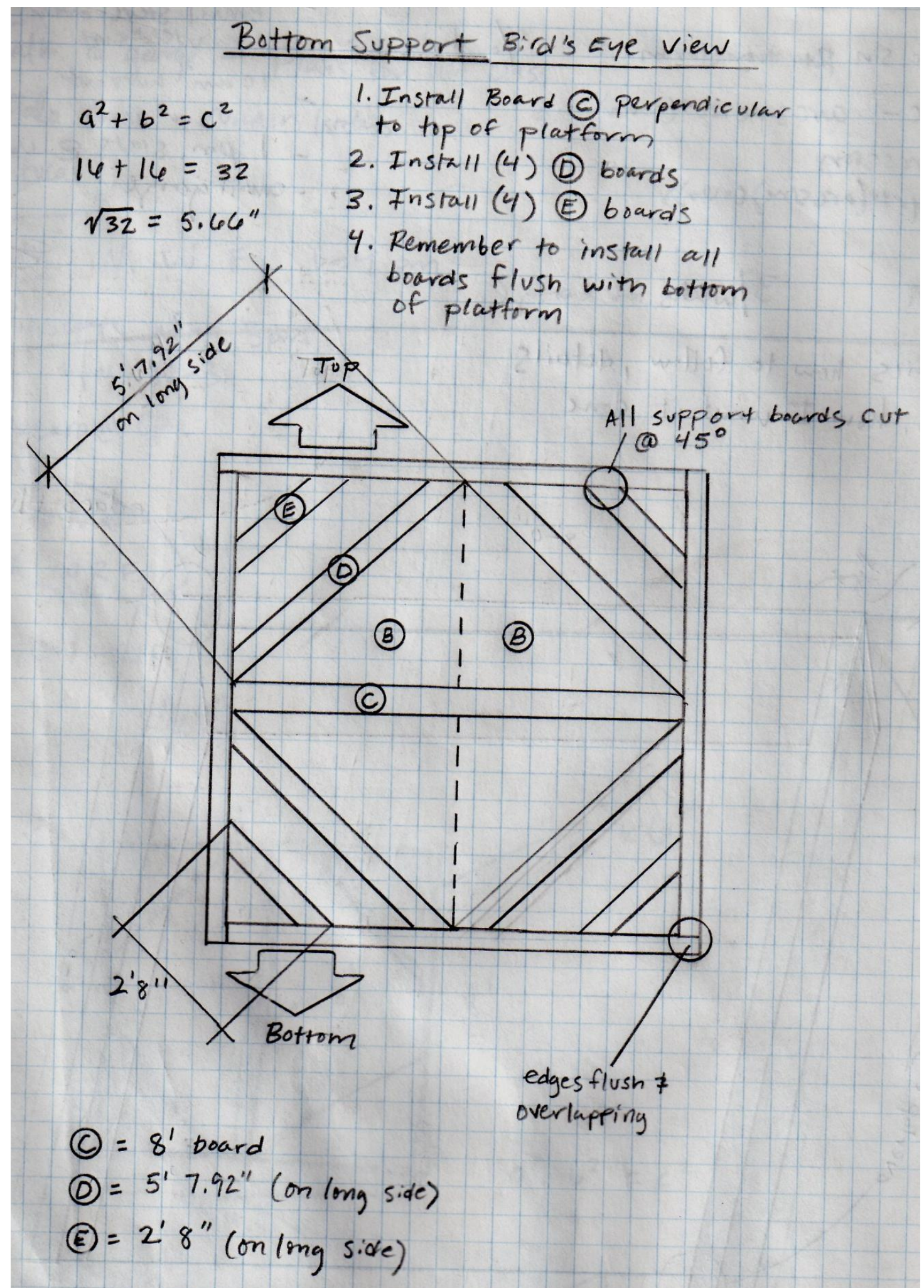


Appendix F (Continued): Testing platform construction plans (2 of 2)

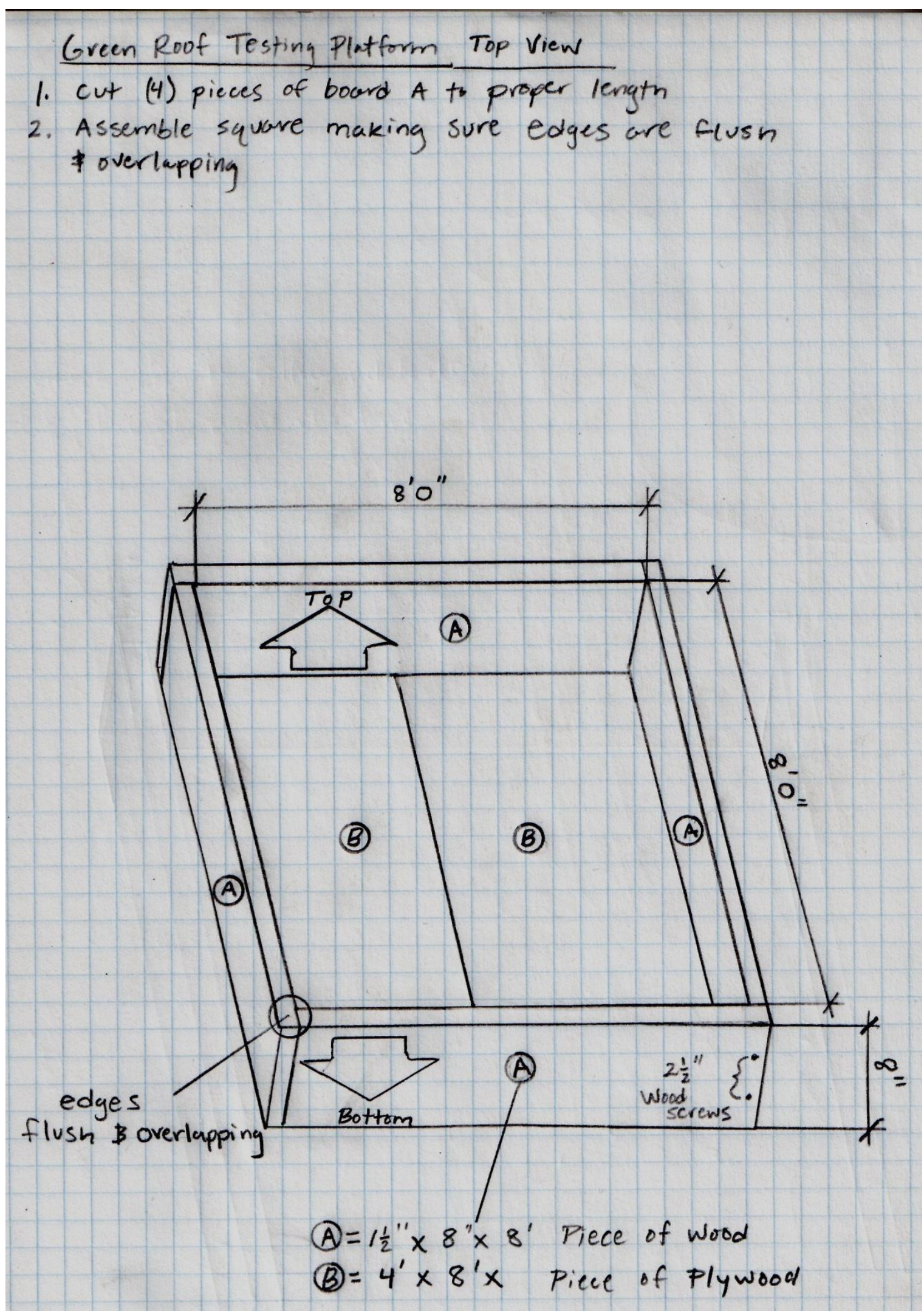


Appendix G, Figure A: A small piece of waterproof membrane, about $4 \mathrm{~cm}$ long, was placed in each or the four corners to bridge the connection between the two boards that conjoin forming a corner

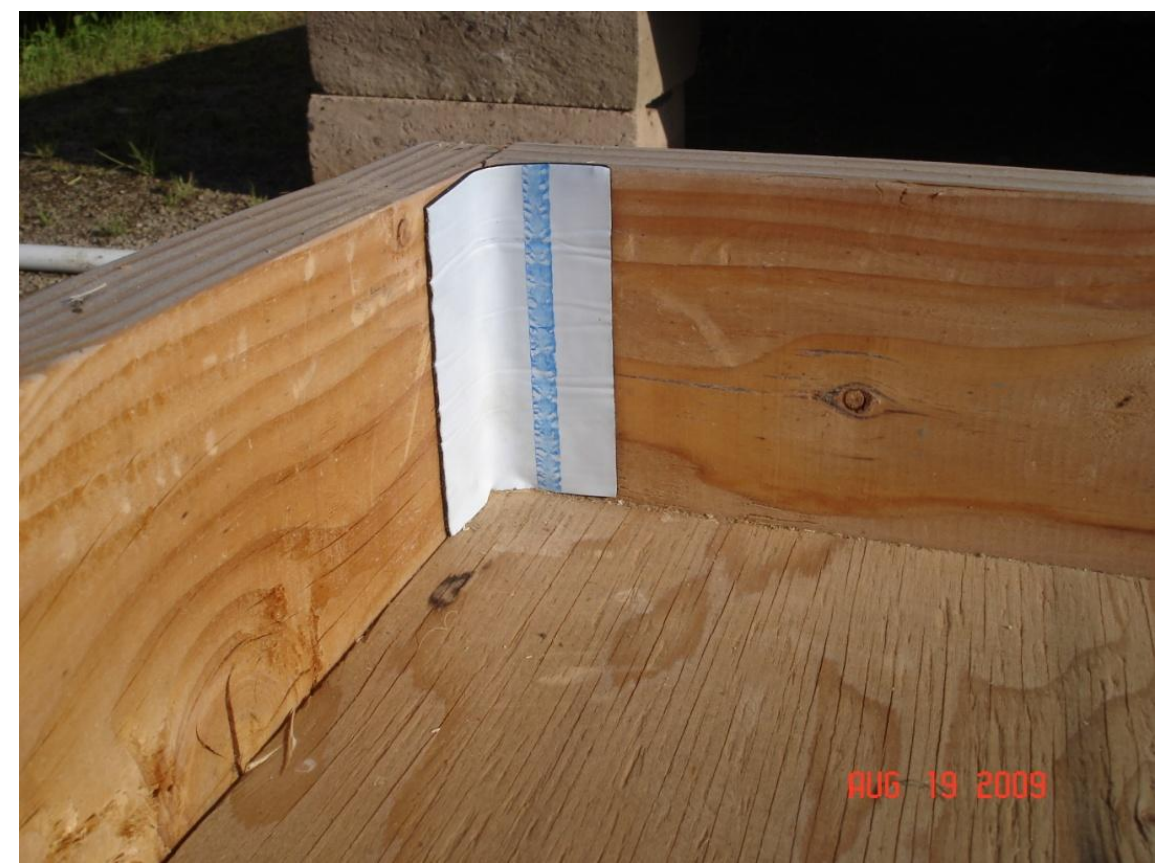

Appendix G, Figure B: The first section of waterproof membrane will be laid on the side board and span across the $90^{\circ}$ angle with the deck. It is easier to handle and apply this layer when it is cut into sections of about $30 \quad 40 \mathrm{~cm}$

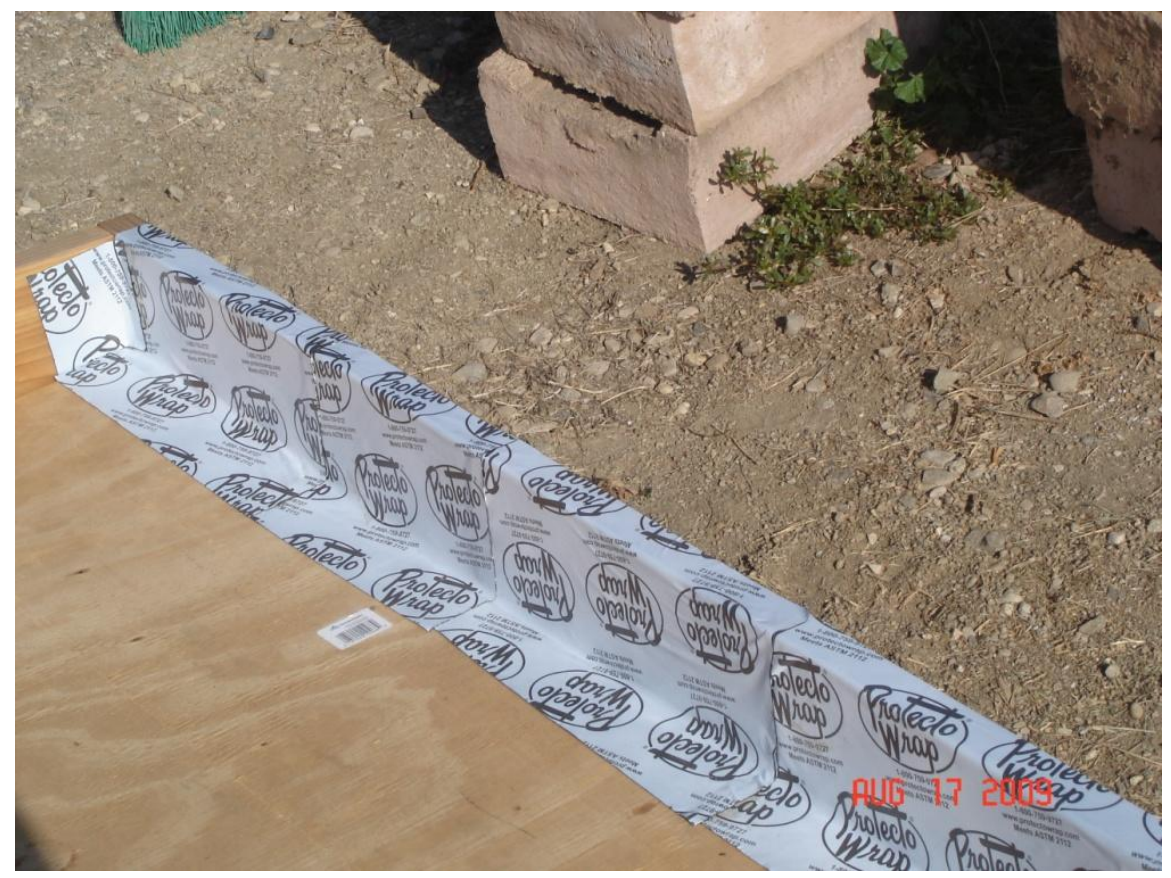


Appendix G, Figure C: By overlapping each membrane layer, starting at the low end and moving up, water will drain more efficiently and will not pool where membrane pieces meet

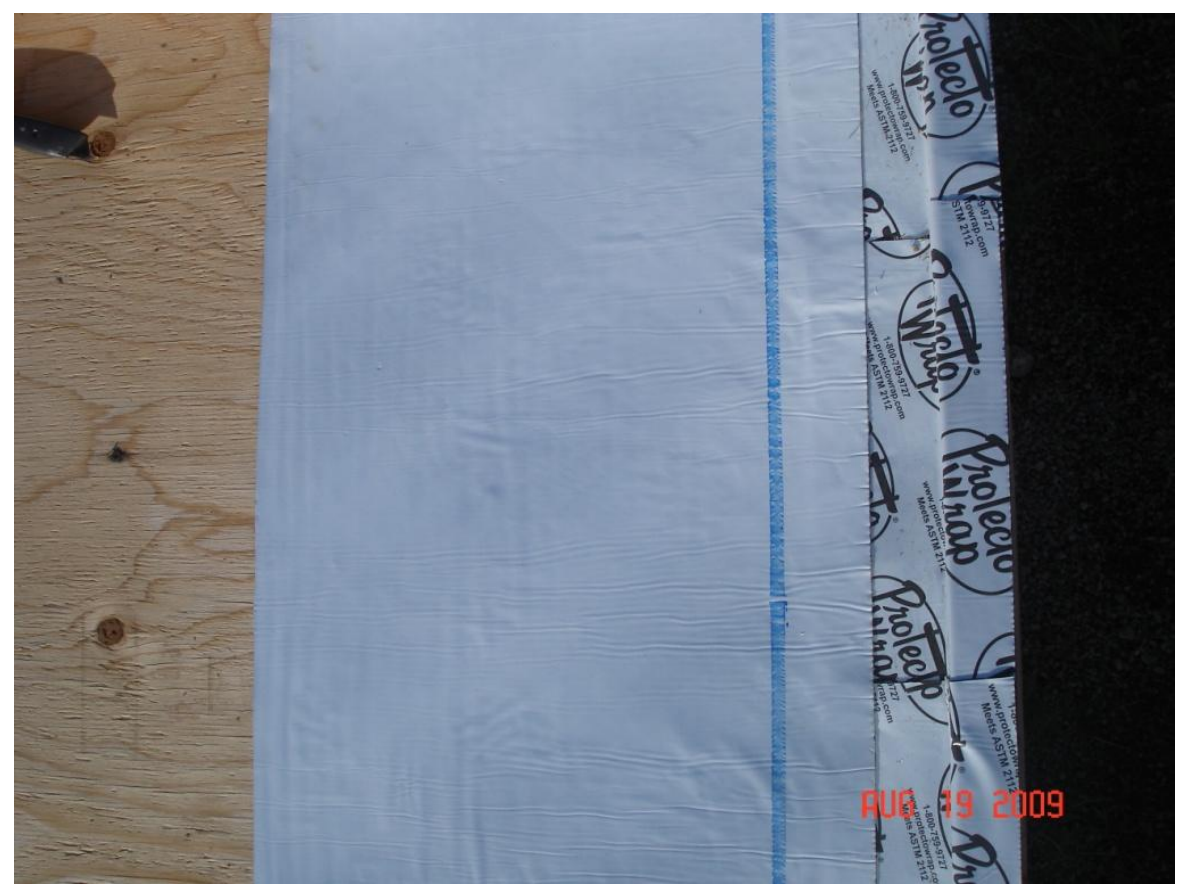

Appendix G, Figure D: At the high end of the platform, the waterproof membrane ends exactly how the low end started except for it lays over the last layer on the deck

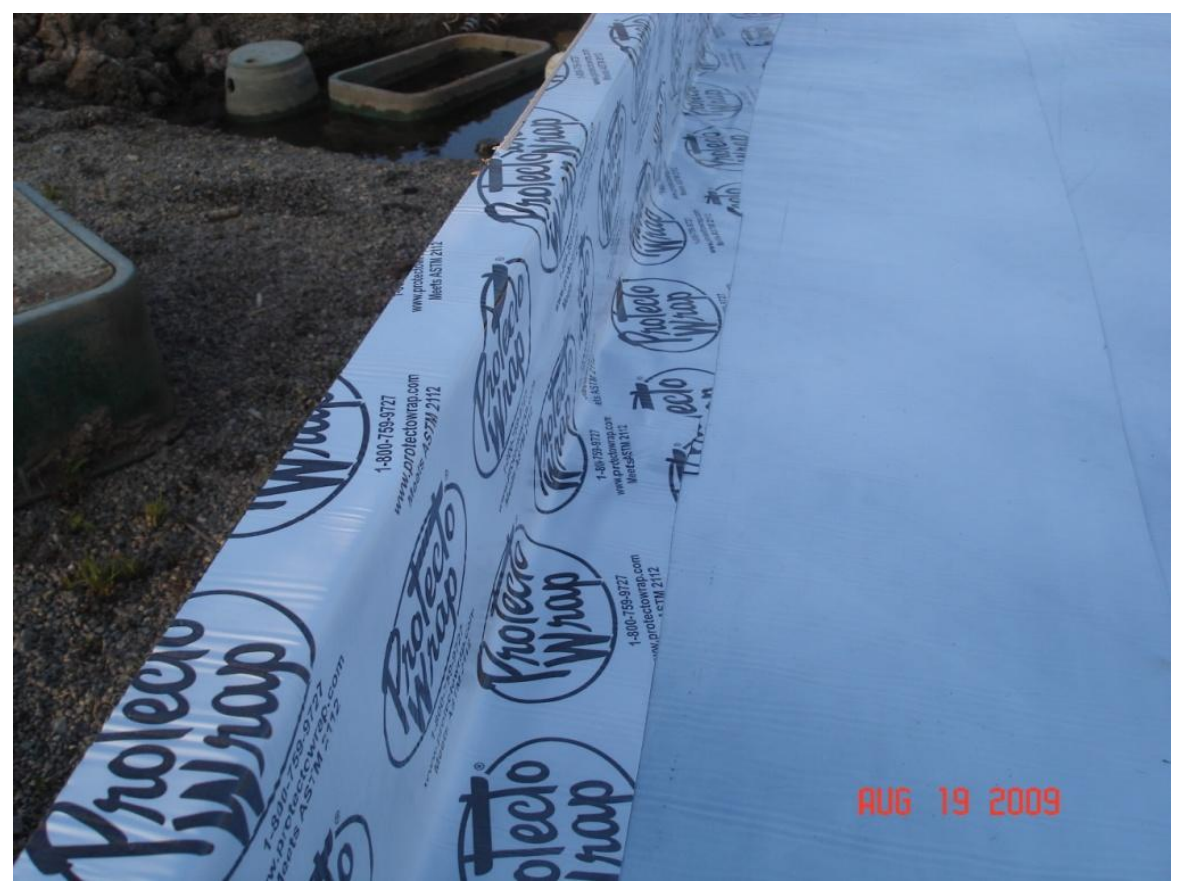


Appendix G, Figure E: A platform with a completed waterproof membrane just before the drainage layer was laid down. The platform slopes from right to left

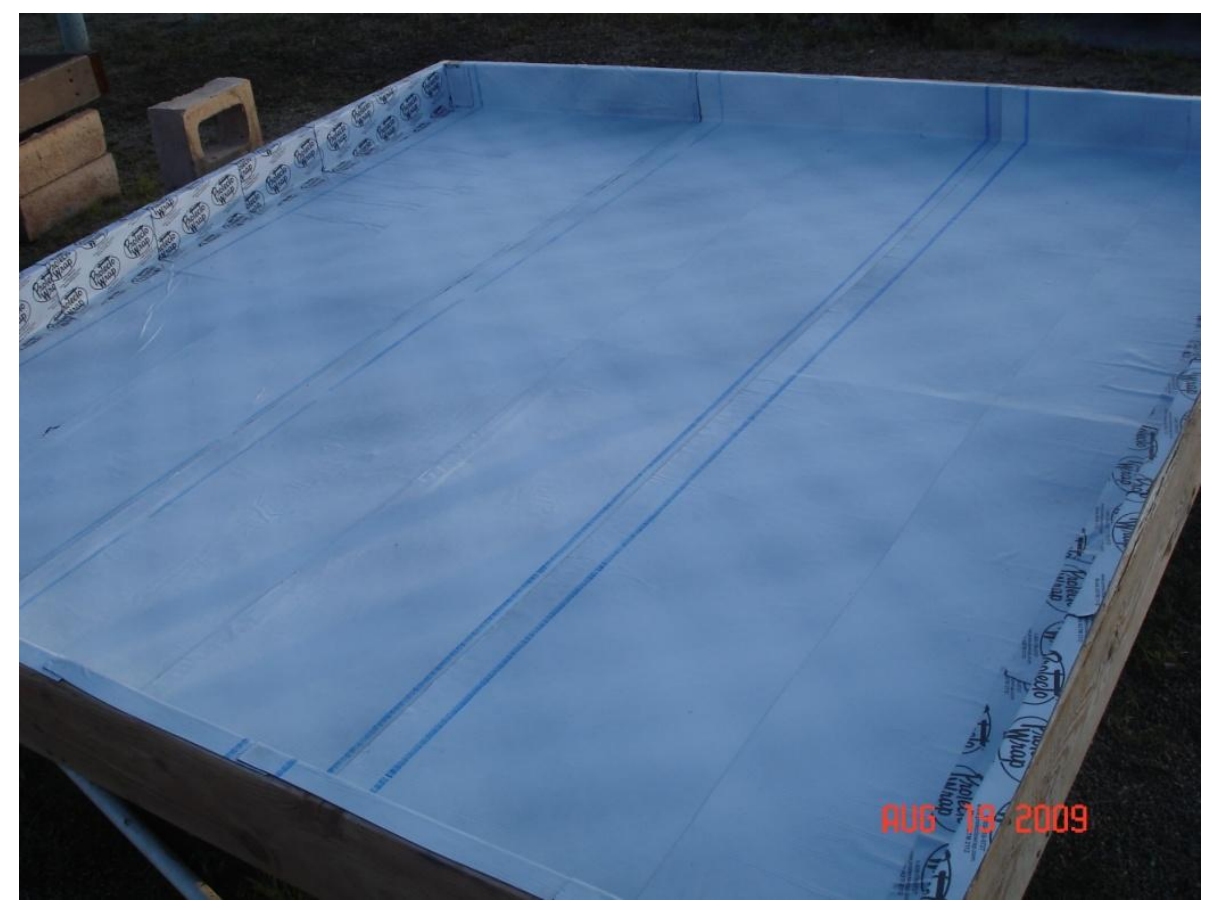

Appendix G, Figure F: Drainage holes were drilled every $15 \mathrm{~cm}$ in the bottom of the frame along the low end of each platform

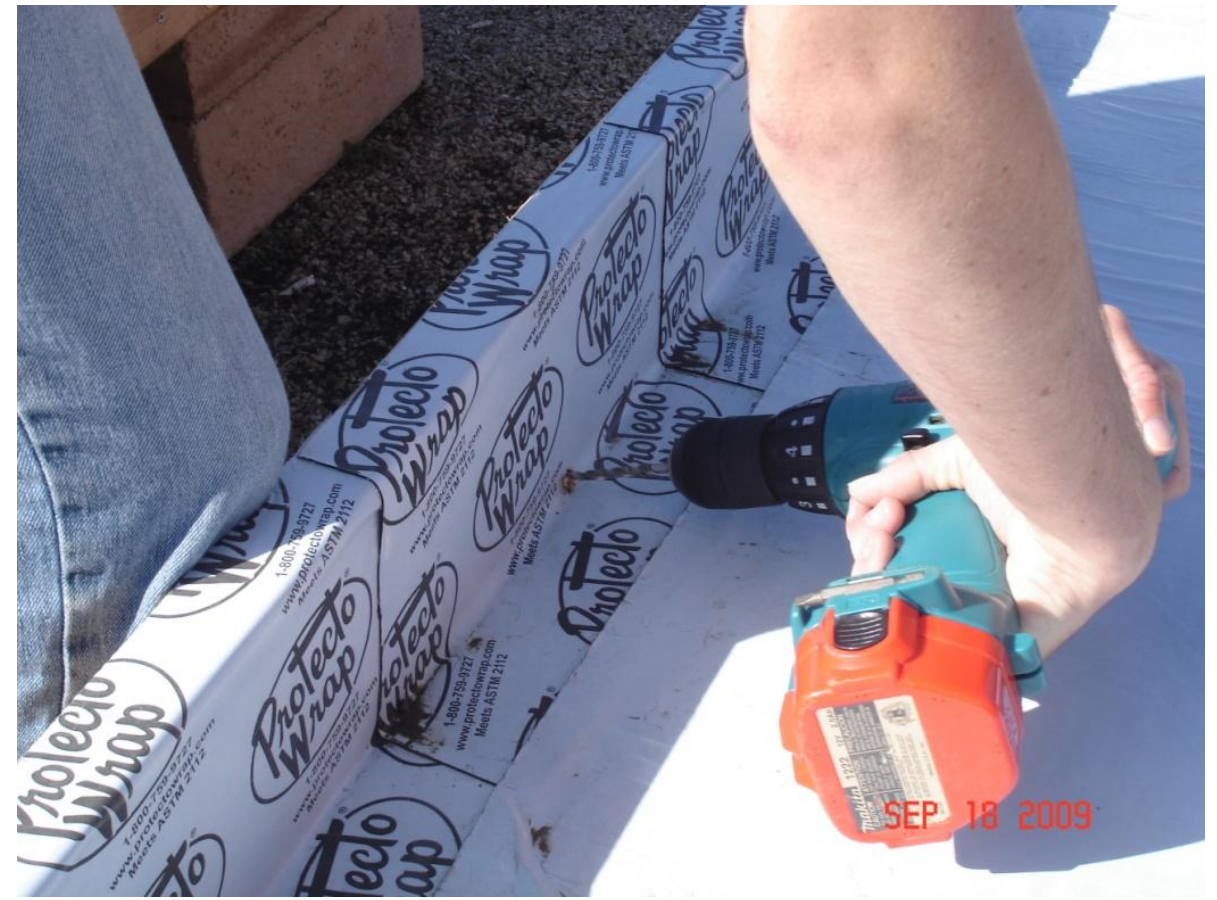


Appendix H, Figure A: Pieces were laid out lengthwise and butted up against one another

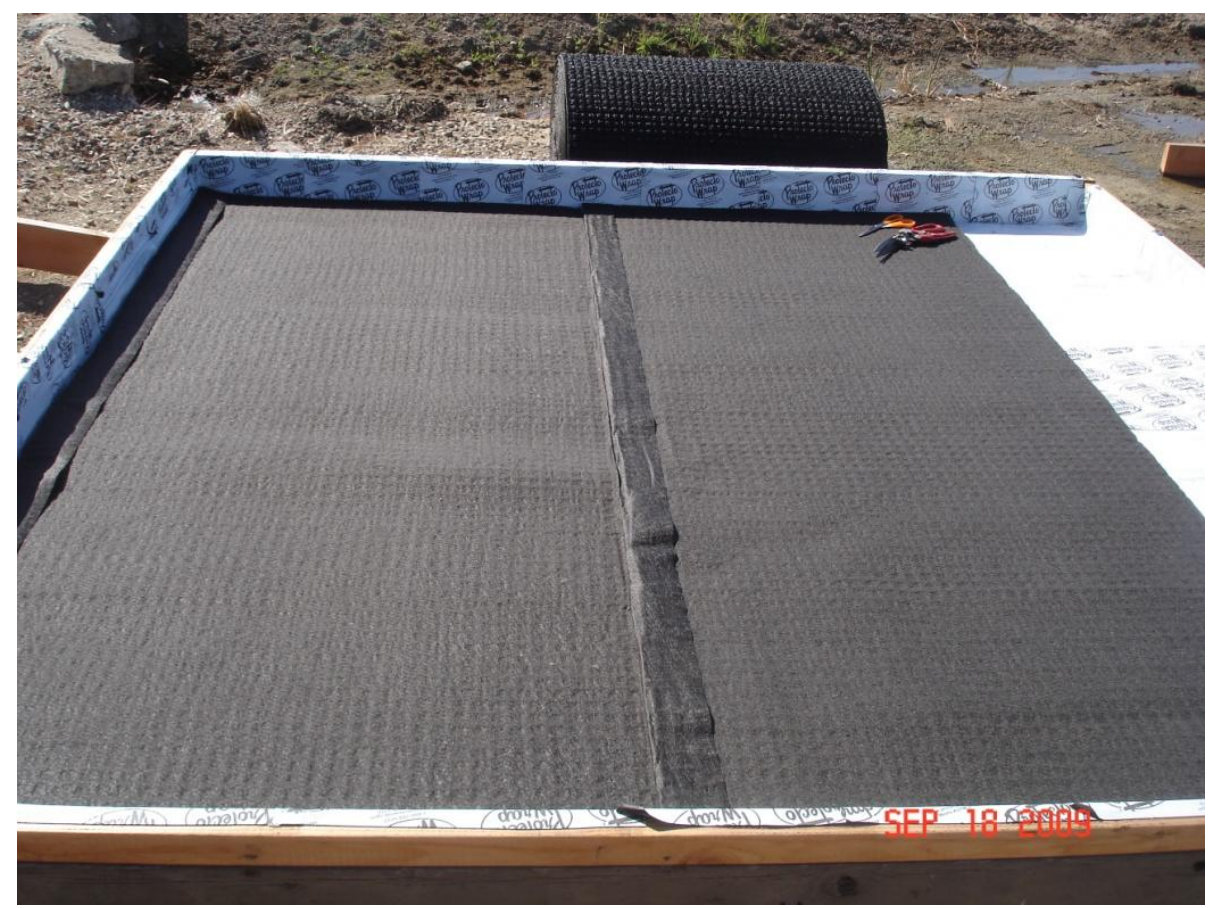

Appendix H, Figure B: Sections of Enkadrain ${ }^{\circledR}$ were secured to each other by using duct tape to tape the loose flap on one side of the drainage layer to the top of the next

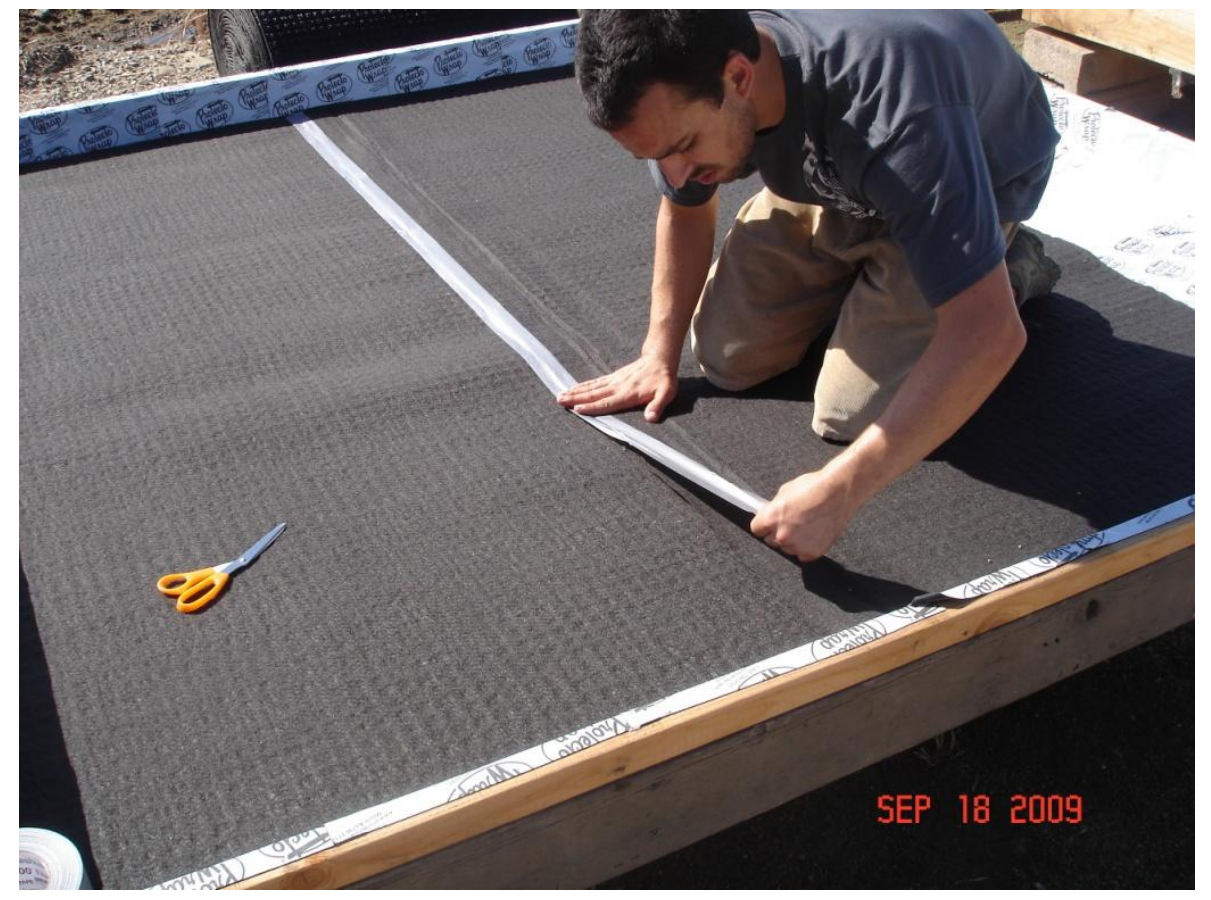


Appendix H, Figure C: Duct tape seals the space where the Enkadrain ${ }^{\circledR}$ meets the waterproof membrane at the edges of the deck to prevent growing media from passing below the filtration cloth and secure the Enkadrain ${ }^{\circledR}$ to the platform

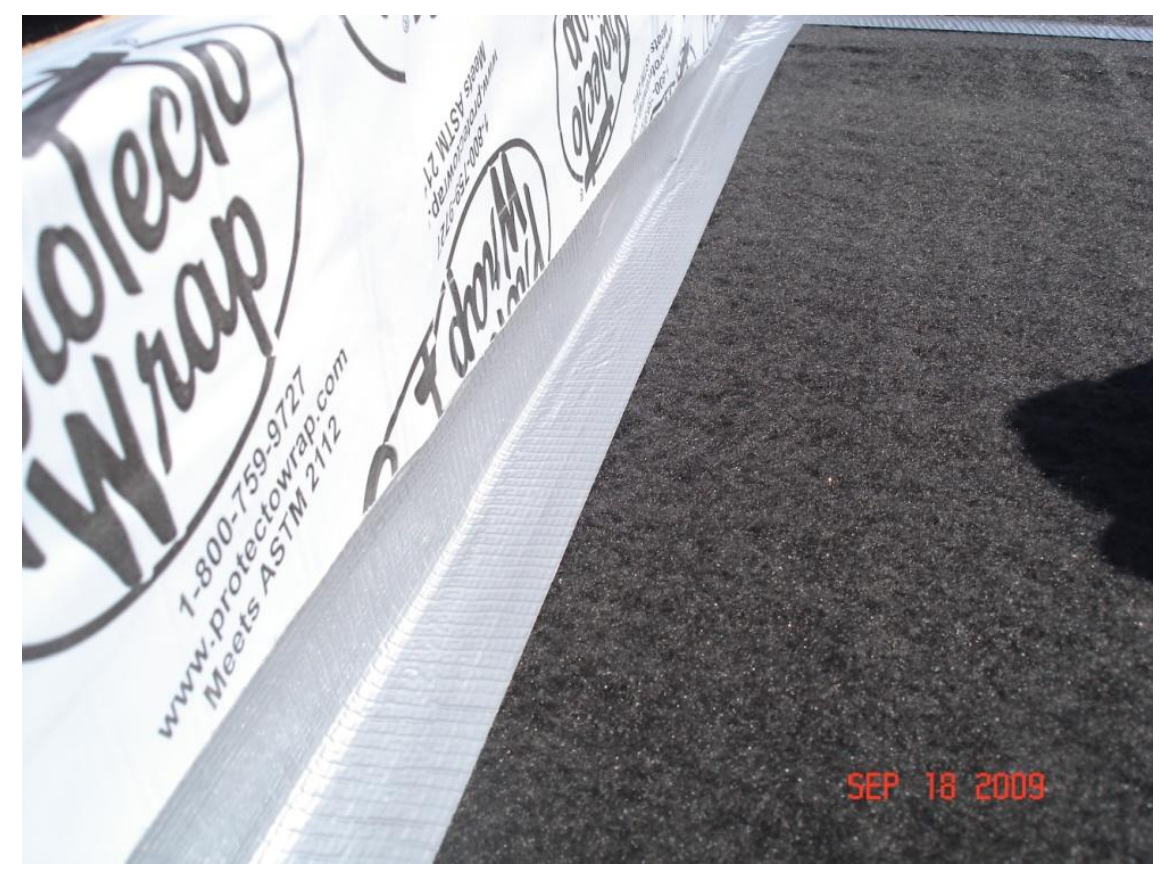

Appendix I, Figure A: An additional layer of EPDM was placed over the Enkadrain ${ }^{\circledR}$ and side boards to mimic the modular waterproof membrane media one is designed

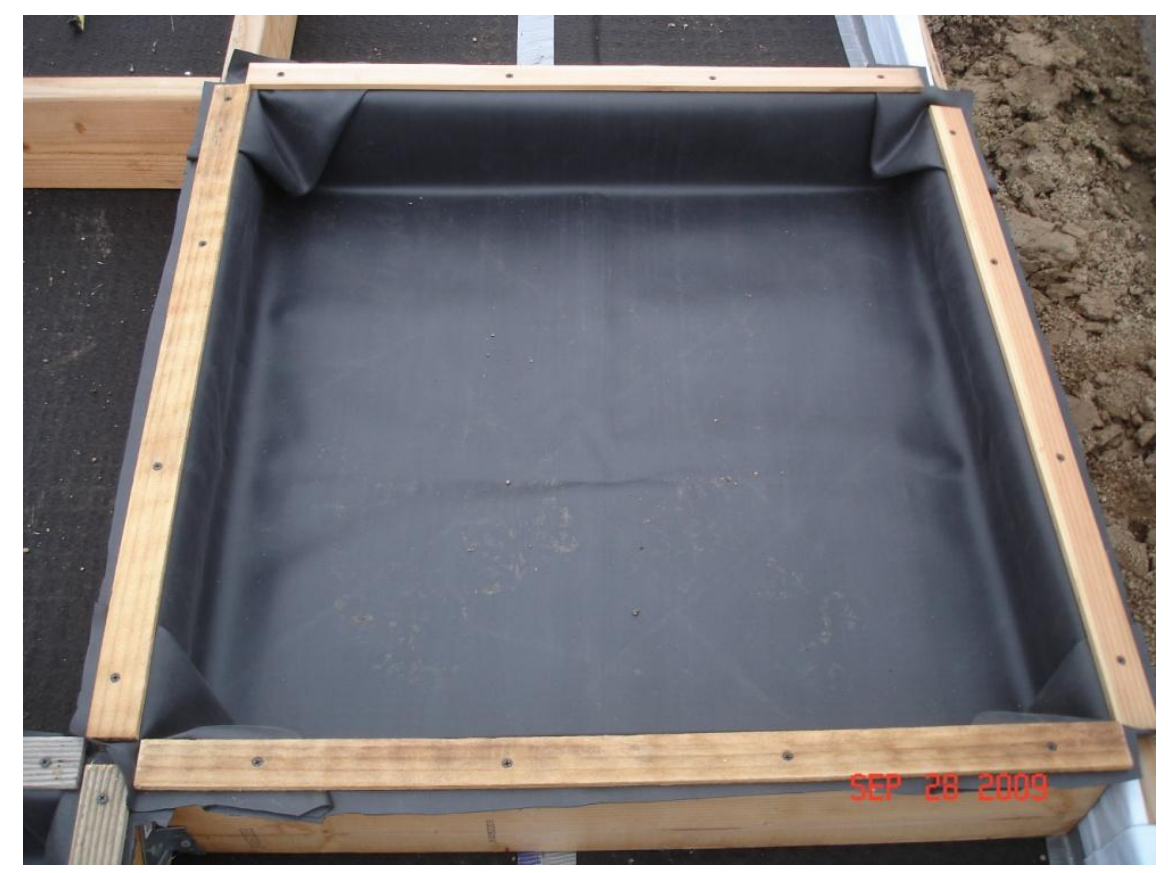


Appendix J, Figure A: A pilot study conducted on medium one showed significant root growth from plug plantings one month after planting

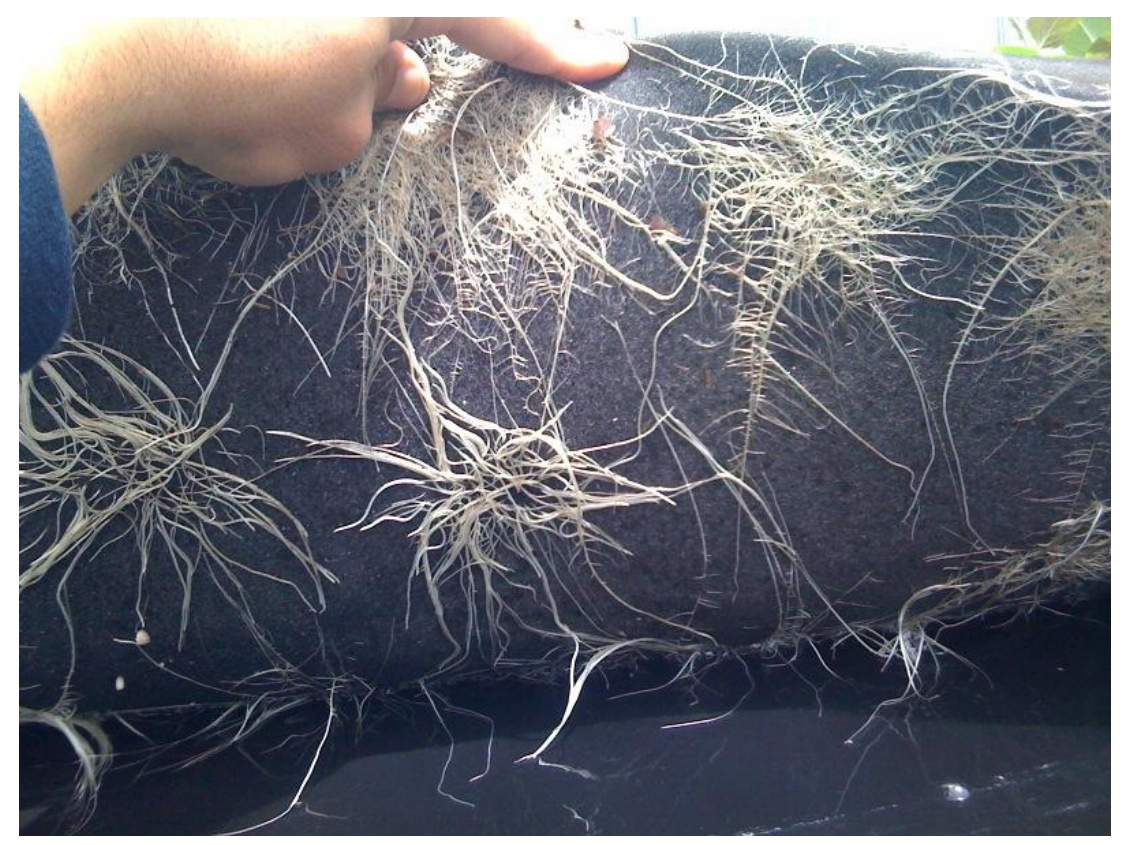

Appendix K: Materials Sources

Freedom Garden Products, 827 IH-35 South, Suite 827D, New Braunfels, TX 78130

Skyland USA, LLC (rooflite), 705 Penn Green Road, P.O. Box 640, Avondale, PA 19311

Roofscapes, Inc., 7135 Germantown Avenue, $2^{\text {nd }}$ Floor, Philadelphia, PA 19119-1842

Colbond-USA, 1301 Sand Hill Road, Enka, NC 28728

Native Sons Wholesale Nursery, 379 West El Campo Road, Arroyo Grande, CA 93420

Bouldin \& Lawson, LLC, P.O. Box 7177, McMinnville, TN, 37111-7177

Pacific Coast Forest Products, 4734 David Rd, Arvin, CA 93203-9665 